المجلة الدولية للدراسات التربوية والنفسية e-ISSN 2520-4149 , p-ISSN 2520-4130

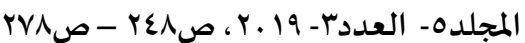

https://doi.org/DOI:10.31559/EPS2019.5.3.3

رفاد للدراسات والأبحاث

www.refaad.com

\title{
دور تكنولوجيا المعلومات في تنمية كفاءة الأداء الإداري لقائدات المدارس المتوسطة بمنطقة القصييم من وجهة نظرهن
}

\author{
علية محممد شرف \\ أستاذ الإدارة التربوية المشارك بجامعة القصيم- المملكة العربية السعودية \\ Dr.alyia@yahoo.com \\ ساره بنت عبد اللطيف محمد الفريتي \\ ماجستير ادارة تربوية- كلية التربية جامعة القصيم- المملكة العربية السعودية \\ sarafuraihy@gmail.com
}

هدفت الدراسة إلى التعرف على دور تكنولوجيا المعلومات في تنمية كفاءة الأداء الإداري لقائدات المدارس المتوسطة بمنطقة القصيم من وجهة نظرهن في ضوء متغيرات الدراسة (الخبرة، المؤهل، الدورات التدريبية)، والوقوف على واقع دور تكنولوجيا المعلومات في تلوريات تنمية كفاءة الأداء الإداري والكشف عن المعوقات التي تحد من دورها في تنمية كفاءة الأداء الإداري، ومتطلبات تفعيلها. ولتحقيق أهداف الدراسة تم الاعتماد على المنهج

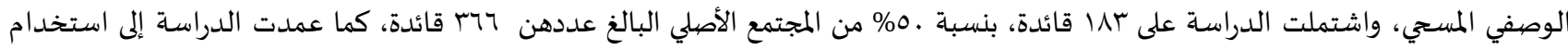
الاستبانة أداةً لجمع البيانات، وقد أسفرت الدراسة عن عدد من النتائج أهمها أن تكنولوجيا المعلومات في تساعد تنمية كفاءة الأداء الإداري بالإضافة

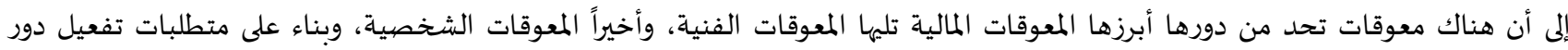

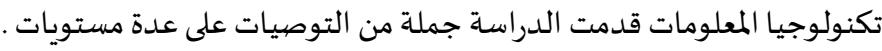
الكلمات المفتاحية: تكنولوجيا المعلومات، الكفاءة، الأداء الإداري، قائدات المدارس (c) (1)

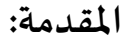

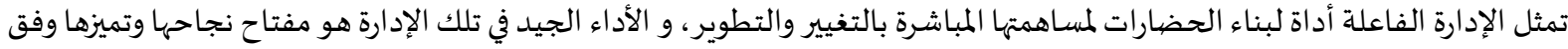

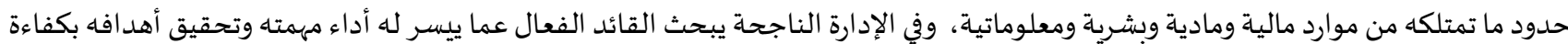
وإتقان من خلال الاستفادة من تكنولوجيا المعلومات، وذلك لاتساع دائرة تأثيرها على جميع القطاعات وما توفره من تسهيلات وخدمات فائقة للقطاع

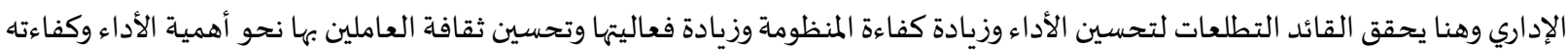

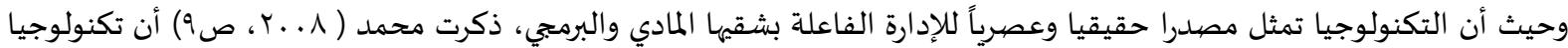

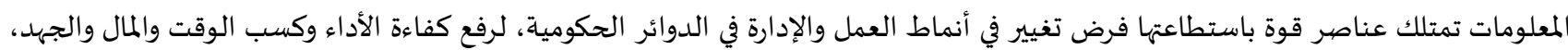
كما توفر الطفرة التكنولوجية الحديثة امكانية الحوار المباشر ودعم اتخاذ القرار.

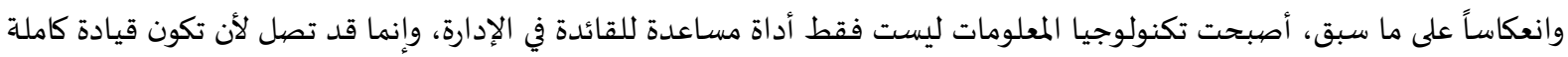

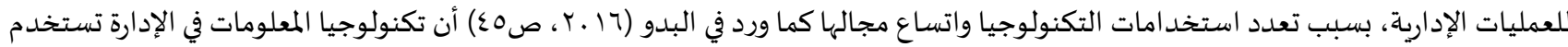
فيما يخص شؤون الموظفين لتوفير كافة الخدمات التي يحتاجها الموظفون بكافة مستوياتهم مثل خطابات التحويل والتعريفات والبيانات الأولية التي

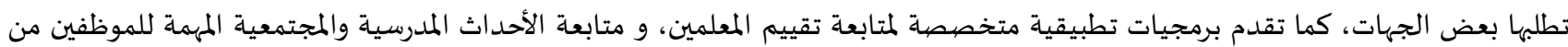
خلال إرسال رسائل نصية باستخدام تقنية الهاتف النقال كالرواتب والأحداث الطارئة والإجازات وغيرها.

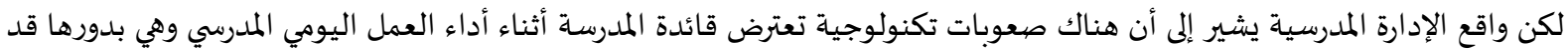

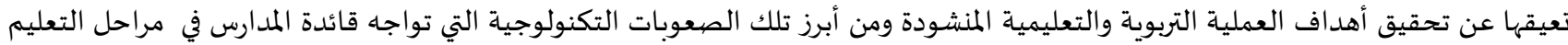

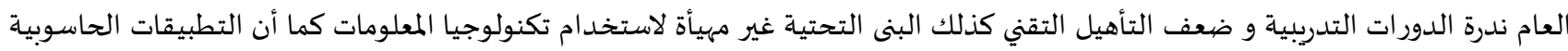


بحاجة ماسـة إلى مزيد من التطوير والترقية لتواكب المتطلبات الحالية للإدارة المدرسية وذلك لنقصها وقصورها من جهة وعدم ترقيتها وتحديثها بشكل

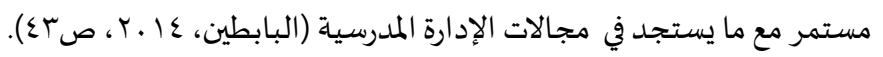

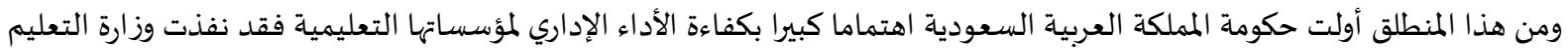

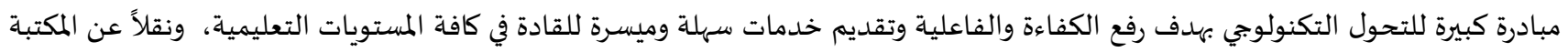

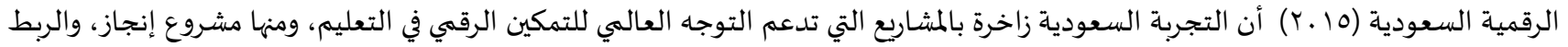

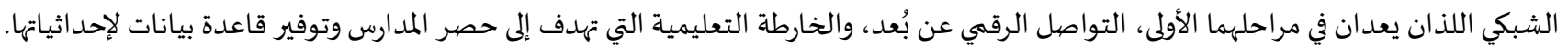

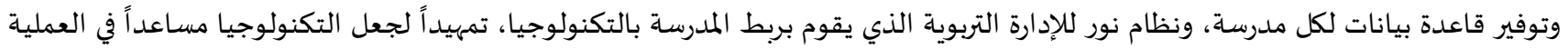
التعليمية والتربوياة. وتجاوباً مع رؤية المملكة العربية السعودية (.r.r) "التي تتطلع لتحسين تنافسية القطاع التعليمي مع غيره من الدول المتقدمة" (رؤية

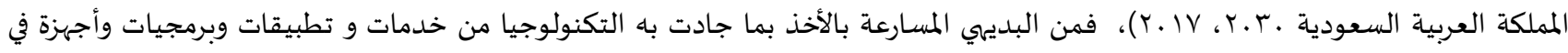

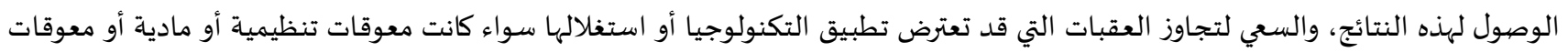
بشرية أو حتى العقبات التي تتعلق بثقافة المجتمع نحو التكنولوجيا.

ماهية تكنولوجيا المعلومات:

ويعد هذا العصر عصر التكنولوجيا التي تمخضت عناه أساليب وتقنيات وأجهزة متطورة فرضت نفسها في مجال خدمة البشرية وأصبحت

غير قابله للاستبدال بل عوضا عن ذلك أصبحت تتطور مع مرور الوقت وتحل محل الكثير من الأساليب القديمة. وقد حظيت التكنولوجيا باهتمام المختصين مما دعى إلى المطالبة بتطوير النظم المختلفة بما يتناسب مع تلك التقنيات، ولم يغفل التقدم

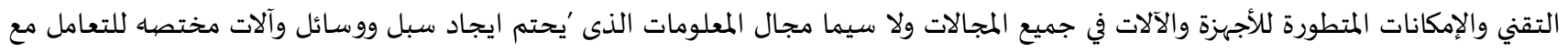

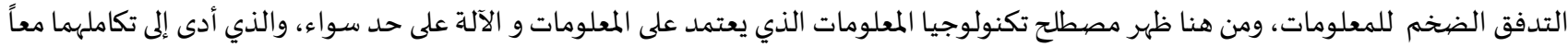

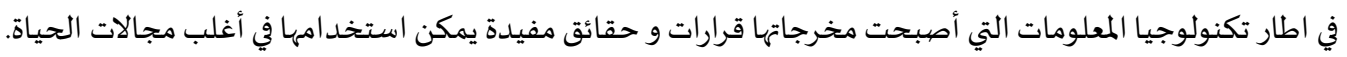

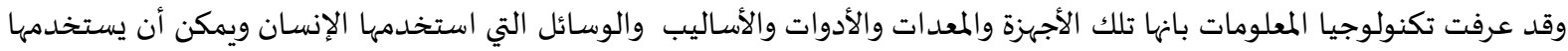

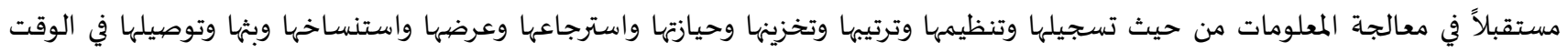

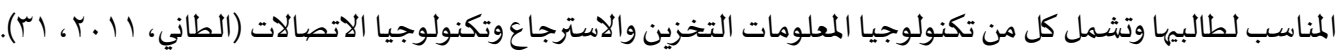

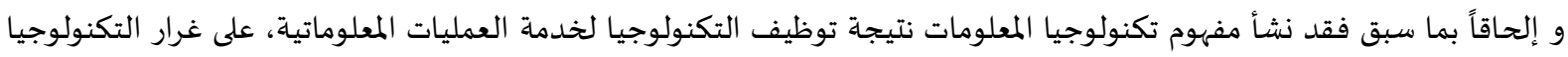

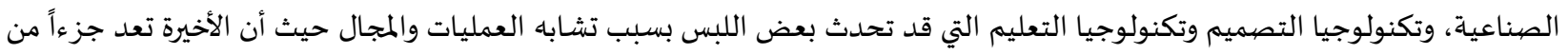
تكنولوجيا المعلومات وتستخدم في العملية التعليمية، وقد تشترك بعض التكنولوجيا في خدمة الجانبين التعليمي والإداري كالحواسيب والطابعات التهات والبريد الإلكتروني.

أبعاد تكنولوجيا المعلومات:

تعددت الآراء حول أبعاد تكنولوجيا المعلومات كل بحسب توجهاء لكن تم الاخذ بالأبعاد الأقرب إلى مجال الإدارة المدرسية والأكثر شمولاًا

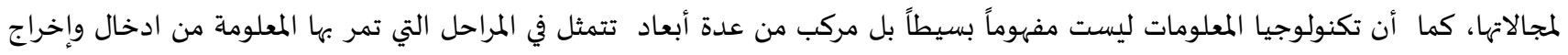

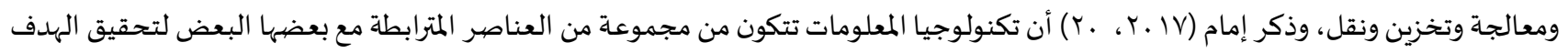

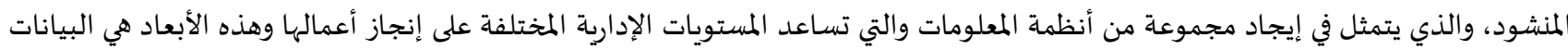

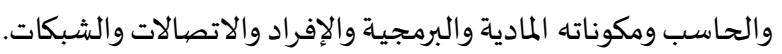

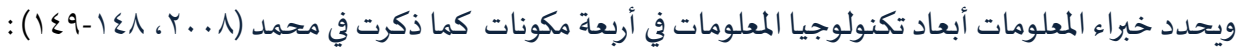

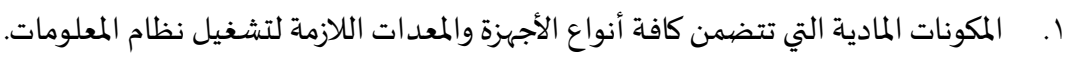

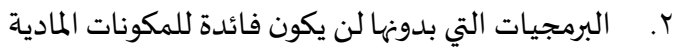

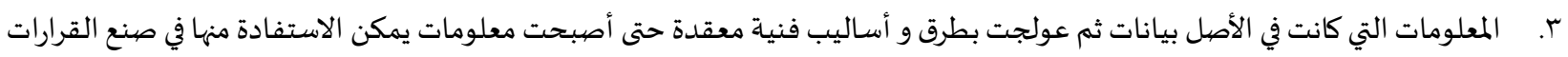
ع. الاتصالات وتضيم كافة وسائل الاتصال السلكية واللاسلكية الضرورية لانتقال المعلومات من مكان تخزينها إلى المستفيدين منها.

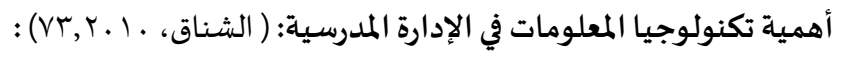
1. توفير الوقت والجهد الكافي للإداريين مما يمكنهم من انجاز اعمال أخرى. 
r. تقوم برامج تكنولوجيا المعلومات بأعمال فنية وإدارية كثيرة بالتالي توفر الأيادي العاملة اللازمة لهذه الأعمال، كذلك تقلل تكلفة العملية

التعليمية والإدارية.

r. تعد افضل وسيلة توفر المعلومات في أسرع وقت ممكن.

ع. توفر تكنولوجيا المعلومات عامل المهارة والإتقان في أداء الأعمال.

آليات استخدام تكنولوجيا المعلومات في الإدارة :

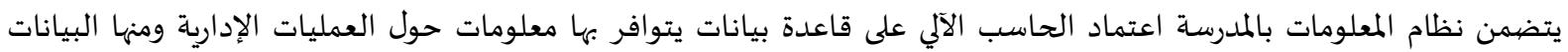
التمويلية مثل التكلفة والعائد وانشطة الميزانية ومعلومات حول الموارد المتاحة البشرية والمادية وكذلك معلومات حول المناهج والتجديدات التربوية وهي تعد عناصر مهمة في بنية نظام المعلومات على مستوى المدرسة ويمكن بيان المهمات الإدارية على مستوى الإدارة المدرسية على المهات النحو التالي (متولي

$:(V \leqslant V, Y, I T$

ا. تنسيق وتوزيع الطلاب : يستخدم الحاسب في توزيع الطلاب بناء على تغذية الحاسوب بمعلومات وفيرة عن الطلاب كالاسم والعنوان ورقم

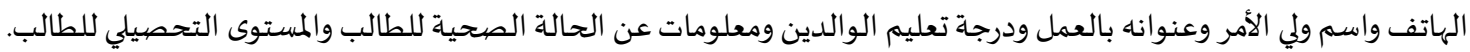

r. ت وضع الجداول المدرسية

r. تسجيل الطلاب ومتابعتهم : فعندما يلتحق الطالب بالمدرسة فإنها ينبغي تسجيل بيانات عديدة مثل الاسم وتاريخ الميلاد والسن ، والعنوان

وبعض المعاملات المالية مثل المصروفات الدراسية والمكافآت التي تصرف نظير تفوقهم أو على شكل إعانات مالية للطلاب. ع. أعمال المكتبات: حيث أن الحاسب الآلي يسهل تنظيم المكتبات ويسهل تصنيف المعليف الكتب ومتابعه أعمال البحث والاستعارة، فهذه العملية

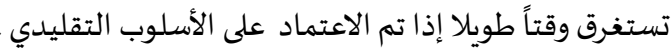

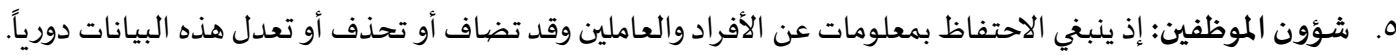

كما تتضح ملامح واقع استخدام تكنولوجيا المعلومات في الإدارة المدرسية في عدد من الخدمات الإدارية الالكترونية التي استحدثت لخدمات

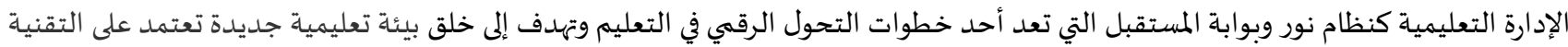
في إيصال المعرفة إلى الطالب، في نفس الوقت توفر مجموعة من التقارير المخصصة للإدارة المدرسية تستطيع من خلالها متابعة حالة تقدم الطلاب و

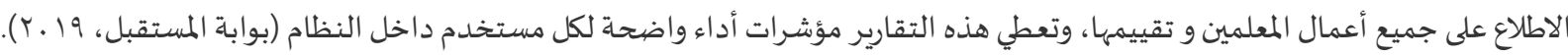
بالإضافة إلى بوابة تواصل التي تعد وسيلة إلكترونية للتواصل في كل ما يخص التعليم، و الاطلاع على مقترحات المستفيدين وملاحظاتهم واستفسارهم وشكاواهم، ومتابعتها مع معالي الوزير وجهات الاختصاص بالوزارة والإدارات المعنية وفق نظام إلكتروني يسهل عملية التواصل، وييسر متابعتها وحلها

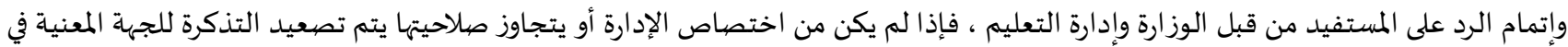

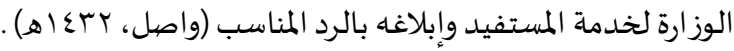

معوقات تفعيل تكنولوجيا المعلومات في الإدارة المدرسية: يحتاج التخلي عن الطرق التقليدية في الإدارة وكسر قواعد العمل التقليدية إلى إدراك أهمية التحول والتغيير التي تتطلب بدورها اجراء

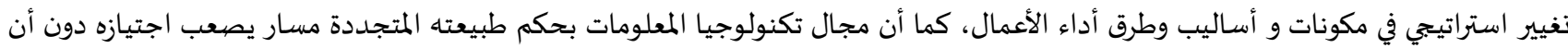
تعترضيء العديد من المعوقات والصعوبات و يشير واقع الإدارة المدرسية إلى أن هناك صعوبات تكنولوجية تعترض قائدة المدرسة أثناء أداء العمل اليومي

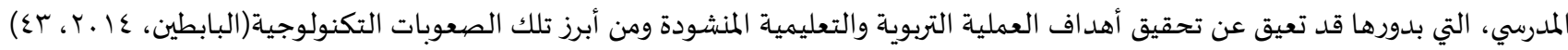
ندرة الدورات التدربية و ضعف التأهيل التقني، البنى التحتية غير مهيأة لاستخدام تكنولوجيا المعلومات، التطبيقات الحاسوبية بحاجة ماسة إلى بـاتي

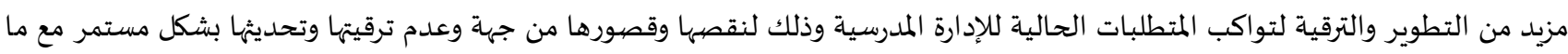
يستجد في مجالات الإدارة المدرسية، و تتلخص معوقات استخدام تكنولوجيا المعلومات في الإدارة المدرسية في: ضعف امتلاك مدير المدرسة أو الطاقم

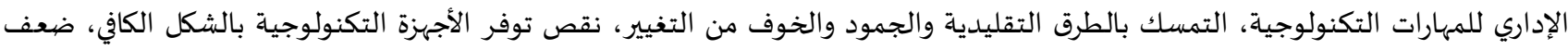

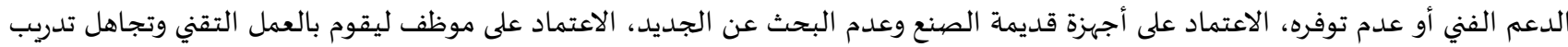
البقية، مشاكل انتهاك الخصوصية وعدم الحفاظ على سرهية البعاد البيانات.

مفهوم كفاءة الأداء الإداري: تلعب الإدارة الدور الأكبر في نجاح العمليات داخل المؤسسات التعليمية و على النقيض تماما قد تساهم في تخلفها، فاستغلال الموارد المادية

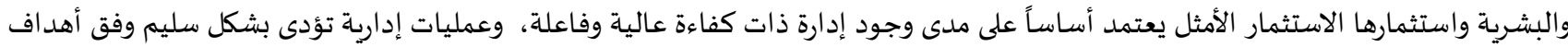


مححددة و استراتيجيات و طرق حديثة، فهناك العديد من المؤسسات التي تملك الموارد المادية والبشرية ولكن لافتقارها للإدارة الجيدة والفاعلة أضحت

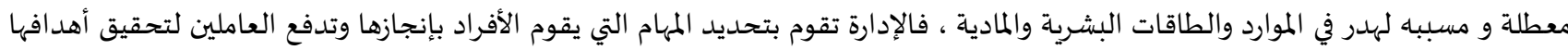
،لأن الدور الأسـاسي للإدارة هو توجياء المؤسسة نحو تحقيق أهدافها بأقل تكلفة وأسرع وقت، فالإدارة التعليمية هي المسئولة عن تنفيذ سياسات الماتهات الدولة

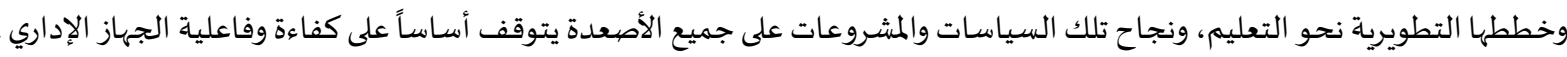

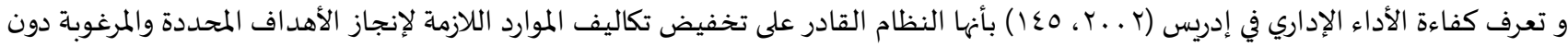

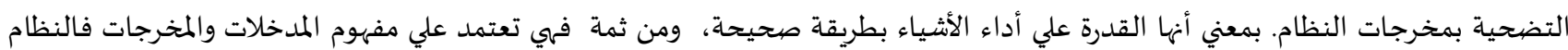
الكفء هو الذي يتمكن من تحقيق مخرجات تفوق المدخلات المستخدمة.

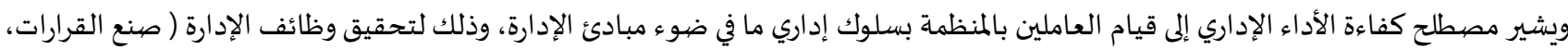

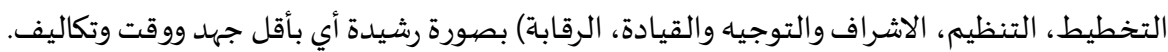

محددات الأداء الإداري :

ا. الجهد المبذول في العمل: يعكس درجة حماس الفرد لأداء العمل ومدي دافعيتها للأداء

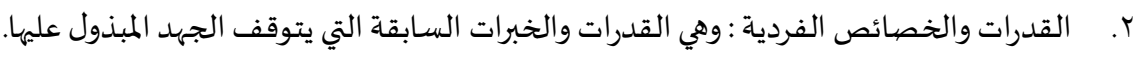

r. إدراك الفرد لدورة الوظيفي: تتمثل في سلوك الفرد الشخصي أثناء الأداء لتصور اته وانطباعاته عن الكيفية التي يمارس فيها عمله في المنظمة

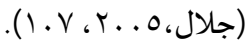

سبل تنمية كفاءة الأداء الإداري :

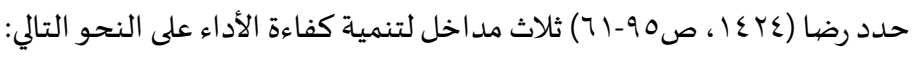

ا. أ. تحسين الموظف:

ويتم ذلك عن طريق التركيز في نواحي القوة لدى الموظف، وتركيز جهود تنمية الاداء في الاستفادة من ما لدياء من مواهب وتنميتها وعلى جانب

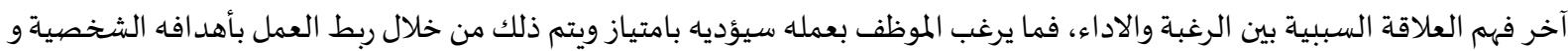
السماح للأفراد بأداء الأعمال التي يرغبون بها أو يبحثون عنها لتوفير الانسجام بين الموظف لرعبه واهتماماته والعمل المؤدى.

r. r. ت تحسين الوظيفة:

وتتمثل في تحديد المهام الضرورية للوظيفة من خلال معرفة مدى ضرورة كل مهمة في العمل خصوصياً أن هناك مهام يتم القيام بها حتى بعد

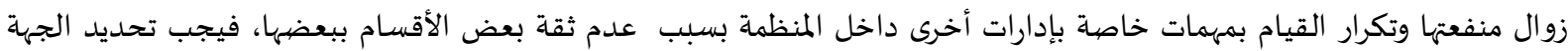

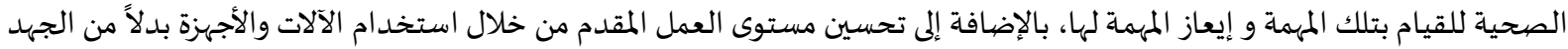

$$
\text { r. البشسين الموقف واستخدام أساليب عمل اكثر فاعلية. }
$$

ويتم ذلك من خلال معرفة مدى مناسبة عدد المستويات التنظيمية والطريقة التي يتم بها تنظيم الجماعة ومدى مناسباه ووضهوح خطوط

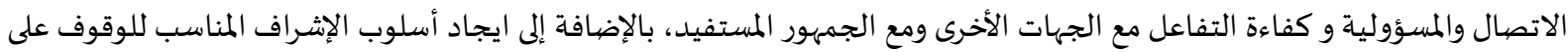
مستوى أداء العاملين. ويتضح مما سبق أن العمليات الإدارية يتم تحسينها من عدة جوانب جميعها جعلت تكنولوجيا المعلومات جزءاً منها من خلال تطوير اداء الموظف عن طريق تدريبه على الأساليب الحديثة في أداء الأعمال، أو تطوير الوظيفة في جانب إدخال التكنولوجيا لرفع كفاءة العمل، أو في جانب الموقف الذي قد يتخذ من تكنولوجيا المعلومات وسيلة فعالة في التخطيط والتنظيم والتنسيق والإشراف.

أثر تكنولوجيا المعلومات على كفاءة الأداء الإداري: على الرغم من الجدل الذي ثار بين الباحثين حول مدى جدوى تكنولوجيا المعلومات وأثرها على الأداء، إلا أنه يكاد يكون هناك شباء اتفاق في

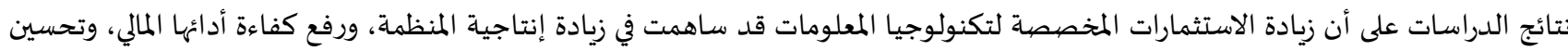
أداء العاملين، ومن ثم يمكن القول بأن تكنولوجيا الخدمات قد ساهمت في تحسين مستويات الأداء في المنظمات الإدارية المعاصرة من خلال تكامل

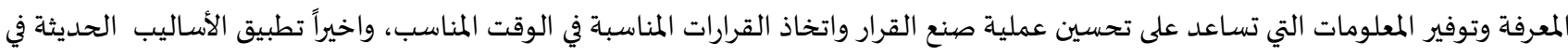

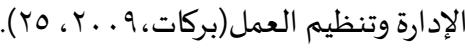


كما توصلت دراسة جلال (ب. . إ) إلى أن الإدارة تحسن من أدائها الإداري عن طريق تطبيق أدوات التكنولوجيا المتقدمة، والعمل على تغيير

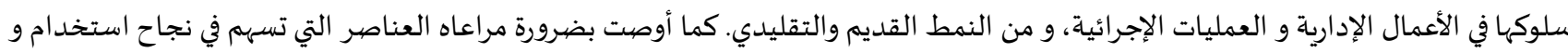

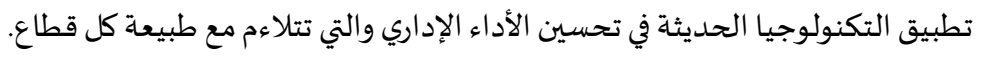

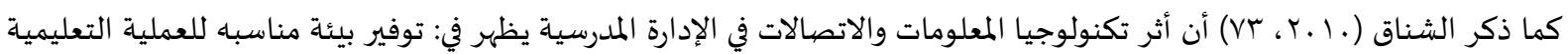

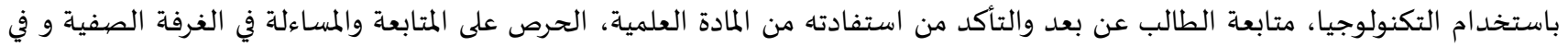

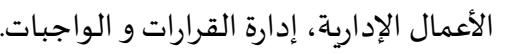

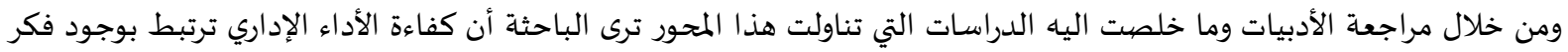

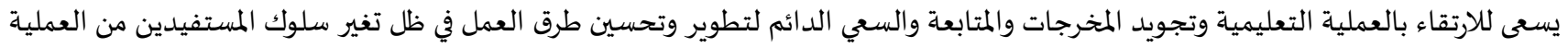

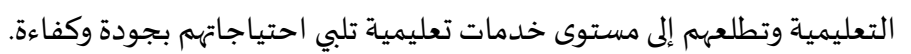

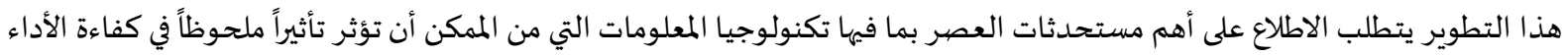

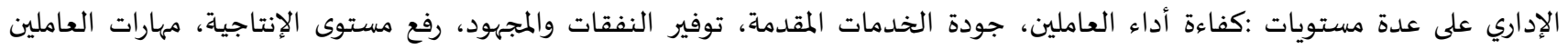
التكنولوجية.

ونتيجة لذلك ينبغي على الإدارة المدرسية السعي لتفعيل دور تكنولوجيا المعلومات و الاتصالات، في ظل المطالبة بجودة الخدمات من قبل

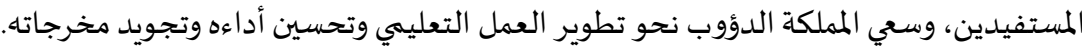

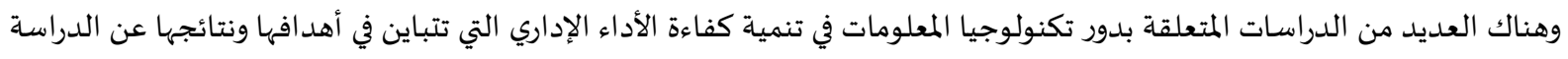
الحالية ومنها

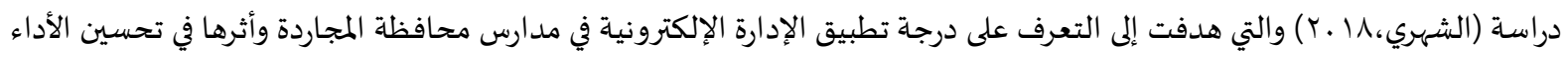

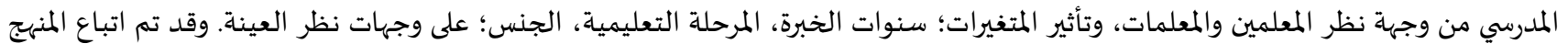

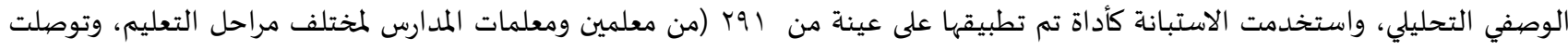

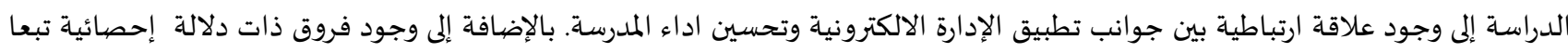

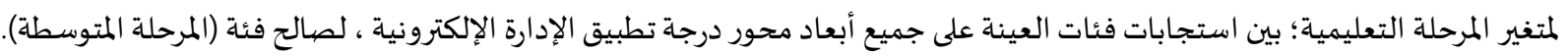

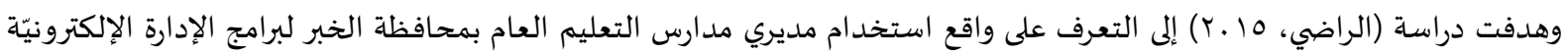

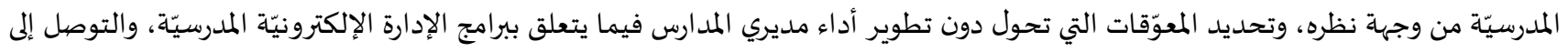

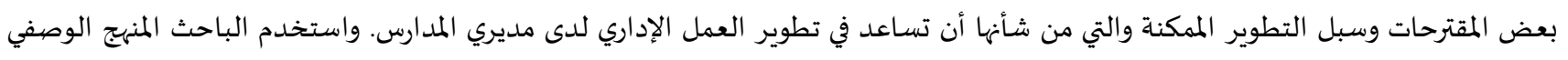

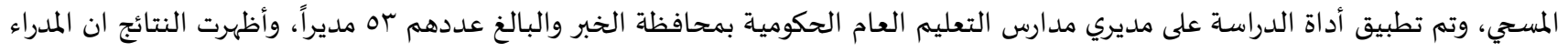

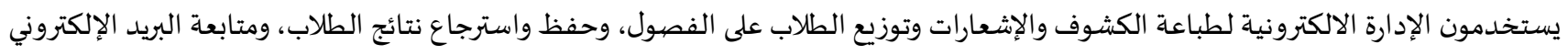

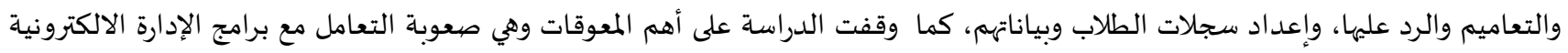

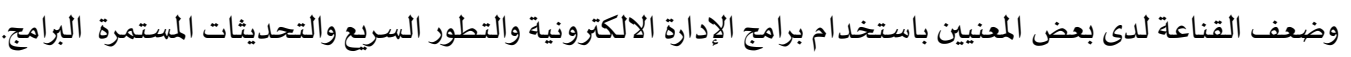

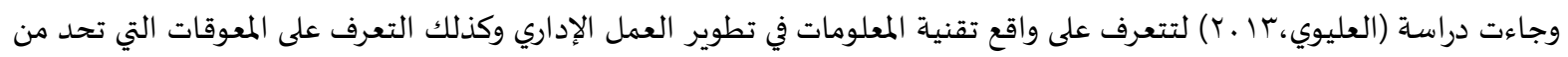

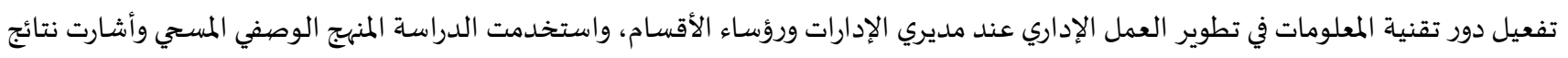

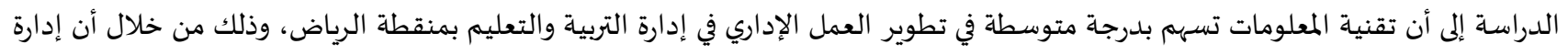

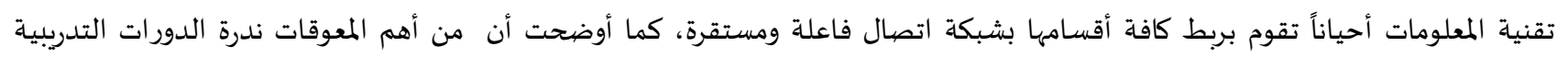

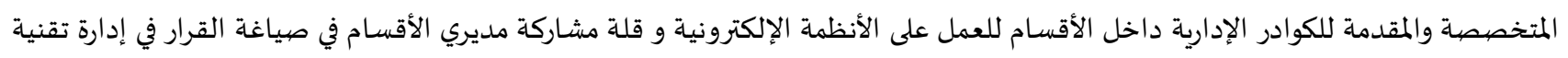
المعلومات بالإضافة إلى ضعف التحفيز المادي والمعنوي لمشغلي الأنظمة الإلكترونية.

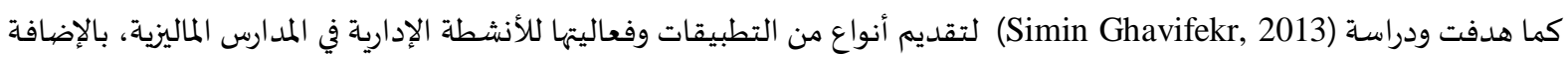

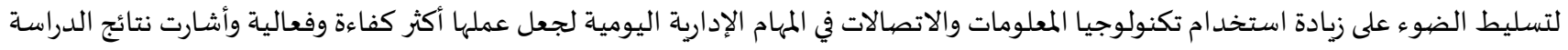

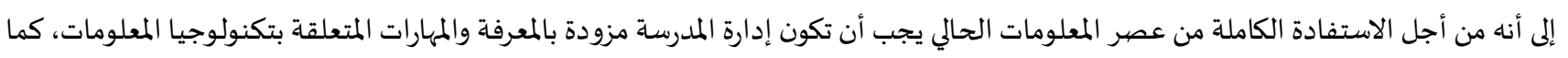

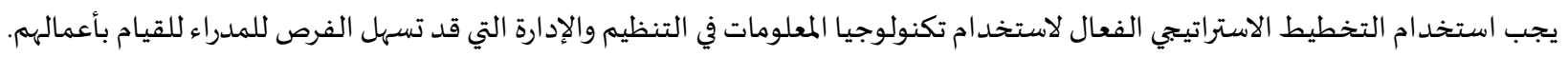

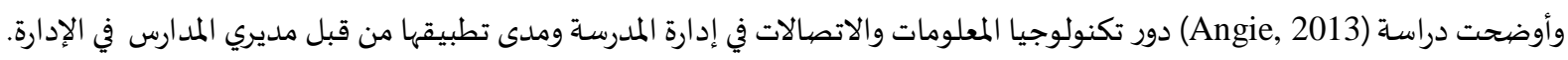

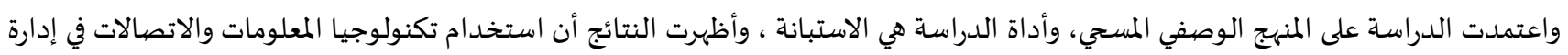


المدرسة ضرورة ومشروع جدير بالاهتمام وخاصة في عصر العولمة، ولكن مدى تطبيقها في المدارس بطيء جدا ومديري المدارس غير أكفاء في التعامل مع

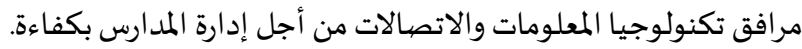
أما دراسة (Makewa, Meremo, Role, 2013) فكشفت عما إذا كان هناك فرق كبير بين تصهورات المعلمين والإداريين على أهمية المعلومات وتكنولوجيا الاتصالات (ICT) في إدارة المدرسة وتقييم مدى استخدام التكنولوجيا من قبل الإداريين، واستخدم المنهج الوصفي المقارن

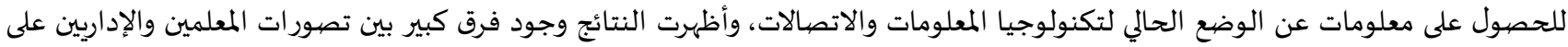

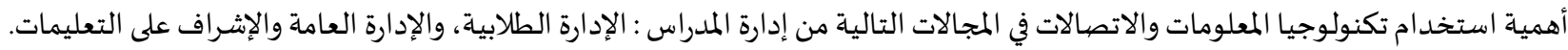

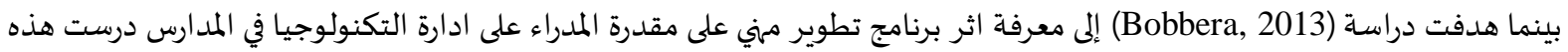
الدراسة البحثية العملية عا مديرا من ولاية فرجينيا في الولايات المتحدة الامريكية، يعملون في منطقة استثمرت موارد مالية كبيرة في اقتناء وتعليم

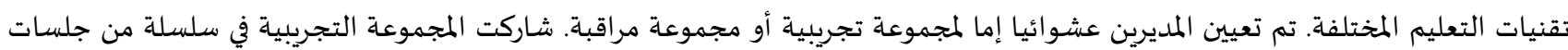
التطوير المهني التي تركز على أساليب التربية التكنولوجية وممارسات القيادة. وقد توصلت هذه الدراسة إلى أن برنامج التطوير المهني الذي يركز على طرق المان

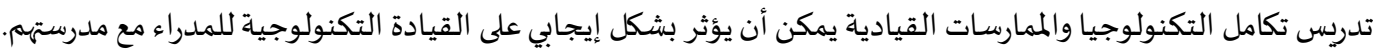
وبحثت دراسة (Akoma, 2012) عن كيفية استخدام قادة المدارس بيانات أداء الطلاب وتحليلها بواسطة أدوات تحليل البيانات القائمة على تكنولوجيا المعلومات للمشاركة في صنع القرار للتحسين المستمر بمدارس احدى المقاطعات في الولايات المتحدة، و شملت هذه الدراسة القادة على ولى مستوى المقاطعة وقادة المدراس والفصول الدراسية، كما استخدمت منهج دراسة الحالة، وقد تم جمع البيانات النوعية من خلال إجراء مقابلات مع

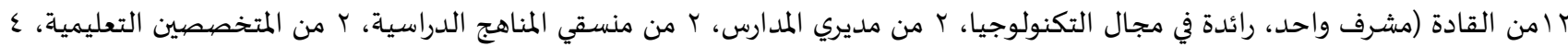

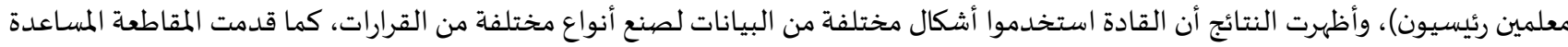

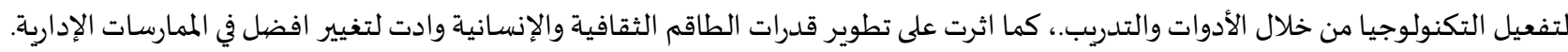
ودراسة ( الهدلق، ج ا ـ ج) التي هدفت الدراسـة للتعرف على واقع الاستخدام الفعلي لتطبيقات تكنولوجيا المعلومات في مجال الإدارة المدرسية بالنسبة لطلاب الماجستير المتخصصين في الإدارة التربوية واستخدمت الدراسة المنهج الوصفي واستخدمت الاستبانة كأداة تم تطبيقها على عينة مكونه

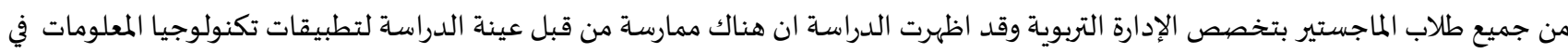
مجال الإدارة المدرسياة بدرجة عالية، ويظهر ذلك من خلال استخدامههم للعديد من البرمجيات التطبيقية/ الانتاجية، بالإضافة إلى وجود أثر فعال

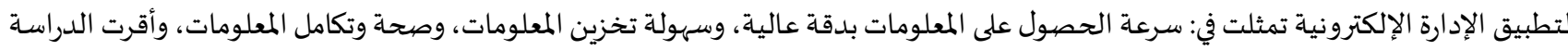
بوجود معوقات تمثلت : ضعف المخصصيات الالية وضعف الكوادر البشرية والقصور في الدورات التدريبية.

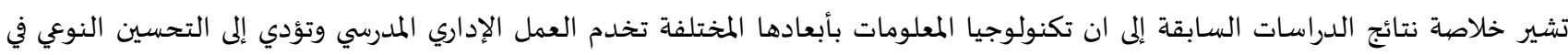
الممارسات الإدارية المختلفة، كما أكدت معظم الدراسات على بعض الماتعات المعات الماتهات الفنية أو المادية أو حتى الثقافية التي قد تحد من امكانية استغلال

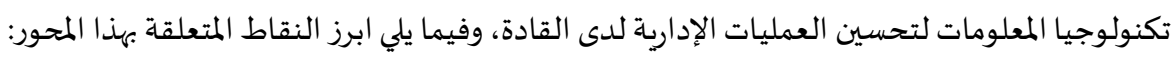

أوجه الشبه بين الدراسة الحالية والدراسـات السـابقة:

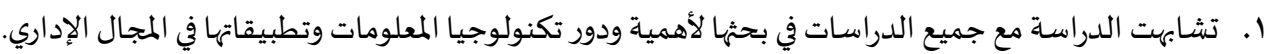

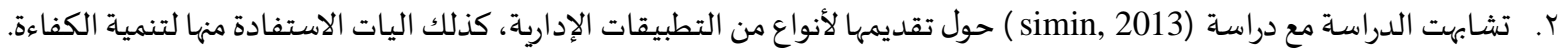

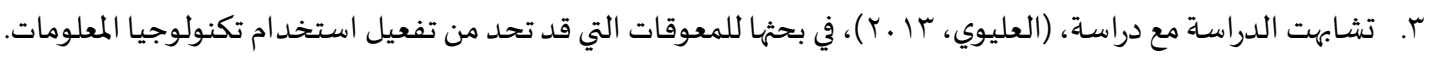

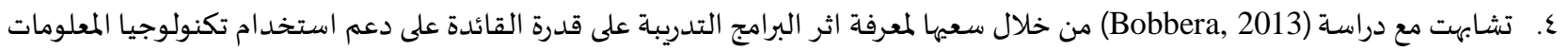
داخل المنظومة الإدارية في المدرسة.

أوجه الاختلاف بين الدراسة الحالية والدراسـات السابقة:

ا. تختلف الدراسـة عن الدراسـات السابقة من خلال تناولها تكنولوجيا المعلومات وطريقة توظيفها لتنمية كفاءة الأداء الإداري.

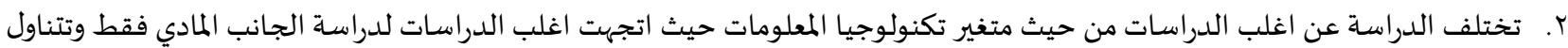
الدراسة الحالية الجانب المادي والبرمجي معاً.

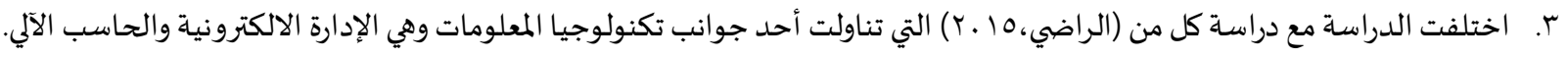

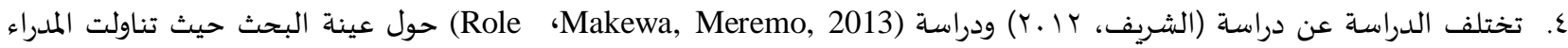
والمعلمين والتي اثرت على نوعية التكنولوجيا المستخدمة حيث تختلف تكنولوجيا المعلومات الإدارية للمدراء عن تكنولوجيا التعليم الخاصية

بالمعلمين. 
اوجـه الاستفادة من الدراسـات السابقة :

وقد استفادت الدراسـة الحالية من الدراسات السابقة بمعرفة أبعاد تكنولوجيا المعلومات المختصة بالإسادارة المدرسية وتحديد منهج الدراسة وأداتهاو أسـاليهها، والاستفادة من الاطر النظرية وأدبيات الدراسات، المراجع التي استندت عليها تلك الدراسات. وعلى ذلك فقد جاءت الدراسة الحالية لتحديد دور ومعوقات تكنولوجيا المعلومات في تنمية كفاءة الأداء الإداري ومتطلبات الإدات تطبيقها من أجل تحقيق الاستفادة المثلى منها، للوصول بالإدارة المدرسية للكفاءة المطلوبة.

مشكلة الدراسة:

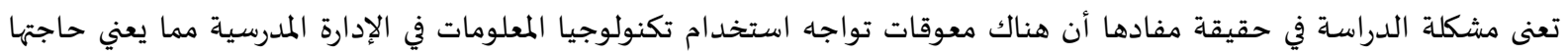

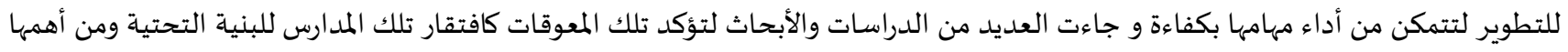

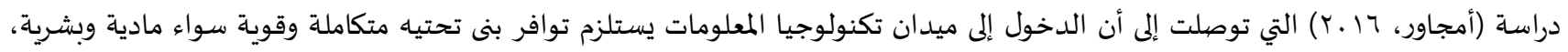

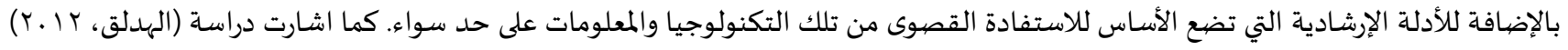

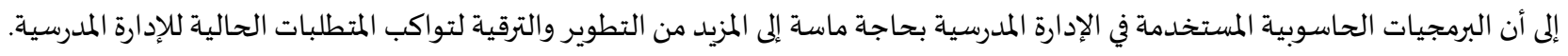

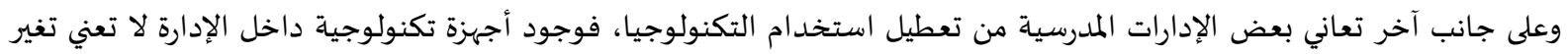

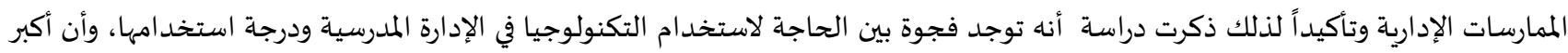

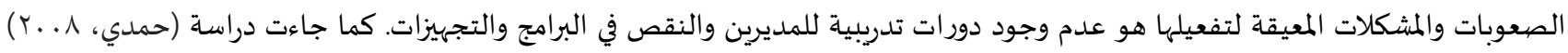

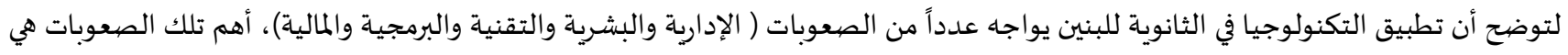

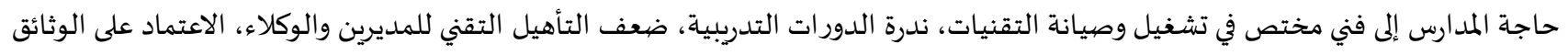

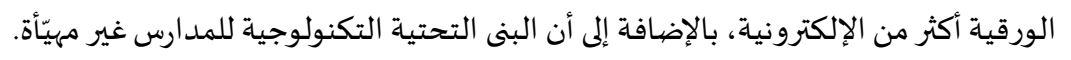

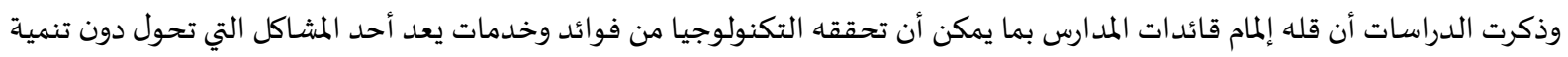

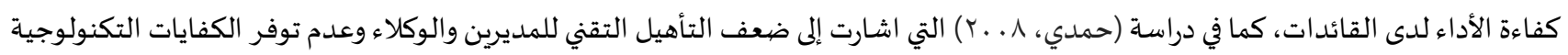

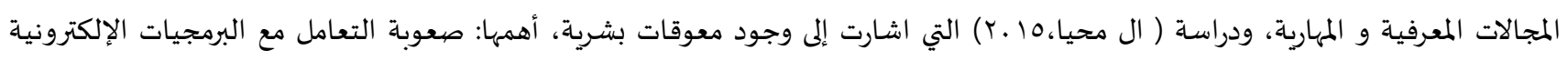

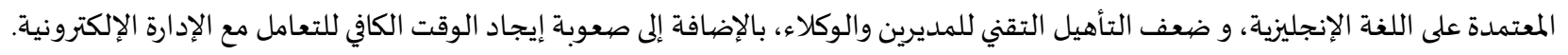

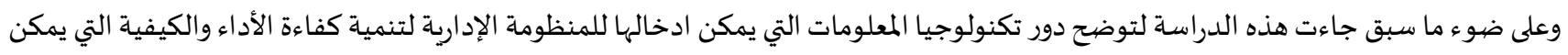

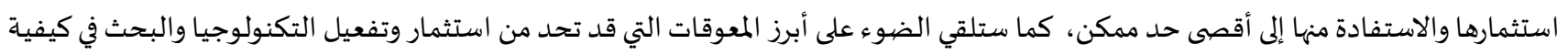

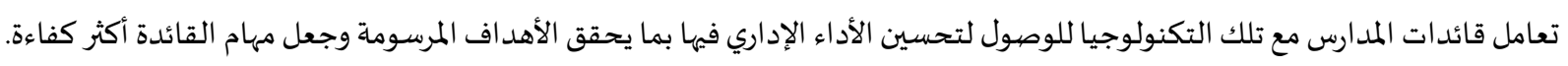
وعليه يمكن تحديد مشكلة الدراسة الحالية في السؤال التالي:

ما دور تكنولوجيا المعلومات في تنمية كفاءة الأداء الإداري لقائدات المدارس المارية المتوسطة في منطقة القصيم من وجهة نظرهن؟ ويتفرع منه الأسئلة الفرعية التالية:

ما واقع دور تكنولوجيا المعلومات في تنمية كفاءة الأداء الإداري لقائدات المدارس في منطقة القصيم من وجهة نظرهن؟ الإبه

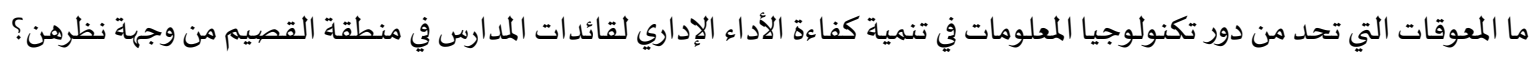

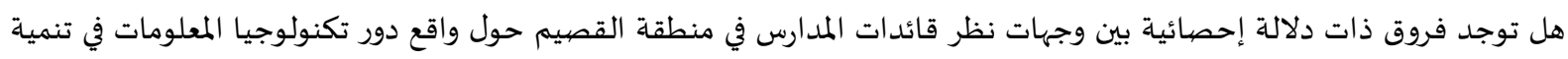

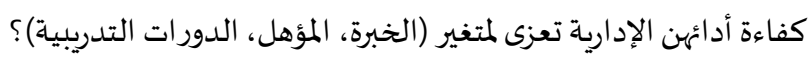

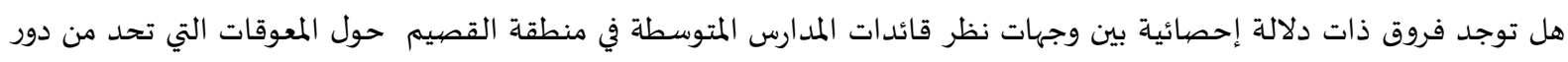

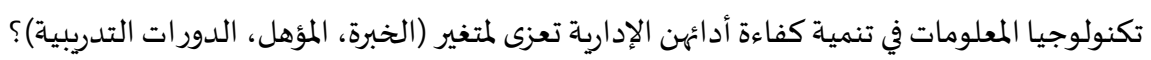

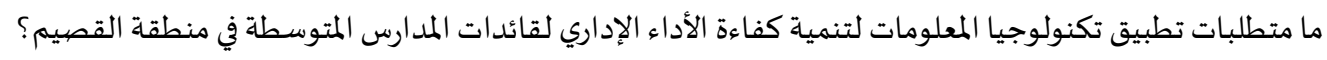

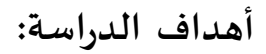

التعرف إلى واقع دور تكنولوجيا المعلومات في تنمية كفاءة الأداء الإداري لقائدات المدارس.

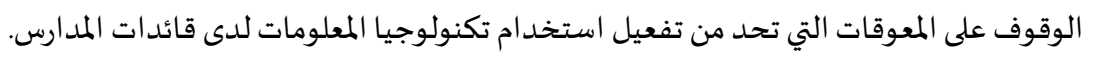
الكشف عن درجة اختلاف وجهات نظر قائدات المدارس حول واقع دور تكنولوجيا المعلومات في تنمية كفاءة أدائهن الإدارية. 
التعرف على درجة اختلاف وجهات نظر قائدات المدارس حول المعوقات التي تحد من دور تكنولوجيا المعلومات في تنمية كفاءة أداههن

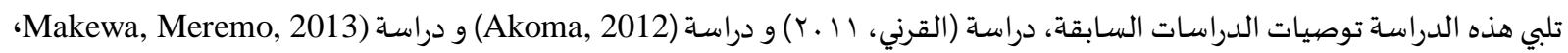
Role )، التي اوصت بأهمية تكنولوجيا المعلومات في المجال الإداري. توفير مادة علمياة قد تفيد القائمين على تطوير العمل الإداري.

الأهمية التطبيقية:

يتوقع أن تخدم هذه الدراسة قائدات المدارس والإداريين العاملين بها في توضيح حيثيات استثمار الموارد التكنولوجية للتحسين والتنمية. تنبع أهمية الدراسة من أثر تكنولوجيا المعلومات في تحسين العمل الإداري والتأثير في كفائتة حيث أن تكنولوجيا المعلومات أحد أهم ركائز

التطوير ومواكبة العصر.

تلبي نتائج الدراسة حاجة القائدات للتنمية المهنية المستدامة. من المتوقع ان تسهم هذه الدراسة بتزويد المسؤولين بوزارة التعليم والإدارات التعليمية ببيانات واضحة عن المستوى التكنولوجي لمنسوبهها.

حسدود الدراسـة:

الحدود الموضوعية: تناولت الدراسـة تكنولوجيا المعلومات وكفاءة الأداء الإداري وتتحدد طبيعة الدراسة بدور مكونات تكنولوجيا المعلومات (

المادية - البرمجية ) التي يمكن توظيفها لتنمية الأداء الإداري. الحدود البشرية: اقتصرت الدراسة الحالية على القائدات الإداريات ( القائدة- الوكيلة) في المدارس المتوسطة في منطقة القصيم. الحدود المكانية: تم تطبيق الدراسة في منطقة القصيم في كل من بريدة، الاسياح، رياض الخبراء، البدائع.

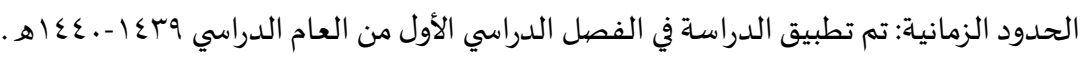

مصبطلحات الدراسـة:

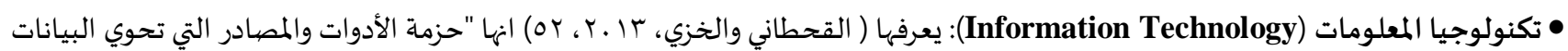
من خلال إدارتها والتواصل بها، ومن تلك الادوات البرمجيات بأنواعها وألواتوسائل الاتصال بأنواعها وما تحويه من وسائل سمعية وبصرية، وما يتصل بذلك كله من مصيادر تتمثل في البنية التحتية اللازمة". وتعرف الباحثة مصطلح تكنولوجيا المعلومات إجر ائياً بأنه الطرق والأساليب والتقنيات المعتمدة في الحصول على المعائه المعلومة ومعالجتها وتخزينها

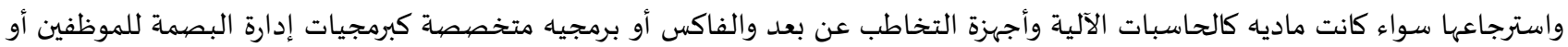
تقييم أداء العاملين أو برمجيات قواعد بيانات للموظفين والطلاب، بالإضافة إلى شبكات الإنترنت والشبكات المحلية داخل المدرسة وغيرها التي تقوم

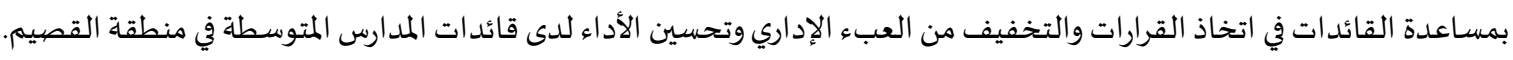
• كفاءة الأداء الإداري (administrative performance Efficiency): هو القدرة على تحقيق الأهداف المرسومة باستخدام الموارد المادية والبشرية، وبمعنى آخر عناصر الانتاج المتاحة الاستخدام الامثل، وتنطوي على القدرة على تحديد أهداف واضحة للعمل والقدرة على اختيار انسب

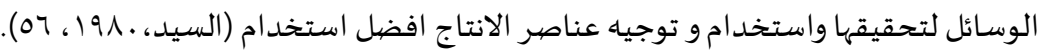

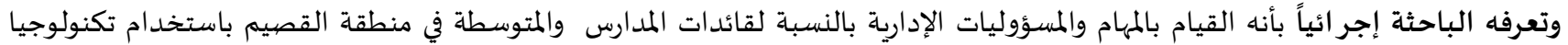

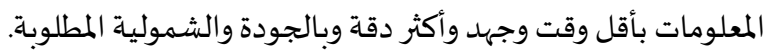
• قائدة المدرسـة (School Leader): عرفها ( الراضي، 10 • (Y) ان قائدة المدرسة هي القائدة التربوية والرئيسة المباشرة والمسؤولة عن جميع العاملين في أحدى مدارس التعليم العام. وتعرفها الباحثة اجر ائياً بأهها مديرة المدرسة التي تقود كل خطوات التهات الدمج والتوظيف لتكنولوجيا المعلومات والاتصالات وتدعمها من خلال كونها نموذجاً يقتدى باه ود اعممه للتنمياة في مدرستها. 
• المدارس المتوسطة (Middle School): هي مرحلة تعليمية مستقلة تلي المرحلة الابتدائية، وتسبق المرحلة الثانوية، "يلتحق بها المتعلم في سن الثانية عشرة من عمره، وهي بذلك تتفق مع الخصائص النفسية والجسمية للطالب في بداية مرحلة المراهقة(وثيقة سياسة التعليم في

المملكة، (1) 17 (1)

وتعرفها الباحثة اجر ائياً بأنها مرحلة تعليمية في التعليم العام يلتحق بها الطالب بعد الحصول على شهادة المرحلة الابتدائية.

الاطار الميداني للدراسـة:

مجتمع الدراسة:

تكون مجتمع الدراسـة من جميع قائدات و وكيلات المدارس المتوسطة في منطقة القصيم وعددهم حبr قائدة ووكيلة (احصياءات تعليم القصيسيم

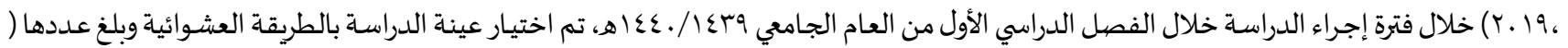

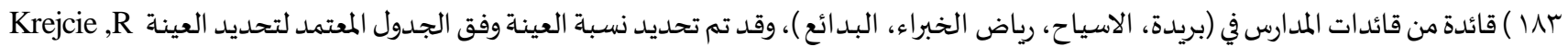
.(\& Morgan, D1970)

خصيائص عينة الدراسة: تم تحديد عدد من المتغيرات الرئيسية لوصف مفردات التهات عينة الدراسـة، وتشمل: (المؤهل العلمي - سنوات الخبرة في العمل الحالي - الدورات

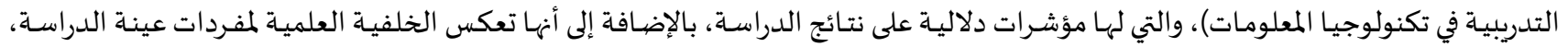

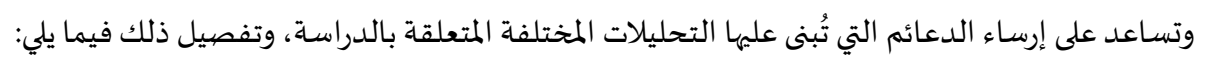
جدول(1) : المتغيرات الرئيسية لوصف عينة الدراسة

\begin{tabular}{|c|c|c|c|}
\hline النسبة & التكرار & & \\
\hline$\Lambda, r$ & 10 & دراسات عليا (دبلوم تربوي - ماجستير - دكتوراه) & \multirow[t]{4}{*}{ 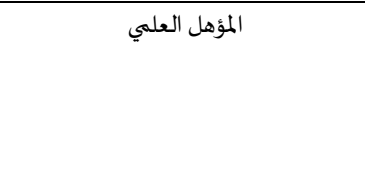 } \\
\hline$V \varepsilon, 9$ & irv & بكالوريوس & \\
\hline 17,9 & r & 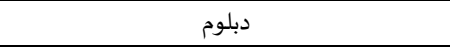 & \\
\hline$\% 1 \ldots$ & int & المجموع & \\
\hline $1 \xi, r$ & rq & اقل من بَ سنوات & \multirow[t]{4}{*}{ سنوات الخبرة في العمل الحالي } \\
\hline 11,7 & $r \varepsilon$ & من r سنوات إلى اقل من 7 سنوات & \\
\hline$T V, Y$ & Irr & I سنوات وأكثر & \\
\hline$\% 1 \ldots$ & int & المجموع & \\
\hline$\varepsilon 1,0$ & $\mathrm{~V} 7$ & لم احضر دورات تدريبية & \multirow[t]{4}{*}{ الدورات التدريبية في تكنولوجيا المعلومات } \\
\hline$\lceil\Lambda, \varepsilon$ & or & حضرت دورة تدريبية واحدة & \\
\hline$r ., 1$ & 00 & حضرت أكثر من دورة تدريبية & \\
\hline$\% 1 .$. & lNr & المجموع & \\
\hline
\end{tabular}

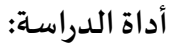

عمدت الدراسة إلى استخدام الاستبانة أداةً لجمع البيانات؛ وذلك نظراً لمناسبتها لأهداف الدراسـة.

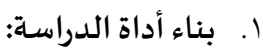

بعد الاطلاع على الأدبيات التربوية، والدراسات السابقة ذات الصلة بموضوع الدراسـة الحالية، وفي ضوء معطيات وتساؤلات الدراسة وأهدافها

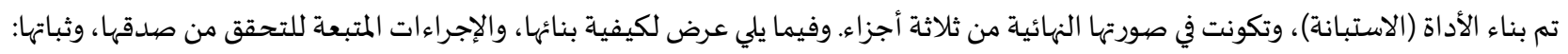

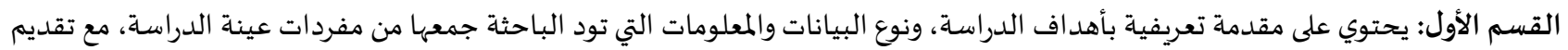

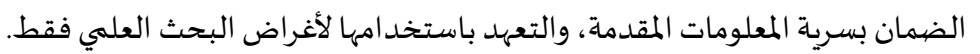

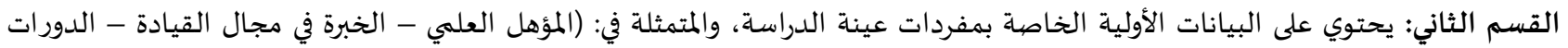
التدربية المختصة بتكنولوجيا المعلومات ). القسم الثالث: ويتكون من (اء) عبارة، موزعاة على ثلاثة محاور أساسية، والجدول (Y-Y) يوضح عدد عبارات الاستبانة، وكيفية توزيعها على المحاور. 
جدول(Y): محاور الاستبانة وعباراتها

\begin{tabular}{|c|c|c|c|}
\hline المجموع & 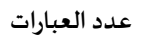 & 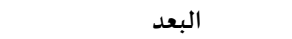 & 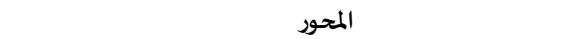 \\
\hline \multirow[t]{4}{*}{10 عبارة } & $\varepsilon$ & المهام الإدارية لقائدة المدرسة & \multirow{4}{*}{ 1- دور تكنولوجيا المعلومات في تنمية كفاءة الأداء الإداري لقائدات } \\
\hline & 0 & التعامل مع البيانات الإدارية & \\
\hline & r & الاجراءات الإدارية & \\
\hline & $r$ & العلاقات الإنسانية والاجتماعية & \\
\hline \multirow[t]{3}{*}{717} & 0 & المعوقات الشخصية & \multirow{3}{*}{ 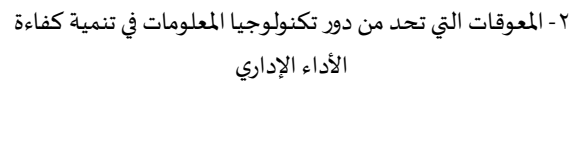 } \\
\hline & $\mathrm{V}$ & المعوقات الفنية & \\
\hline & $\varepsilon$ & المعوقات المالية & \\
\hline \multirow[t]{3}{*}{ 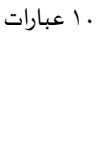 } & r & المتطلبات الشخصية & \multirow[t]{3}{*}{ r- متطلبات تطبيق تكنولوجيا المعلومات لتنمية كفاءة الأداء الإداري } \\
\hline & $\varepsilon$ & المتطلبات الفنية المتية & \\
\hline & $r$ & المتطلبات المالية & \\
\hline
\end{tabular}

تم استخدام مقياس ليكرت الخماسي للحصول على استجابات مفردات عينة الدراسة، وفق درجات الموافقة التالية: (أوفق بشـة - أوفق -

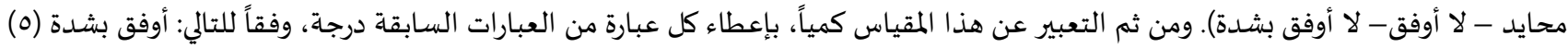

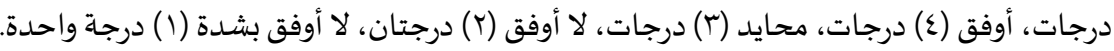

ولتحديد طول فئات مقياس ليكرت الخماسي، تم حساب المدى بطرح الحد الأعلى من الحد الأدنى (0- (1 ع)، ثم تم تقسيماه على أكبر قيمة

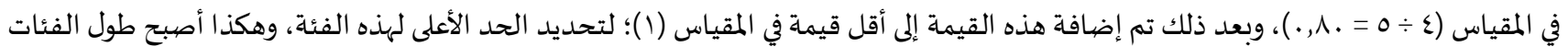
كما هو موضح في الجدول التالي:

جدول(Y): تقسيم فئات مقياس ليكرت الخماسي (حدود متوسطات الاستجابات)

\begin{tabular}{|c|c|c|c|}
\hline \multicolumn{2}{|c|}{ حدود الفئة } & \multirow[t]{2}{*}{ الفئة } & \multirow[t]{2}{*}{ م } \\
\hline إلى & من من & & \\
\hline $0, \ldots$ & $\varepsilon, Y I$ & أوفق بشدة & 1 \\
\hline$\varepsilon, Y$. & $r, \varepsilon 1$ & أوفق & $r$ \\
\hline$r, \varepsilon$. & $r, 71$ & محايد & $r$ \\
\hline$r, 7$. & 1,11 & لا أوفق & $\varepsilon$ \\
\hline 1,A. & $1, \ldots$ & لا أوفق بشدة & 0 \\
\hline
\end{tabular}

وتم استخدام طول المدى في الحصول على حكم موضوعي على متوسطات استجابات مفردات عينة الدراسة، بعد معالجتها إحصيائياً.

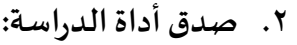
تم التأكد من صبدق أداة الدراسة من خلال: • الصداق الظاهري لأداة الدراسة (صدق المحكِّمين):

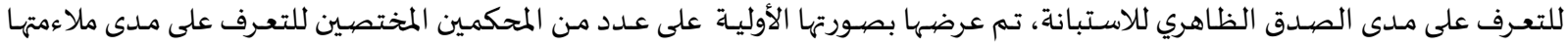

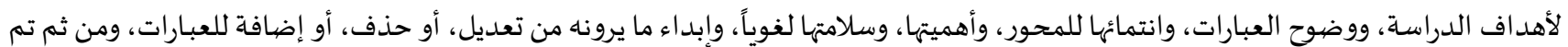
إجراء التعديلات اللازمة التي اتفق عليها غالبية المحكمين، وإخراج الاستبانة بصهورتها النهائية.

$$
\text { صددق الاتساق الداخلي للأداة: }
$$

للتحقق من صدق الاتساق الداخلي للاستبانة، تم حسـاب معامل ارتباط بيرسون (Pearson's Correlation Coefficient)؛ للتعرف على درجـة ارتباط كل عبارة من عبارات الاستبانة بالدرجـة الكلية للبعد الذي تنتهي إليـه العبارة، وتوضهح الجـداول التالية معاملات الارتباط لكل محور من المحاور بما فيها من عبارات. 
جدول(ع): معاملات الارتباط للمحاور

\begin{tabular}{|c|c|c|c|c|}
\hline \multicolumn{5}{|c|}{ المحور الأول: (دور تكنولوجيا المعلومات في تنمية كفاءة الأداء الإداري لقائدات المدارس) } \\
\hline معامل الارتباط بالبعد & رقم العبارة & معامل الارتباط بالبعد & رقم العبارة & البعد \\
\hline$* * ., 9.9$ & r & $*^{* *}$, A V V & 1 & \multirow[t]{2}{*}{ المهام الإدارية لقائدة المدرسة } \\
\hline${ }^{* *} \cdot, \wedge \wedge \varepsilon$ & $\varepsilon$ & **, , גזr & r & \\
\hline${ }^{* *} .$, A $Y_{0}$ & $\wedge$ & **., V97 & 0 & \multirow{3}{*}{ التعامل مع البيانات الإدارية } \\
\hline **.,100 & 9 & $*^{* *}, 779$ & 7 & \\
\hline- & - & **., ᄉ Y $\varepsilon$ & $\mathrm{v}$ & \\
\hline **., ^乏१ & ir & $*^{* *}, \mathrm{~V} \varepsilon r$ & 1. & \multirow[t]{2}{*}{ الاجراءات الإدارية } \\
\hline - & - & ${ }^{* *} \cdot, \wedge . \varepsilon$ & 11 & \\
\hline${ }^{* *} \cdot, \wedge \cdot 1$ & 10 & ${ }^{* *} \cdot, \wedge 11$ & ir & \multirow[t]{2}{*}{ العلاقات الإنسانية والاجتماعية العاعية } \\
\hline- & - & $*^{* *}, q . r$ & I乏 & \\
\hline \multicolumn{5}{|c|}{ المحور الثاني: (المعوقات التي تحد من دور تكنولوجيا المعلومات في تنمية كفاءة الأداء الإداري) } \\
\hline 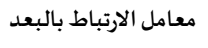 & 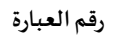 & معامل الارتباط بالبعد & 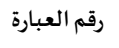 & 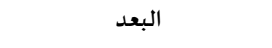 \\
\hline${ }^{* *}, \mathrm{Vr}$. & $\varepsilon$ & **., Trv & 1 & \multirow[t]{3}{*}{ 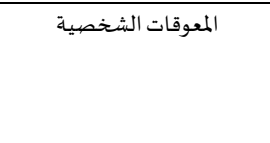 } \\
\hline **., Үा. & $\circ$ & $*^{* *}, \mathrm{v9} 0$ & r & \\
\hline - & - & **.,7ו1 & $r$ & \\
\hline **.,人ץ. & 1. & **,, 7 T & 7 & \multirow[t]{4}{*}{ 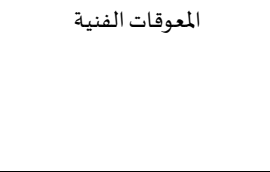 } \\
\hline **.,TVY & 11 & **, , 10. & v & \\
\hline${ }^{* *}$, , OV $\varepsilon$ & ir & ${ }^{* *} \cdot, \wedge \varepsilon \varepsilon$ & $\wedge$ & \\
\hline- & - & ${ }^{* *} \cdot, \mathrm{Vr} /$ & 9 & \\
\hline **.,AVr & 10 & $*^{* *}, \mathrm{\Lambda \wedge V}$ & ir & \multirow[t]{2}{*}{ 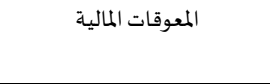 } \\
\hline${ }^{* *} \cdot, \wedge .7$ & 17 & $* * ., 10$ & $1 \varepsilon$ & \\
\hline \multicolumn{5}{|c|}{ المححور الثالث: (متطلبات تطبيق تكنولوجيا المعلومات لتنمية كفاءة الأداء الإداري) } \\
\hline 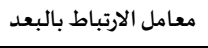 & 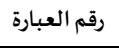 & 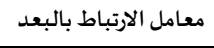 & 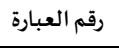 & 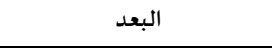 \\
\hline **., $9 \varepsilon$. & $r$ & **., qrr & 1 & \multirow[t]{2}{*}{ المتطلبات الشخصية } \\
\hline- & - & ${ }^{* *} ., 909$ & $r$ & \\
\hline$*^{* *}, 9991$ & 7 & ${ }^{* *} ., 9 \leq V$ & $\varepsilon$ & \multirow[t]{2}{*}{ المتطلبات الفنية } \\
\hline **.,人rr & $\mathrm{v}$ & **., qVV & 0 & \\
\hline${ }^{* *} \cdot, \Lambda Y Y$ & 1. & ${ }^{* *},, 9 \wedge 1$ & $\wedge$ & \multirow[t]{2}{*}{ المتطلبات المالية } \\
\hline - & - & **.,9V। & 9 & \\
\hline
\end{tabular}

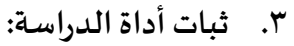
تم التأكد من ثبات أداة الدراسة من خلال استخدام معامل الثبات ألفا كرونباخ (معادلة ألفا كرونباخ) (م) (Cronbach's Alpha)، ويوضح الجدول (0) قيم معاملات الثبات ألفا كرونباخ لكل محور من محاور الاستبانة. جدول (0): معامل ألفا كرونباخ لقياس ثبات أداة الدراسة

\begin{tabular}{|c|c|c|c|}
\hline ثبات المحتور & عدد العبارات & \multicolumn{2}{|c|}{ 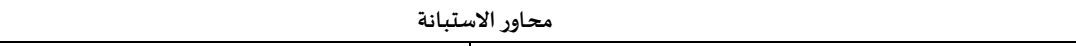 } \\
\hline$\cdot, \wedge \wedge \varepsilon \varepsilon$ & $\varepsilon$ & المهام الإدارية لقائدة المدرسة & \multirow{4}{*}{ 1- دور تكنولوجيا المعلومات في تنمية كفاءة الأداء الإداري لقائدات } \\
\hline$\cdot, \wedge 01 \%$ & ० & التعامل مع البيانات الإدارية & \\
\hline.,$\times 1.7$ & $r$ & الاجراءات الإدارية & \\
\hline$\cdot, \mathrm{\vee A} \cdot 1$ & $r$ & العلاقات الإنسانية والاجتماعية & \\
\hline., $\mathrm{\vee १ \wedge \Lambda}$ & 0 & المعوقات الشخصية & \multirow{3}{*}{ ץ - المعوقات التي تحد من دور تكنولوجيا المعلومات في تنمية كفاءة الأداء } \\
\hline$\cdot, \wedge \cdot \vee \cdot$ & v & 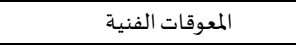 & \\
\hline . AVTr & $\varepsilon$ & المعوقات المالية & \\
\hline., 9 м ल & $r$ & المتطلبات الشخصية & \multirow[t]{3}{*}{ r- متطلبات تطبيق تكنولوجيا المعلومات لتنمية كفاءة الأداء الإداري } \\
\hline., $90 \leqslant \varepsilon$ & $\varepsilon$ & المتطلبات الفنية & \\
\hline., 9109 & $r$ & المتطلبات المالية & \\
\hline , VOTV & $\varepsilon$ & \multicolumn{2}{|c|}{ الثبات العام } \\
\hline
\end{tabular}

يتضح من الجدول (V) أن معامل الثبات العام عالٍ حيث بلغ (VOrV,.))، وهذا يدل على أن الاستبانة بصيورتها النهائية تتمتع بدرجة ثبات مرتفعة يمكن الاعتماد عليها في التطبيق الميد اني للدراسـة. 
تحليل نتائج اسئلة الدراسة وتفسيرها: أولاً: إجابة السؤال الأول: ما و اقع دور تكنولوجيا المعلومات في تنمية كفاءة الأداء الإداري لقائدات المدارس المتوسطة في منطقة القصيم من وجهة نظرهن ؟ و أجابة

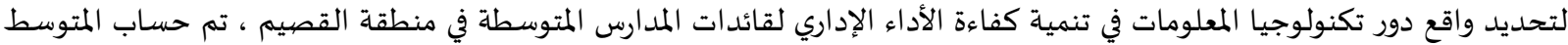

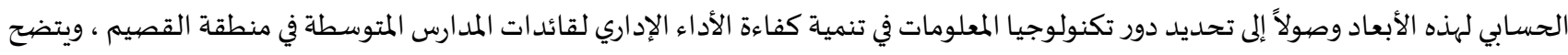
ذلك من جدول (7) - (7)

جدول (7) استجابات مفردات عينة الدراسة على و اقع دور تكنولوجيا المعلومات في تنمية كفاءة الأداء الإداري لقائدات المدارس المتوسطة في منطقة القصيم

\begin{tabular}{|c|c|c|c|c|}
\hline 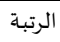 & الانحراف المعياري & المتوسط الحسابي & البعد & م \\
\hline 1 &., $0 . \mathrm{r}$ & $\varepsilon, \sum \Lambda$ & المهام الإدارية لقائدة المدرسة & 1 \\
\hline$r$ &., 0.7 & $\varepsilon, r \varepsilon$ & التعامل مع البيانات الإدارية & r \\
\hline r & . ore & $\varepsilon, \mathrm{rv}$ & 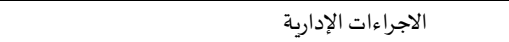 & $r$ \\
\hline$\varepsilon$ &., 710 & $\varepsilon, r_{0}$ & العلاقات الإنسانية والاجتماعية & $\varepsilon$ \\
\hline - & ., 200 & $\varepsilon, r v$ & \multicolumn{2}{|c|}{ و اقع دور تكنولوجيا المعلومات في تنمية كفاءة الأداء الإداري لقائدات المدارس المتوسطة في منطقة القصيم } \\
\hline
\end{tabular}

يتضح من خلال النتائج الموضحة أعلاه أن عينة الدراسة وافقن بشدة على دور تكنولوجيا المعلومات في تنمية كفاءة الأداء الإداري لقائدات

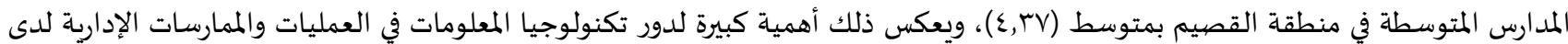

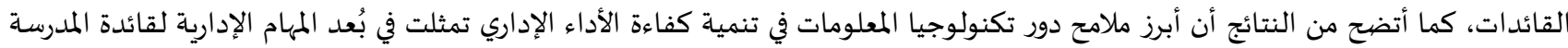

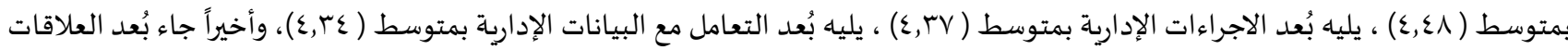
الإنسانية والاجتماعية بمتوسط ( 0 , ع)، و يعزى ذلك لدور دمج تكنولوجيا المعلومات بأجهزتها وبرمجياتها في الإدارة المدرسية حيث تجعل التكنولوجيا

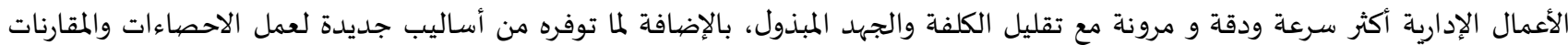

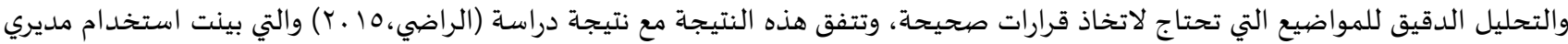

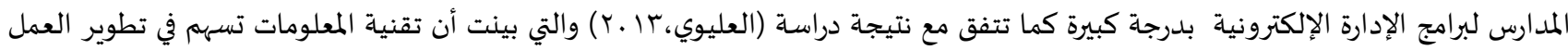

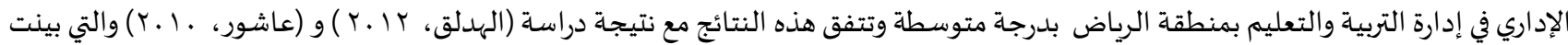
أن هناك ممارسة لتطبيقات تكنولوجيا المعلومات بدرجة عالية. البُعد الأول: المهام الإدارية لقائدة المدرسهة:

للتعرف على واقع دور تكنولوجيا المعلومات في تنمية كفاءة الأداء الإداري لقائدات المدارس المتوسطة في منطقة الماتدة القصيم فيما يتعلق ببُعد المهام الإدارية لقائدة المدرساة، تم حساب التكرارات، والنسب المئوية، والمتوسطات الحسابية، والانحرافات المعيارية، والرتب لاستجابات عينة الدراسة على عبارات بُعد المهام الإدارية لقائدة المدرسة ، وجاءت النتائج كما يلي: جدول (V): و اقع دور تكنولوجيا المعلومات في تنمية كفاءة الأداء الإداري في بُعد المهام الإدارية لقائدة المدرسة

\begin{tabular}{|c|c|c|c|c|c|c|c|c|c|c|c|}
\hline \multirow[t]{2}{*}{ الرتبة } & \multirow[t]{2}{*}{ درجة التحقق } & \multirow{2}{*}{ المعياري } & \multirow{2}{*}{ الحسبابي } & \multicolumn{5}{|c|}{ درجة الموافقة } & التكرار & \multirow[t]{2}{*}{ العبارات } & \multirow[t]{2}{*}{ م } \\
\hline & & & & لاأو افق بشدة & لا أو افق & محايد & أو افق & أو افق بشدة & النسبة \% & & \\
\hline \multirow[t]{2}{*}{1} & \multirow[t]{2}{*}{ كبيرة جداً } & \multirow[t]{2}{*}{., $70 \mathrm{r}$} & \multirow[t]{2}{*}{$\varepsilon, 00$} & 1 & $r$ & $\varepsilon$ & $7 \varepsilon$ & $11 r$ & ك & \multirow{2}{*}{ يوفر استخدم تكنولوجية المدروار المعلومات في } & r \\
\hline & & & &., 0 & 1,1 & $r, Y$ & ro & $71, Y$ & $\%$ & & \\
\hline \multirow[t]{2}{*}{$r$} & \multirow[t]{2}{*}{ كبيرة جداً } & \multirow[t]{2}{*}{., $01 Y$} & \multirow[t]{2}{*}{$\varepsilon, \varepsilon 9$} & - & 1 & 。 & $\Lambda$. & $9 V$ & ك & \multirow{2}{*}{ 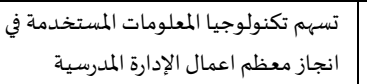 } & 1 \\
\hline & & & & - &., 0 & $r, \mathrm{~V}$ & $\varepsilon r, \lambda$ & or & $\%$ & & \\
\hline \multirow[t]{2}{*}{$r$} & \multirow[t]{2}{*}{ كبيرة جداً } & \multirow[t]{2}{*}{ רוד, } & \multirow[t]{2}{*}{$\varepsilon, \varepsilon 7$} & 1 & - & $\wedge$ & va & 97 & ك ك & \multirow{2}{*}{ تالإداري أداء مهامه الإدارية } & $\varepsilon$ \\
\hline & & & &., 0 & - & $\varepsilon, \varepsilon$ & $\varepsilon r, \uparrow$ & $O r, O$ & $\%$ & & \\
\hline \multirow[t]{2}{*}{$\varepsilon$} & \multirow[t]{2}{*}{ كبيرة جداً } & \multirow[t]{2}{*}{., 70} & \multirow[t]{2}{*}{$\varepsilon, \varepsilon T$} & - & $r$ & 1. & $\mathrm{ru}$ & $9 r$ & ك & \multirow{2}{*}{ 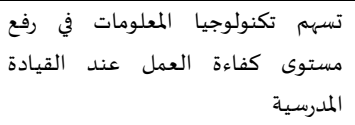 } & $r$ \\
\hline & & & & - & 1,1 & 0,0 & $\varepsilon r, 7$ & $0 ., 1$ & $\%$ & & \\
\hline \multicolumn{3}{|c|}{., $0 . \mathrm{r}$} & & $\varepsilon, \varepsilon \wedge$ & \multicolumn{6}{|c|}{ المتوسط العام } & \\
\hline
\end{tabular}

يتضح في الجدول (9) أن مفردات عينة الدراسة وافقن بشـة على دور تكنولوجيا المعلومات في تنمية كفاءة الأداء الإداري لقائدات المدارس

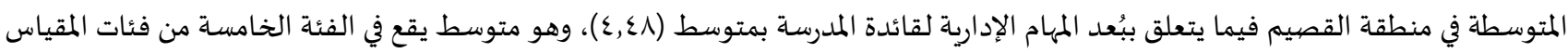
الخماسي (من إ, ع إلى . .,0)، وهي الفئة التي تشير إلى خيار أوافق بشدة على أداة الدراسة. 
كما يتضح أن عينة الدراسة موافقات بشدة على أربعة من أدوار تكنولوجيا المعلومات في تنمية كفاءة الأداء الإداري لقائدات المدارس

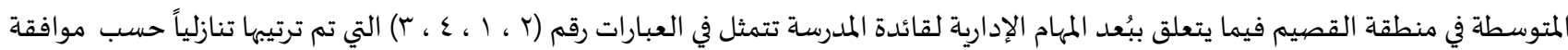

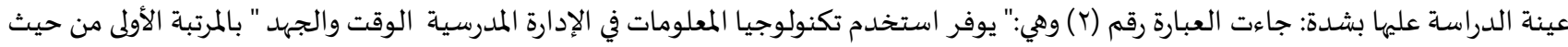

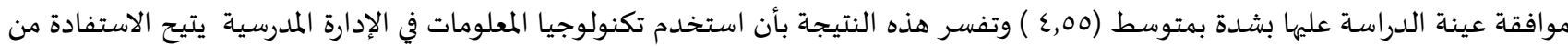

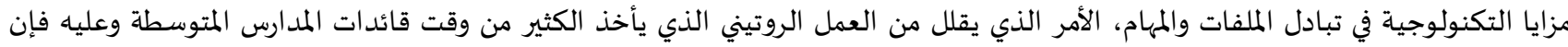

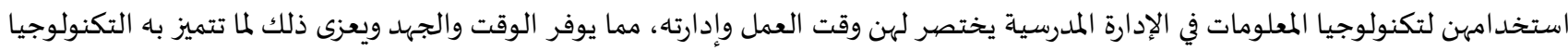

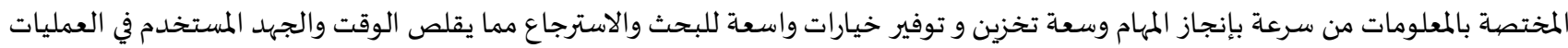
الإدارية المختلفة.

جاءت العبارة رقم (1) وهي:" تسهم تكنولوجيا المعلومات المستخدمة في انجاز معظم اعمال الإدارة المدرسية " بالمرتبة الثانية من حيث موافقة عينة الدراسـة عليها بشدة بمتوسط (9)؛,ع ) وتفسر هذه النتيجة بأن استخدم تكنولوجيا المعلومات تتيح إنجاز المهام من خلال العمل الإلكتروني في الإدارة المدرسية كتنظيم وحفظ الملفات واتخاذ القرارات والتوصيات الفورية وتحليل النتائج وإصدار أحكام أحسام متعلقة بمستويات أداء الطالبات بدقة ونظام وسرعة مما يؤكد اسهام تكنولوجيا المعلومات في انجاز معظم اعمال الإدارة المدرسية بكفاءة،

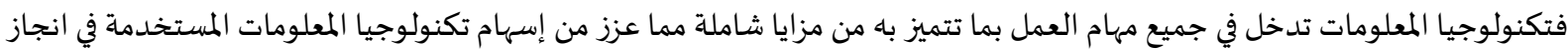
معظم اعمال الإدارة المدرسية. جاءت العبارة رقم (ع) وهي:" تيسر تكنولوجيا المعلومات على الطاقم الإداري أداء مهامه الإدارية " بالمرتبة الثالثة من حيث موافقة عينة

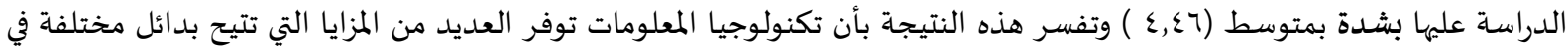

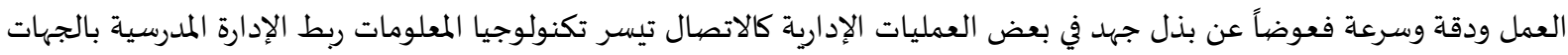

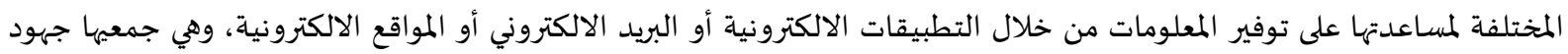

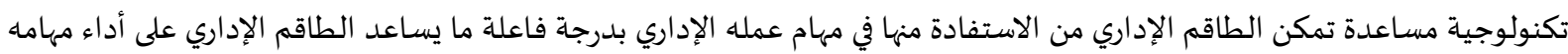

$$
\text { الإدارياة بيسر وسهولة. }
$$

جاءت العبارة رقم (r) وهي:" تسهم تكنولوجيا المعلومات في رفع مستوى كفاءة العمل عند القيادة المدرسية " بالمرتبة الرابعة من حيث

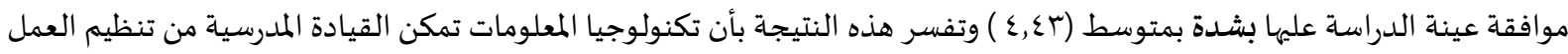

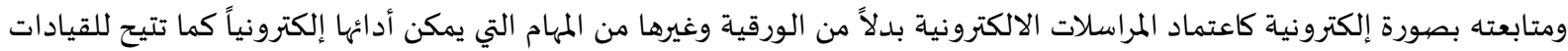

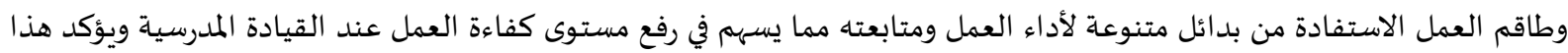

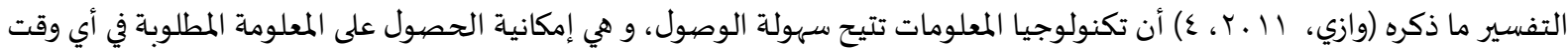

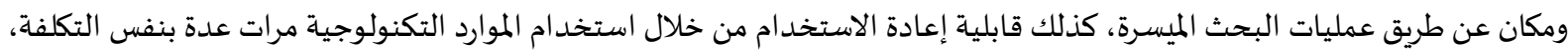
كما لا يمكن إغفال الإنتاجياة، التي تعني زيادة الكفاءة عن طريق التقليل من التكلفة والزمن اللازمين للعمليات الإدارية بإنتاجياء أفضل. البُعد الثاني: التعامل مع البيانات الإدارية:

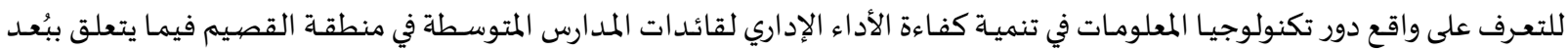

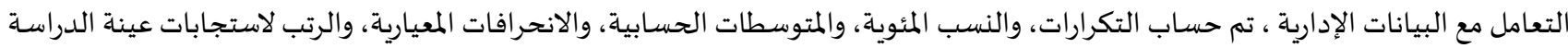
على عبارات بُعد التعامل مع البيانات الإدارية ، وجاءت البدات النتائج كما يلي: جدول(^): و اقع دور تكنولوجيا المعلومات في تنمية كفاءة الأداء الإداري في بُعد التعامل مع البيانات الإدارية

\begin{tabular}{|c|c|c|c|c|c|c|c|c|c|c|c|}
\hline \multirow[t]{2}{*}{ الرتبة } & \multirow{2}{*}{ التحقق درجة } & \multirow{2}{*}{ المعياري } & \multirow{2}{*}{ المتوسابي } & \multicolumn{5}{|c|}{ درجة الموافقة } & \multirow{2}{*}{ النسبة \% التكرار } & \multirow[t]{2}{*}{ العبارات } & \multirow[t]{2}{*}{ م } \\
\hline & & & & لا أو افق بشدة & لا أو افق & محايد & أو افق & أو افق بشدة & & & \\
\hline \multirow[t]{2}{*}{1} & \multirow{2}{*}{ كبيرة جداً } & \multirow{2}{*}{., 0.1} & \multirow[t]{2}{*}{$\varepsilon, \pi T$} & - & - & $r$ & 70 & 117 & ك & \multirow{2}{*}{\multicolumn{2}{|c|}{ 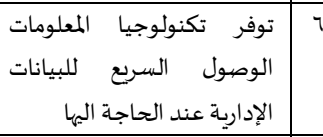 }} \\
\hline & & & & - & - & 1,1 & ro,o & Tr, & $\%$ & & \\
\hline \multirow[t]{2}{*}{$r$} & \multirow[t]{2}{*}{ كبيرة جداً } & \multirow[t]{2}{*}{., $\mathrm{OVT}$} & \multirow[t]{2}{*}{$\varepsilon, \varepsilon \wedge$} & - & - & $\mathrm{v}$ & 11 & 90 & ك & \multirow{2}{*}{\multicolumn{2}{|c|}{ 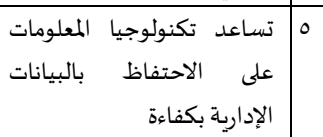 }} \\
\hline & & & & - & - & $r, \lambda$ & $\varepsilon \varepsilon, r$ & 01,9 & $\%$ & & \\
\hline \multirow[t]{2}{*}{$r$} & \multirow[t]{2}{*}{ كبيرة جداً } & \multirow[t]{2}{*}{. TVV } & \multirow[t]{2}{*}{$\varepsilon, r \varepsilon$} & - & $r$ & 10 & $\Lambda \varepsilon$ & NT & ك & \multirow{2}{*}{ 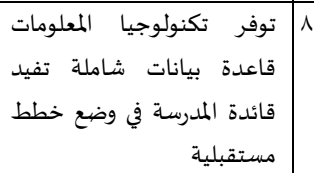 } & $\Lambda$ \\
\hline & & & & - & 1,1 & $\Lambda, r$ & $\{0,9$ & $\varepsilon \varepsilon, \lambda$ & $\%$ & & \\
\hline
\end{tabular}

r.. 


\begin{tabular}{|c|c|c|c|c|c|c|c|c|c|c|c|}
\hline \multirow[t]{2}{*}{$\varepsilon$} & \multirow{2}{*}{ كبيرة جداً } & \multirow{2}{*}{, , VTr } & \multirow[t]{2}{*}{$\varepsilon, Y T$} & - & 0 & IV & $9 \varepsilon$ & $7 V$ & ك & \multirow{2}{*}{ قائدة المدرسة تكنولوجيا المعلومات } & 9 \\
\hline & & & & - & $r, V$ & $q, r$ & $01, \varepsilon$ & $r 7,7$ & $\%$ & & \\
\hline \multirow[t]{2}{*}{0} & \multirow[t]{2}{*}{ كبيرة } & \multirow[t]{2}{*}{$\cdot, \lambda \backslash \wedge$} & \multirow[t]{2}{*}{$\varepsilon, . \varepsilon$} & - & 9 & $r$. & $\Lambda$ & 07 & ك & \multirow{2}{*}{ 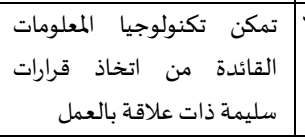 } & V \\
\hline & & & & - & $\varepsilon, q$ & $17, \varepsilon$ & $\varepsilon \wedge, 1$ & $r_{.}, \tau$ & $\%$ & & \\
\hline \multicolumn{2}{|r|}{., 0.7} & & $\varepsilon, r \varepsilon$ & \multicolumn{6}{|c|}{ المتوسط العام } & & \\
\hline
\end{tabular}

يتضح من جدول (^) أن عينة الدراسة موافقات بشدة على دور تكنولوجيا المعلومات في تنمية كفاءة الأداء الإداري لقائدات المدارس

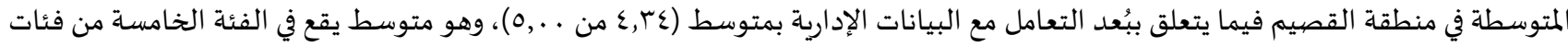

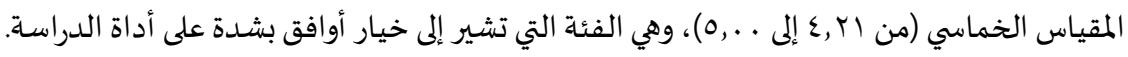

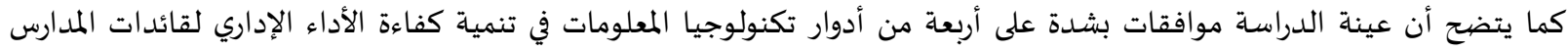

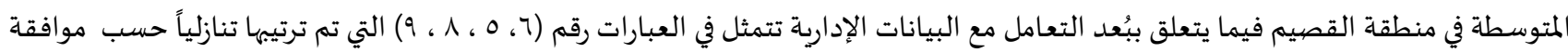
عينة الدراسة عليها بشدة ، كالتالي:

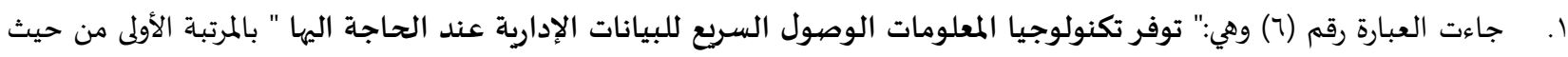

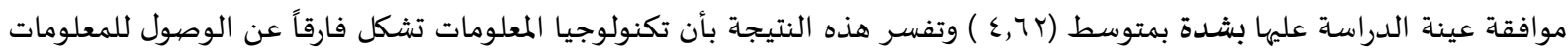

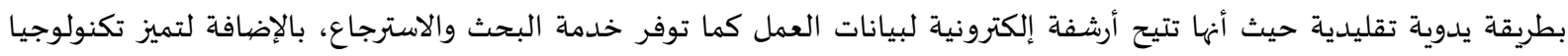

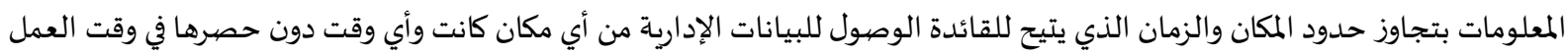

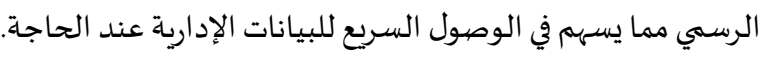

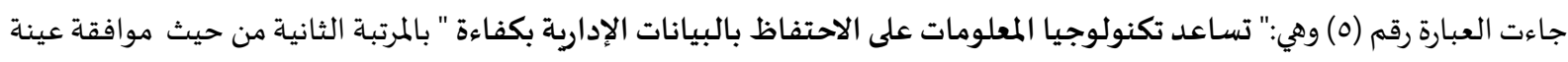

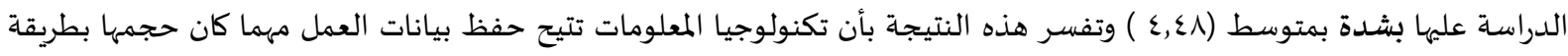

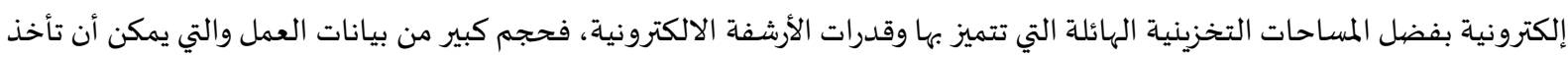

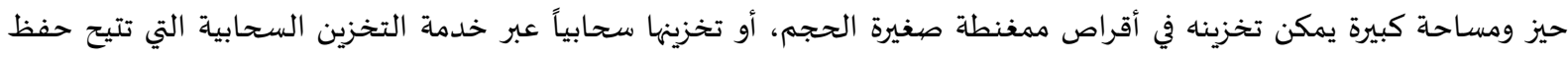

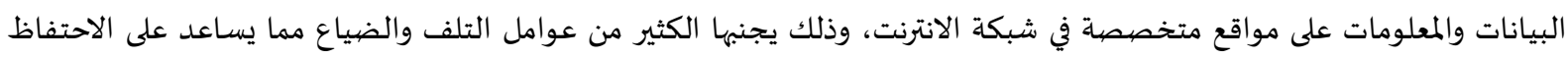
بالبيانات الإدارية بكفاءة.

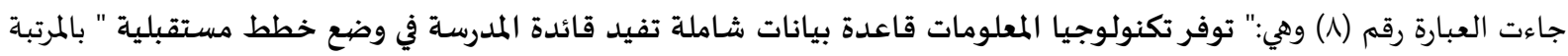

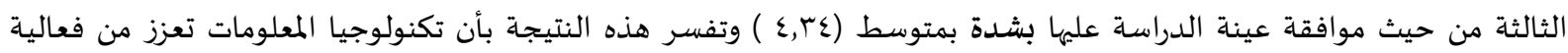

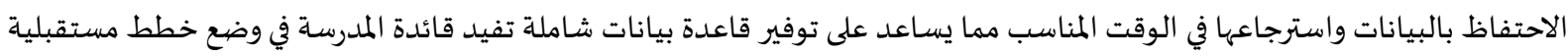

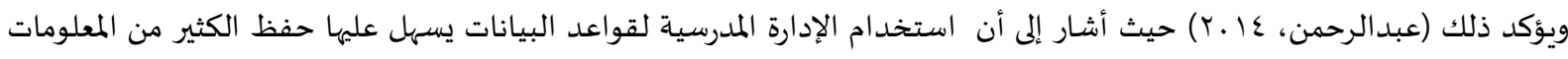

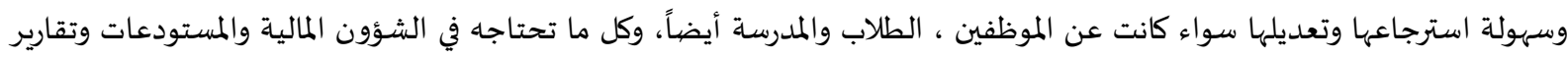

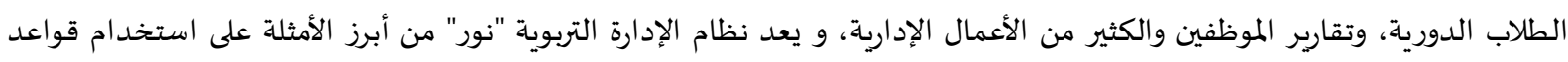

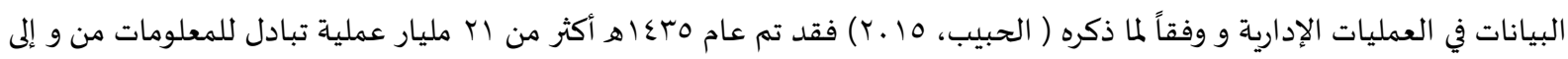

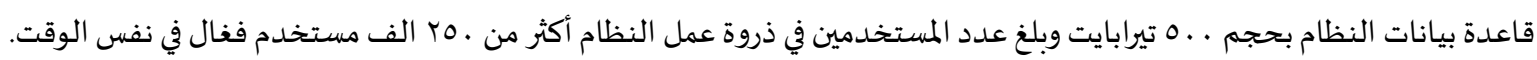

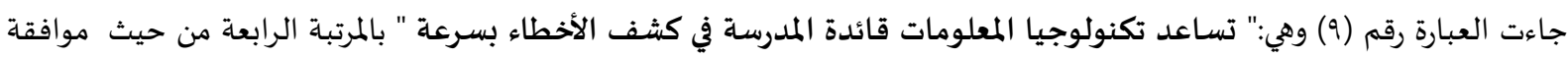

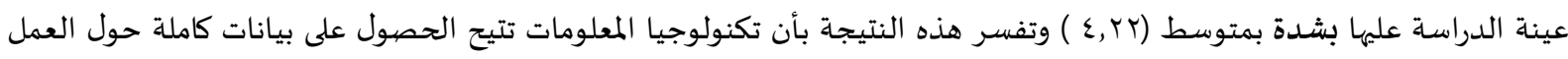

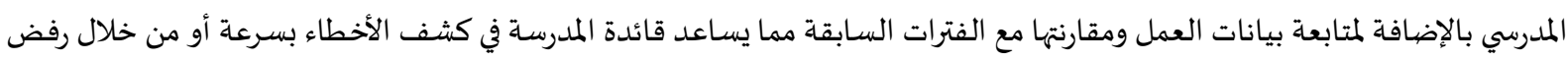
بعض البرمجيات للإدخال الخاطئ للمعلومات.

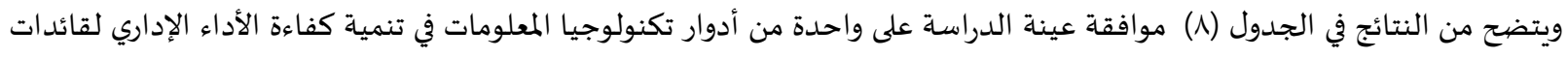

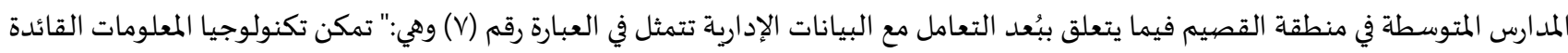

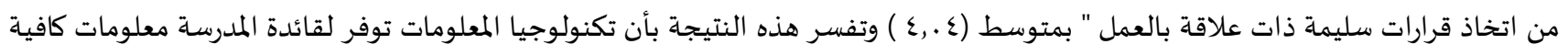

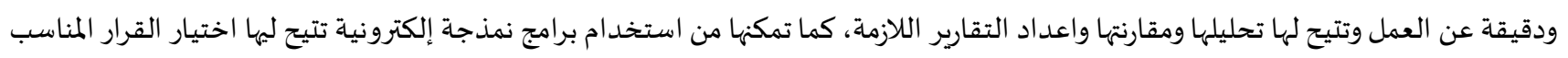

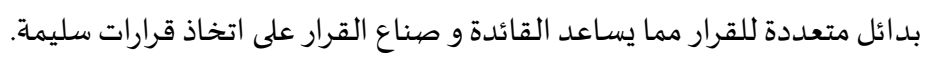


البُعد الثالث: الاجراءات الإدارية:

للتعرف على واقع دور تكنولوجيا المعلومات في تنمية كفاءة الأداء الإداري لقائدات المدارس المتوسطة في منطقة القصيم فيما يتعلق ببُعد

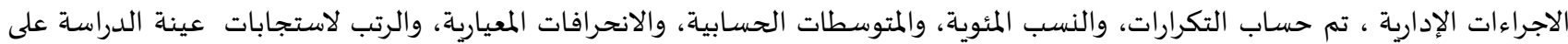

عبارات بُعد الاجراءات الإدارية. .

جدول (9): و اقع دور تكنولوجيا المعلومات في تنمية كفاءة الأداء الإداري في بُعد الإجراءات الإدارية لقائدة المدرسة

\begin{tabular}{|c|c|c|c|c|c|c|c|c|c|c|c|}
\hline \multirow[t]{2}{*}{ الرتبة } & \multirow{2}{*}{ التحقق درجة } & \multirow{2}{*}{ المعياري - الانحراف } & \multirow{2}{*}{ المستوسط المتي } & \multicolumn{5}{|c|}{ درجة الموافقة } & التكرار & \multirow[t]{2}{*}{ العبارات } & \multirow[t]{2}{*}{ م } \\
\hline & & & & ل أل أو افق & لا أو افق & محايد & أو افق & 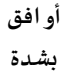 & النسبة \% & & \\
\hline \multirow[t]{2}{*}{1} & \multirow[t]{2}{*}{ كبيرة جداً } & \multirow[t]{2}{*}{., 711} & \multirow[t]{2}{*}{$\varepsilon, \varepsilon \vee$} & - & 1 & 9 & V7 & qV & ك & \multirow{2}{*}{ تساعد تكنولوجيا المعلومات على تيسير } & \multirow[t]{2}{*}{ IT } \\
\hline & & & & - &., 0 & $\varepsilon, q$ & $\varepsilon 1,7$ & or,. & $\%$ & & \\
\hline \multirow[t]{2}{*}{ r } & \multirow[t]{2}{*}{ كبيرة جداً } & \multirow[t]{2}{*}{., $7 \backslash \varepsilon$} & \multirow[t]{2}{*}{$\varepsilon, \varepsilon r$} & - & r & 7 & м & $\wedge \mathrm{V}$ & ك & \multirow{2}{*}{ 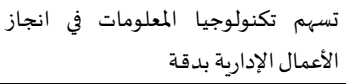 } & \multirow[t]{2}{*}{11} \\
\hline & & & & - & 1,1 & $r, r$ & $\{\wedge, 1$ & $\varepsilon V, 0$ & $\%$ & & \\
\hline \multirow[t]{2}{*}{$r$} & \multirow[t]{2}{*}{ كبيرة جداً } & \multirow[t]{2}{*}{, $\vee \vee \vee 0$} & \multirow[t]{2}{*}{$\varepsilon, Y, T$} & - & v & 11 & 17 & VT & ك & \multirow{2}{*}{ تحد تكنولوجيا المعلومات من الإجراءات الراتينية التي تعيق انجاز العمل الإداري } & \multirow[t]{2}{*}{1.} \\
\hline & & & & - & $r, \Lambda$ & $9, \wedge$ & $\varepsilon \vee,$. & $r q, r$ & $\%$ & & \\
\hline & .,O & & $\varepsilon, r V$ & & & & & سط الع & & & \\
\hline
\end{tabular}

وفقا للجدول (9) فقد جاء هذا البعد في المرتبة الثانية بعد المهام الإدارية لقائدة المدرسة ،وعينة الدراسة موافقات بشدة على دور تكنولوجيا المعلومات

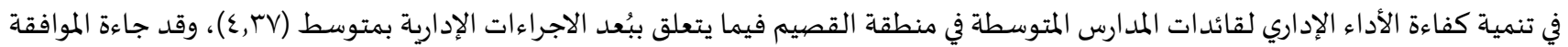

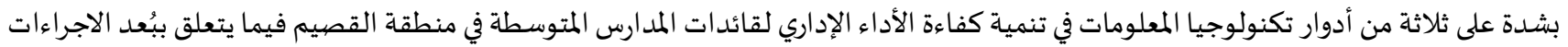

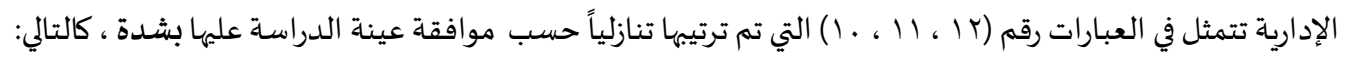

ا. جاءت العبارة رقم (r ا ) وهي:" تساعد تكنولوجيا المعلومات على تيسير اجراءات القبول والتسجيل " بالمرتبة الأولى من حيث موافقة عينة

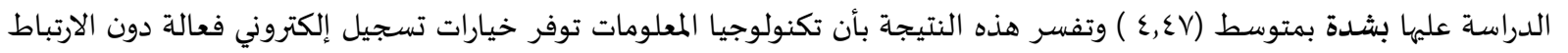

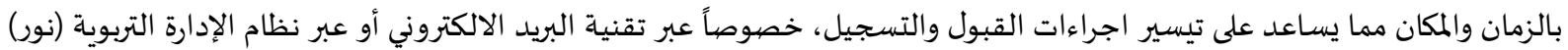

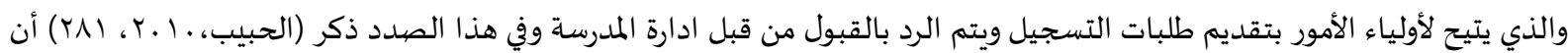
نظام نور هو منظومة 0 نظام متكامل من أهمها نظام قبول المستجدئ لاءين.

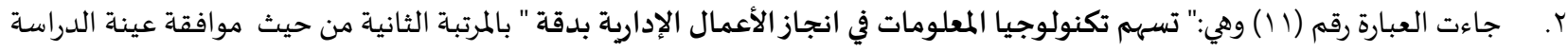
عليها بشدة بمتوسط (r),ع ) وتفسر هذه النتيجة بأن تكنولوجيا المعلومات تقوم بإنجاز الأعمال الإدارية بطريقة تقنية احترافية ونسبة

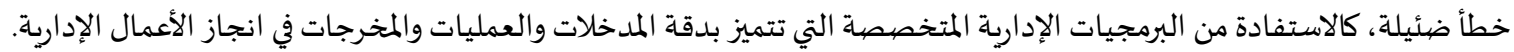

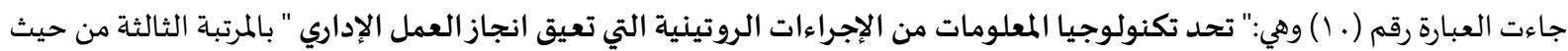
موافقة عينة الدراسـة عليها بشـة بمتوسط (Y Y, ع ) وتفسر هذه النتيجة بأن تكنولوجيا المعلومات تتيح إنجاز العمل بطرق إلكترونياة فعالة

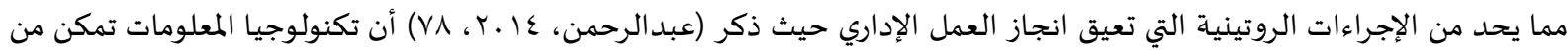
اعداد التقارير والخطابات ومن ثم حفظها كقوالب بحيث يتم الوصول إلهاء واجراء التعديلات اللازمة واستخدامها مرات عديدة ونقلها و

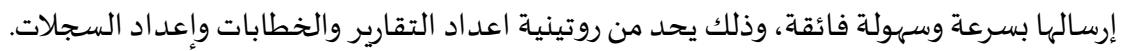

البُعد الر ابع: العلاقات الإنسانية والاجتماعية:

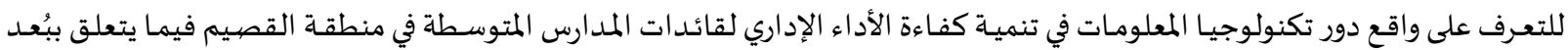

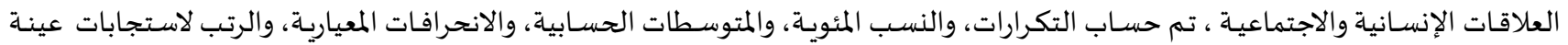

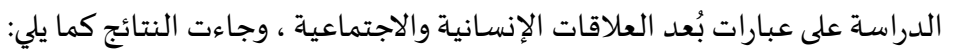


جدول ( ـ (): و اقع دور تكنولوجيا المعلومات في تنمية كفاءة الأداء الإداري فيما يتعلق في بُعد العلاقات الانسانية والاجتماعية

\begin{tabular}{|c|c|c|c|c|c|c|c|c|c|c|c|}
\hline \multirow[t]{2}{*}{ الرتبة } & \multirow{2}{*}{ التحقق درجة } & \multirow{2}{*}{ المعياري - الانحراف } & \multirow{2}{*}{ المتوسط المسبي } & \multicolumn{5}{|c|}{ درجة الموافقة } & التكرار & \multirow[t]{2}{*}{ العبارات } & \multirow[t]{2}{*}{ م } \\
\hline & & & & لا أو افق بشـدة & لا لا أو افق & محايد & أو افق & أو افق بشدة & النسبة \% & & \\
\hline \multirow[t]{2}{*}{1} & كبيرة & \multirow{2}{*}{.,VYY } & \multirow[t]{2}{*}{$\varepsilon, r \varepsilon$} & - & $r$ & 11 & $\mathrm{V7}$ & 17 & ك & \multirow{2}{*}{ تبن المدرسة تكنولوجيا المعلومات في تفعيل العلاقة } & \multirow[t]{2}{*}{10} \\
\hline & جدا & & & - & 1,7 & 9,1 & $\varepsilon 1,7$ & $\varepsilon V$ & $\%$ & & \\
\hline \multirow[t]{2}{*}{ r } & كبيرة & \multirow[t]{2}{*}{$\cdot, \vee \cdot \wedge$} & \multirow[t]{2}{*}{$\varepsilon, \Gamma \wedge$} & 1 & r & 10 & 91 & $v \varepsilon$ & ك & \multirow{2}{*}{ تحقيق أهد تكنوافها } & \multirow[t]{2}{*}{$1 \varepsilon$} \\
\hline & جدا & & &., 0 & 1,1 & $\Lambda, r$ & $\varepsilon 9,1$ & $\varepsilon \cdot, \varepsilon$ & $\%$ & & \\
\hline \multirow[t]{2}{*}{ r } & \multirow[t]{2}{*}{ كبيرة } & \multirow[t]{2}{*}{., V^. } & \multirow[t]{2}{*}{$\varepsilon, 1 r$} & - & 0 & $r$. & $\Lambda \varepsilon$ & $7 \varepsilon$ & ك & \multirow{2}{*}{ تؤناصر المنظومة الإدارية بالمدرسة إلمات تقوية العلاقة بين } & \multirow[t]{2}{*}{ ir } \\
\hline & & & & - & $r, V$ & $17, \varepsilon$ & $\varepsilon 0,9$ & ro & $\%$ & & \\
\hline \multicolumn{2}{|c|}{., 710} & & $\varepsilon, Y_{0}$ & \multicolumn{8}{|c|}{ المتوسط العام } \\
\hline
\end{tabular}

يتضح في الجدول (• () أن عينة الدراسة موافقات بشدة على دور تكنولوجيا المعلومات في تنمية كفاءة الأداء الإداري لقائدات المدارس

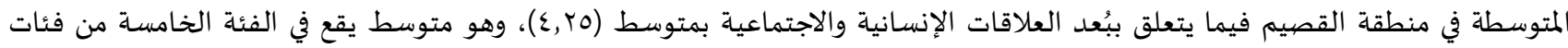

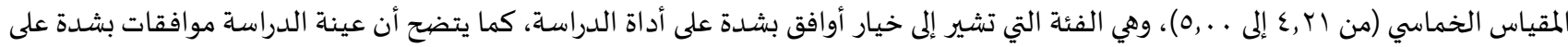

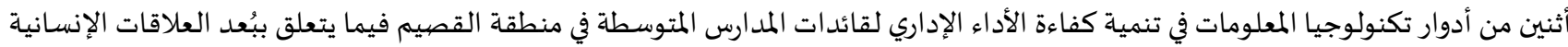

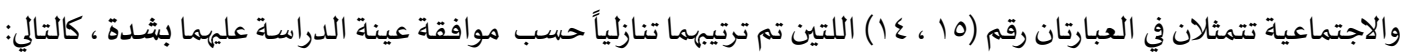

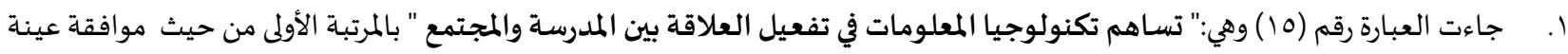

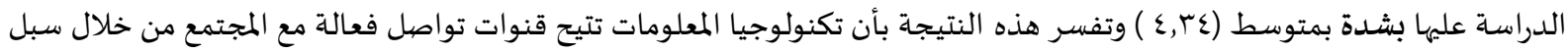
الاتصال الإلكترونية ويعزى ذلك لما تحققه التكنولوجيا من تيسير سبل التواصل الذاتي و تقليل التعقيد من خلال خلق التهئ بيئة تفاعلية

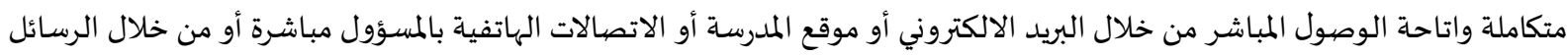
النصية أو احدى منصات التواصل الاجتماعي التي تسهم بتبادل المعلومات من المجتمع للمدرسة والعكس، مما يسهم في تفعيل العلاقة بين

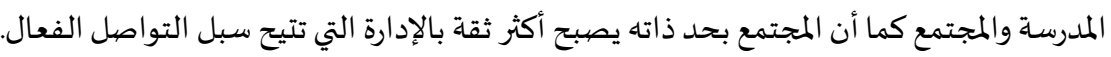

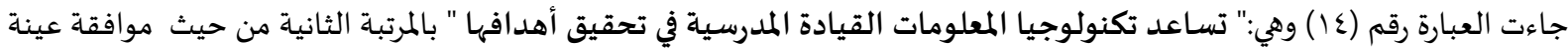
الدراسة عليها بشدة بمتوسط (^^ر, ع ) وتفسر هذه النتيجة بأن تكنولوجيا المعلومات تحسن من الأداء وتزيد من سرعتاه مما يساعد القيادة

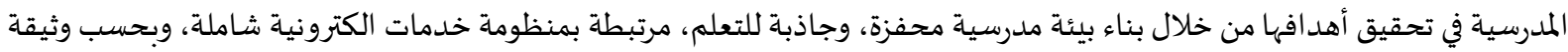

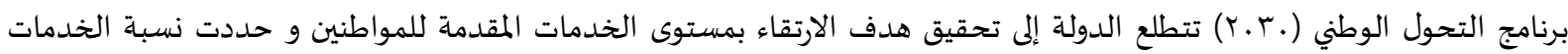

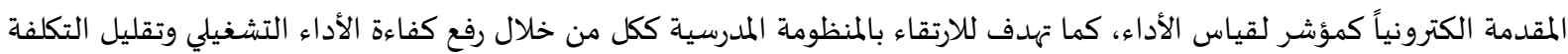
المهدرة و الاستفادة القصهى من الامكانات البشرية والموارد والتجهيزات ويتحقق ذلك من خلال تفعيل دور التقنيات الحديثة المساندة في منظومة العمل التعليمي.

ويتضح من النتائج في الجدول (• () أن عينة الدراسة موافقات على واحدة من أدوار تكنولوجيا المعلومات في تنمية كفاءة الأداء الإداري

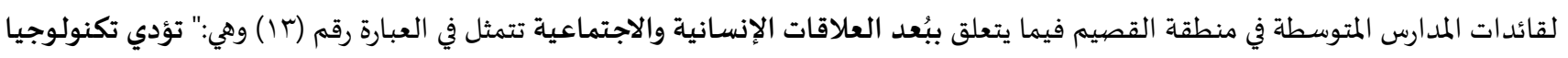
المعلومات إلى تقوية العلاقة بين عناصر المنظومة الإدارية بالمدرسة " بمتوسط (r (, ) ) وتفسر هذه النتيجة بأن تكنولوجيا المعلومات تتيح تواصل

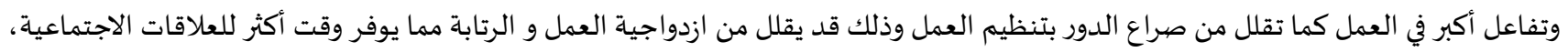

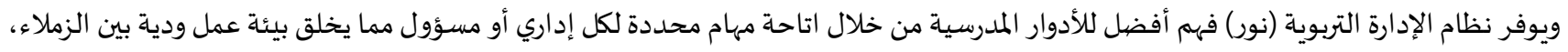

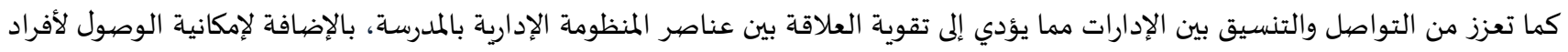

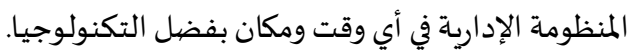

ثانياً: إجابـة السؤال الثـاني: مـا المعوقـات التي تحسد مـن دور تكنولوجيـا المعلومـات في تنميـة كفـاءة الأداء الإداري لقائدات المـدارس المتوسطة في

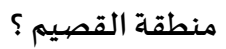

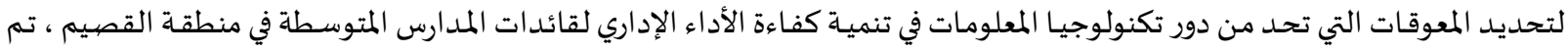

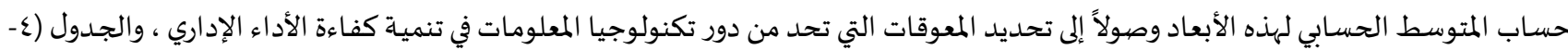
7) يوضح النتائج العامة لهذا المحور. 


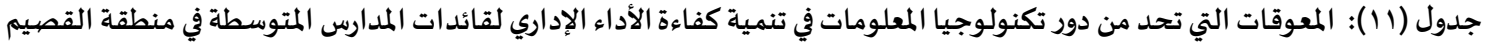

\begin{tabular}{|c|c|c|c|c|}
\hline الرتبة & الانحراف المعياري & المتوسط الحسابي & البعد & م \\
\hline$r$ & , NTO & $r, r \varepsilon$ & المعوقات الشخصية & 1 \\
\hline r & . & $\varepsilon, 1$. & المعوقات الفنية & $r$ \\
\hline 1 &.,$Y r \varepsilon$ & $\varepsilon, r Y$ & المعوقات المالية & $r$ \\
\hline - & . OVT & $r, 94$ & 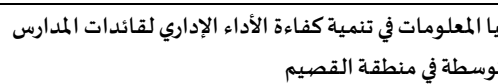 & \\
\hline
\end{tabular}

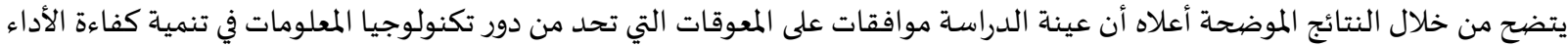

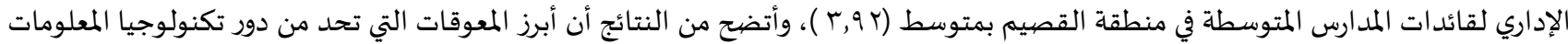

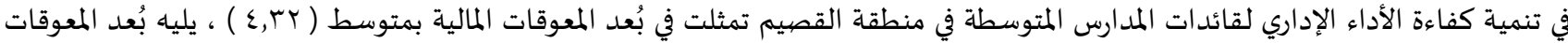

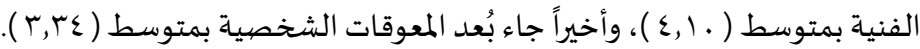

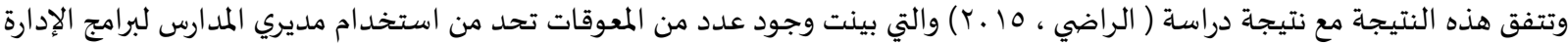

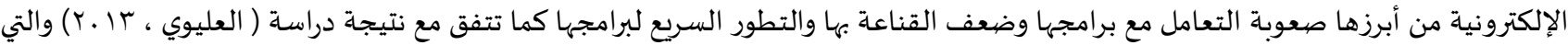

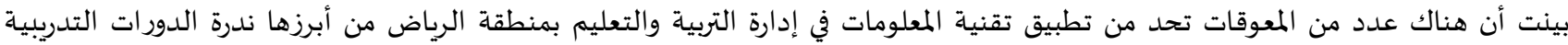

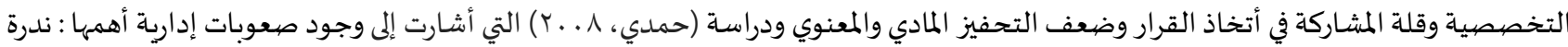

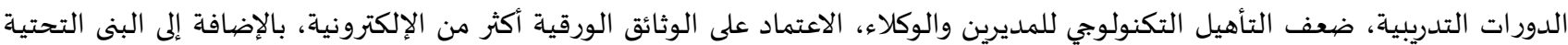

الإنشائية للمدارس الغير مهيّأة.

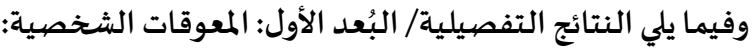

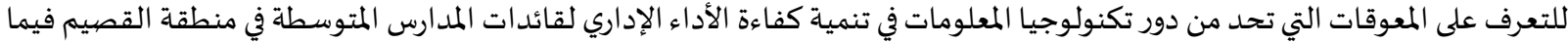

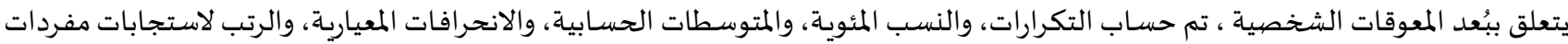
عينة الدراسة على عبارات بُعد المعوقات الشخصية ، وجاءت النتائج كما يلي:

جدول (r ا): المعوقات التي تحد من دور تكنولوجيا المعلومات في تنمية كفاءة الأداء الإداري فيما يتعلق ببُعد المعوقات الشخصية

\begin{tabular}{|c|c|c|c|c|c|c|c|c|c|c|c|}
\hline \multirow[t]{2}{*}{ الرتبة } & \multirow{2}{*}{ التحقق } & \multirow{2}{*}{ 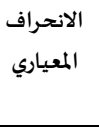 } & \multirow{2}{*}{ 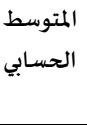 } & \multicolumn{5}{|c|}{ درجة الموافقة } & التكرار & \multirow[t]{2}{*}{ العبارات } & \multirow[t]{2}{*}{ م } \\
\hline & & & & لا أو افق بشدة & لا أو افق & محايد & أو افق & أو أو افق & النسبة \% & & \\
\hline \multirow[t]{2}{*}{1} & & \multirow[t]{2}{*}{$1, .11$} & \multirow[t]{2}{*}{$r, 9 \Lambda$} & $\varepsilon$ & iv & $r$. & $\wedge$. & Tr & ك & \multirow{2}{*}{ لاستخدام تكنولوجيا المعلومات المافية لدى الطاقم الإداري } & \multirow[t]{2}{*}{ r } \\
\hline & & & & $r, Y$ & $9, \Gamma$ & $1 ., 9$ & $\varepsilon r, V$ & $r r, q$ & $\%$ & & \\
\hline \multirow[t]{2}{*}{ r } & \multirow[t]{2}{*}{ متوسطة } & \multirow[t]{2}{*}{$1, .7}$. & \multirow[t]{2}{*}{$r, 91$} & $r$ & $r T$ & $T \varepsilon$ & v. & $7 \pi$ & ك & \multirow{2}{*}{ كثترة الأعباء الإدارية لدى القائدة تحد من } & \multirow[t]{2}{*}{ r } \\
\hline & & & & 1,7 & $1 Y, T$ & $1 r, 1$ & $r \lambda, r$ & $r \varepsilon, \varepsilon$ & $\%$ & & \\
\hline \multirow[t]{2}{*}{$r$} & \multirow[t]{2}{*}{ متوسطة } & \multirow[t]{2}{*}{$1,1 \vee 9$} & \multirow[t]{2}{*}{$r, .1$} & 11 & 71 & $\varepsilon$. & 纟o & r & ك & \multirow{2}{*}{ 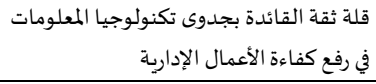 } & \multirow[t]{2}{*}{$\varepsilon$} \\
\hline & & & & 7 & $r r, r$ & $r 1,9$ & $r \varepsilon, 7$ & $1 \varepsilon, Y$ & $\%$ & & \\
\hline \multirow[t]{2}{*}{$\varepsilon$} & \multirow[t]{2}{*}{ متوسطة } & \multirow[t]{2}{*}{$1,1 M 1$} & \multirow[t]{2}{*}{$r, 91$} & $1 \varepsilon$ & Tr & $\varepsilon r$ & rᄉ & ro & ك ك & \multirow{2}{*}{ 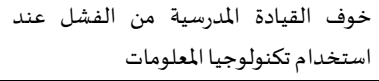 } & \multirow[t]{2}{*}{1} \\
\hline & & & & $v, v$ & $r \varepsilon, r$ & $r r, 0$ & $r \cdot, \Lambda$ & $\mid r, v$ & $\%$ & & \\
\hline \multirow[t]{2}{*}{0} & متوسطة & \multirow[t]{2}{*}{$1, r \wedge 0$} & \multirow[t]{2}{*}{$r, \mathrm{VV}$} & ru & 79 & r & rv & rt & ك ك & \multirow{2}{*}{ تفضيل القائدة العمل بالطرق التقليدية على } & \multirow[t]{2}{*}{ 。 } \\
\hline & & & & $10, r$ & $r V, V$ & $1 \varepsilon, Y$ & r., r & $1 T, 7$ & $\%$ & & \\
\hline \multicolumn{3}{|c|}{. Aro } & & $r, r \varepsilon$ & \multicolumn{7}{|c|}{ المتوسط العام } \\
\hline
\end{tabular}

يتضح في الجدول(r ا ) أن مفردات عينة الدراسة محايدات في موافقتهن حول المعوقات التي تحد من دور تكنولوجيا المعلومات في تنمية كفاءة

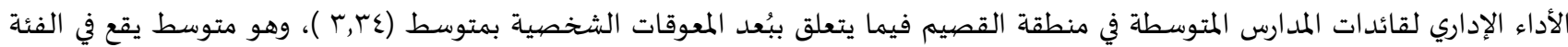

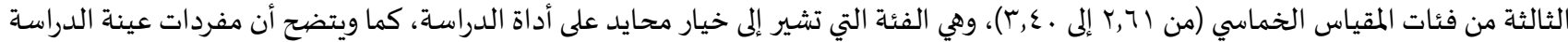

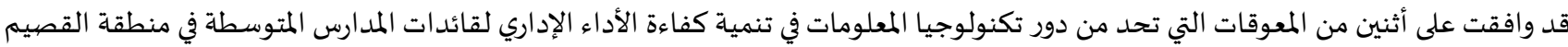

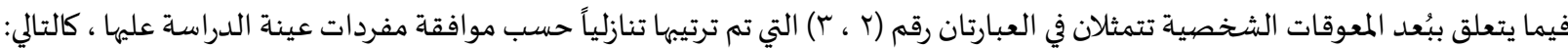

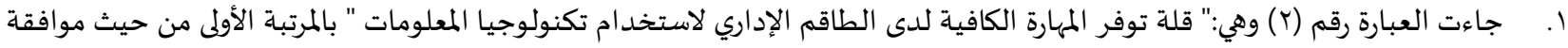

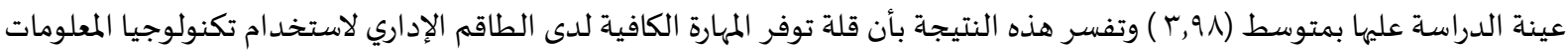


قد تعزى لضعف الخبرات التكنولوجية وقلة الممارسـة أو مقاومة الطاقم الإداري للأساليب التكنولوجية الحديثة مما قد يقلل من القدرة على

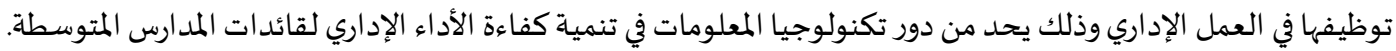
جاءت العبارة رقم (r) وهي:" كثرة الأعباء الإدارية لدى القائدة تحد من استخدام تكنولوجيا المعلومات " بالمرتبة الثانية من حيث موافقة

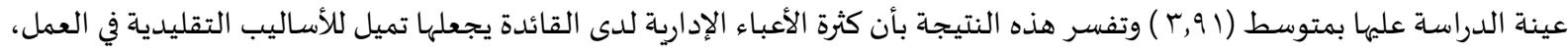

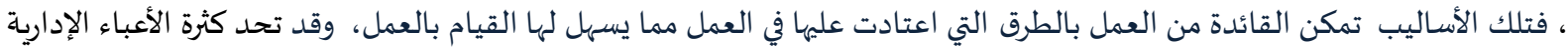

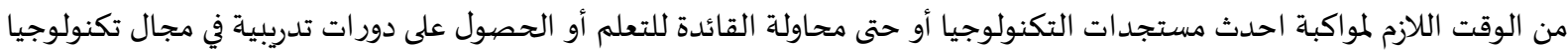

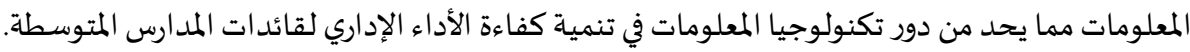

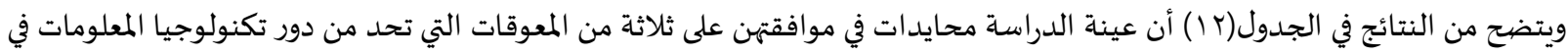

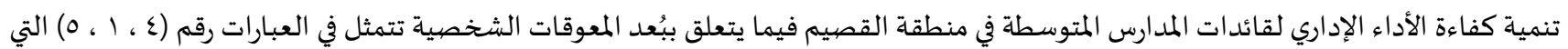

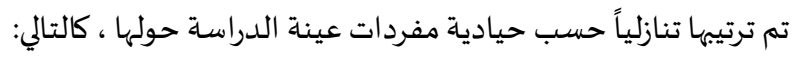
ا. جاءت العبارة رقم (ع) وهي:" قلة ثقة القائدة بجدوى تكنولوجيا المعائة المعلومات في رفع كفاءة الأعمال الإدارية " بالمرتبة الأولى من حيث حيادية

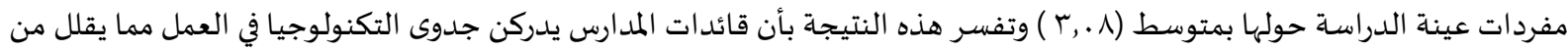

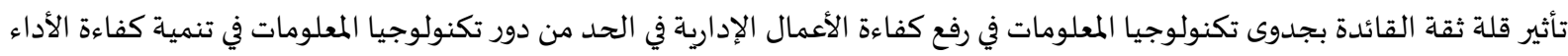
الإداري وتعزى الباحثة تلك النتيجة للوعي التكنولوجي الذي أصبحت تتمتع به القائدات بسبب نهج التطور والتحديث الذي تتخذه الدولي الدولة لمواكبة احدث مستجدات التكنولوجيا. جاءت العبارة رقم (1) وهي:" خوف القيادة المدرسية من الفشل عند استخدام تكنولوجيا المعلومات " بالمرتبة الثانية من حيث حيادية عينة

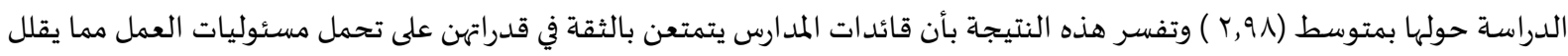
من تأثير خوف القيادة المدرسية من الفشل عند استخدام تكنولوجيا المعلومات كما تعزى الباحثة تلك النتيجة لقناعة القيادة المدرسية

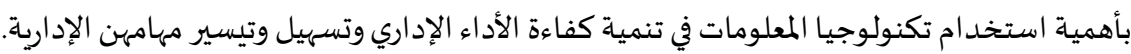

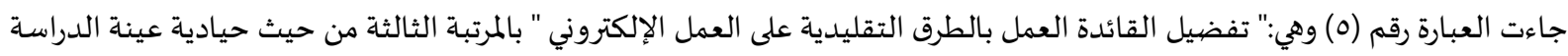
حولها بمتوسط (r,VV ) وتفسر هذه النتيجة بأن قائدات المدارس لديهم إدراك كافي بجدوى العمل الإلكتروني في حفظ بيانات العمل وتبادل

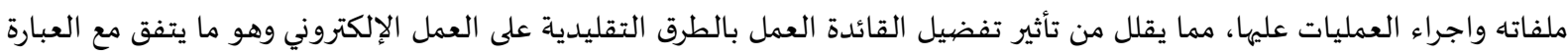
السابقة التي تنص على أن القائدات لا يمانعن استخداء ام تكنولوجيا المعلومات واستبد الها بالطرق التقليدية خوفاً من الفشل.

البُعد الثاني: المعوقات الفنية:

للتعرف على المعوقات التي تحد من دور تكنولوجيا المعلومات في تنمية كفاءة الأداء الإداري لقائدات المدارس المتوسطة في منطقة القصيم فيما

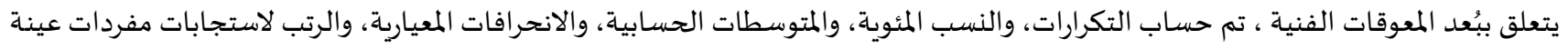

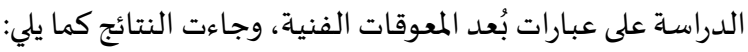

جدول (rا ): المعوقات التي تحد من دور تكنولوجيا المعلومات في تنمية كفاءة الأداء الإداري لقائدات المدارس المتوسطة في منطقة القصيم فيما يتعلق ببُعد

\begin{tabular}{|c|c|c|c|c|c|c|c|c|c|c|c|}
\hline \multicolumn{12}{|c|}{ المعوقات الفنية } \\
\hline \multirow[t]{2}{*}{ الرتبة الر } & \multirow{2}{*}{ 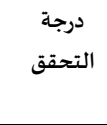 } & \multirow{2}{*}{ 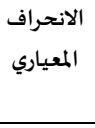 } & \multirow{2}{*}{ 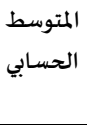 } & \multicolumn{5}{|c|}{ درجة الموافقة } & \multirow{2}{*}{ النسبة التكرار } & \multirow[t]{2}{*}{ العبارات } & \multirow[t]{2}{*}{ م } \\
\hline & & & & لا لأو افق & أو الو & محايد & أو افق & أو أو افق & & & \\
\hline \multirow[t]{2}{*}{1} & \multirow[t]{2}{*}{ كبيرة جداً } & \multirow[t]{2}{*}{ 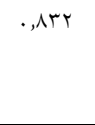 } & \multirow[t]{2}{*}{$\varepsilon, \varepsilon$. } & 1 & 7 & iv & $0 \leqslant$ & 1.0 & ك & \multirow{2}{*}{ 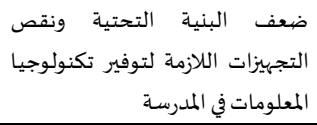 } & \multirow[t]{2}{*}{ v } \\
\hline & & & &., 0 & $r, r$ & $9, r$ & $r q, 0$ & $o v, \varepsilon$ & $\%$ & & \\
\hline \multirow[t]{2}{*}{ r } & كبيرة جداً & \multirow[t]{2}{*}{., 940} & \multirow[t]{2}{*}{$\varepsilon, r \varepsilon$} & 1 & ir & $1 \varepsilon$ & 0. & 1.0 & ك ك & \multirow{2}{*}{ ضبل التكنو الصيانة و الدعم الفني من } & \multirow[t]{2}{*}{$\wedge$} \\
\hline & & & &., 0 & $v, 1$ & $v, v$ & $r v, r$ & $o v, \varepsilon$ & $\%$ & & \\
\hline \multirow[t]{2}{*}{$r$} & \multirow[t]{2}{*}{ كبيرة ل } & \multirow[t]{2}{*}{., $91 \mathrm{~V}$} & \multirow[t]{2}{*}{$\varepsilon, 11$} & $r$ & Ir & 10 & $\mathrm{VI}$ & $\mathrm{vu}$ & ك ك & \multirow{2}{*}{ العتصل الإدام تكنولوجيا المعلومات في في المؤهلة } & \multirow[t]{2}{*}{9} \\
\hline & & & & 1,1 & 7,7 & $\lambda, r$ & $\varepsilon 1,0$ & $\varepsilon r, 7$ & $\%$ & & \\
\hline \multirow[t]{2}{*}{$\varepsilon$} & & \multirow[t]{2}{*}{ - AVA } & \multirow[t]{2}{*}{$\varepsilon, \mid V$} & 1 & 11 & 11 & vi & vo & ك & \multirow{2}{*}{ القائدات على تكنولورجيا المعلومات لبعض } & \multirow[t]{2}{*}{7} \\
\hline & & & &., 0 & 7 & 9,1 & $\varepsilon r, Y$ & $\varepsilon 1$ & $\%$ & & \\
\hline \multirow[t]{2}{*}{0} & \multirow[t]{2}{*}{ 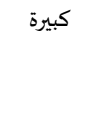 } & \multirow[t]{2}{*}{ (974, } & \multirow[t]{2}{*}{$\varepsilon, I V$} & 1 & 17 & iv & 10 & $\Lambda \varepsilon$ & ك & \multirow{2}{*}{ كثرة اعطال الأجهزة المخصصة للعمل } & \multirow[t]{2}{*}{1.} \\
\hline & & & &., 0 & $\Lambda, \mathrm{V}$ & $9, r$ & ro,7 & $\{0, q$ & $\%$ & & \\
\hline
\end{tabular}




\begin{tabular}{|c|c|c|c|c|c|c|c|c|c|c|c|}
\hline \multirow[t]{2}{*}{7} & كبيرة & $1, .17$ & r,人 & - & rᄉ & rᄉ & $V \varepsilon$ & or & ك & \multirow{2}{*}{ صعوبة التخطيط والتنسيق بين } & \multirow[t]{2}{*}{ IT } \\
\hline & & & & - & $10, r$ & $10, r$ & $\varepsilon ., \varepsilon$ & rq & $\%$ & & \\
\hline \multirow[t]{3}{*}{$v$} & كبيرة & $1, .17$ & $r, 7 r$ & r & r & r & $u$ & $\varepsilon \varepsilon$ & ك ك & \multirow{2}{*}{ تالمعلوض المواقع وأجهزة تكنولوجيات } & \multirow[t]{2}{*}{11} \\
\hline & & & & 1,1 & 19,8 & 11 & $r v, r$ & $T \varepsilon$ & $\%$ & & \\
\hline & \multicolumn{2}{|c|}{. $77 \varepsilon$} & & $\varepsilon, 1$. & \multicolumn{7}{|c|}{ المتوسط العام } \\
\hline
\end{tabular}

يتضح في الجدول(r أ أن عينة الدراسة قدوافقت على المعوقات التي تحد من دور تكنولوجيا المعلومات في تنمية كفاءة الأداء الإداري لقائدات

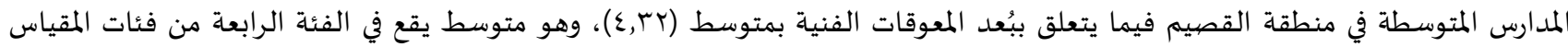

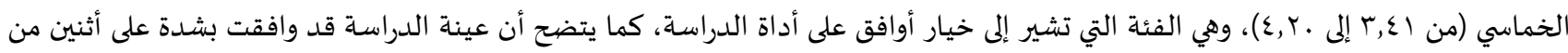

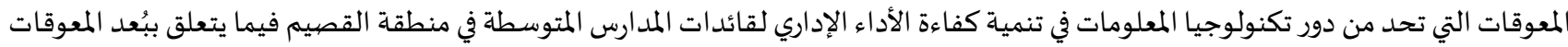

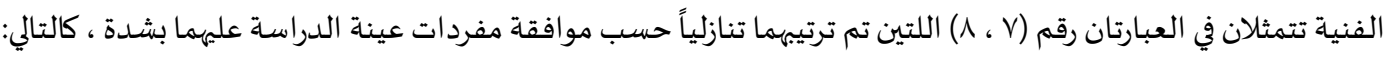

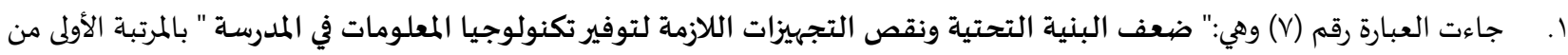

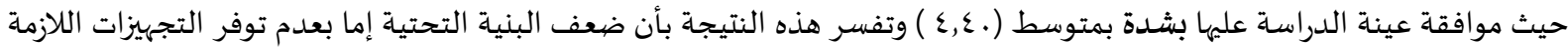

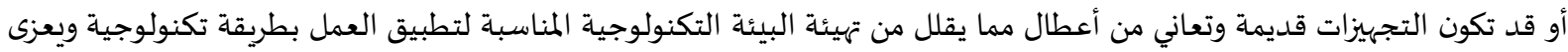

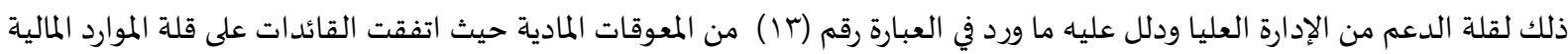

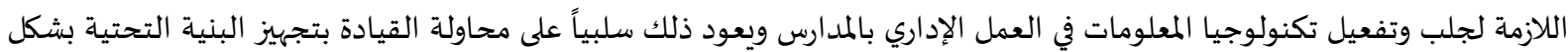

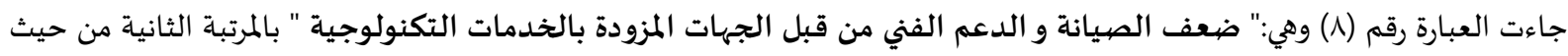

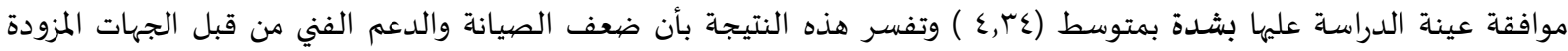

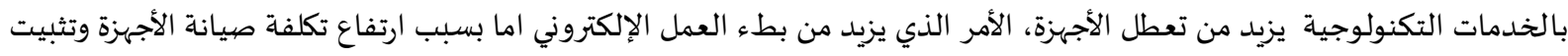

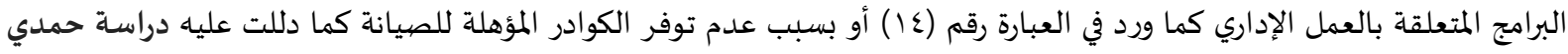

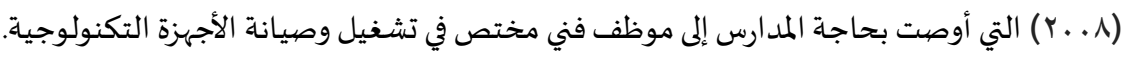

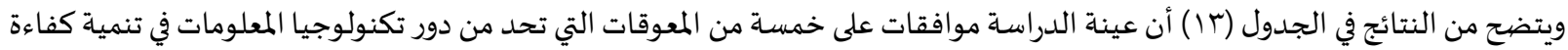

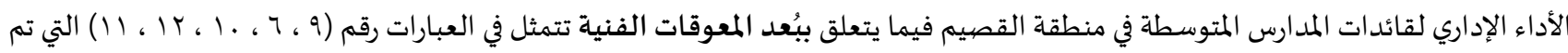
ترتيها تنازلياً حسب موافقة عينة الدراسة علهيا ، كالتالي:

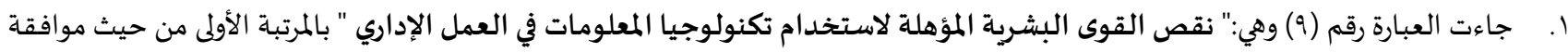

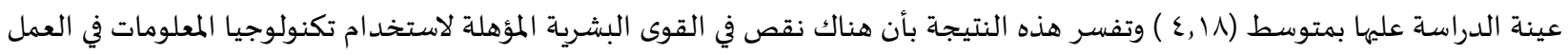

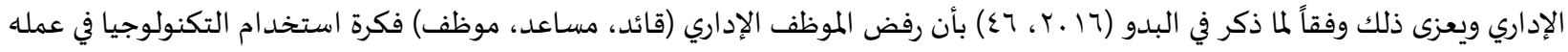

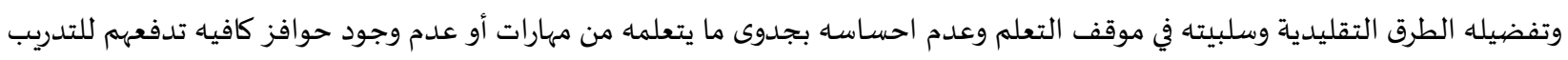

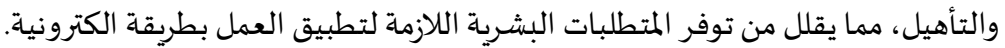

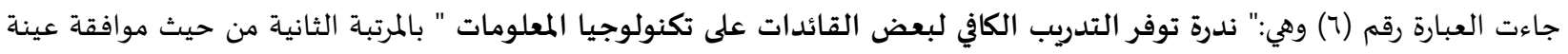

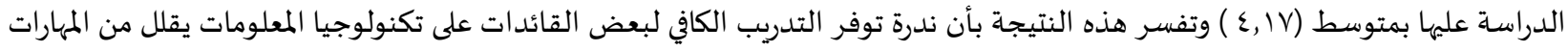

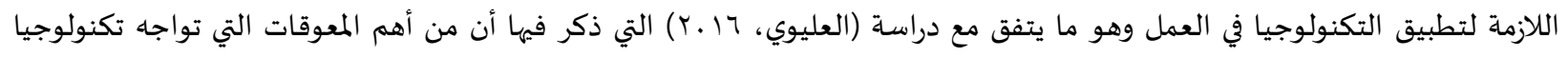

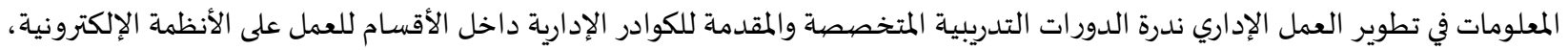

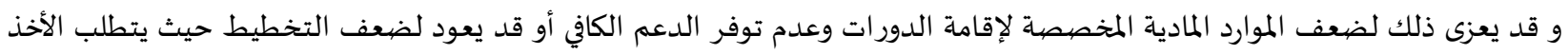

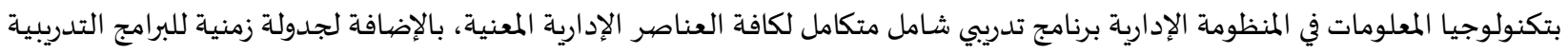

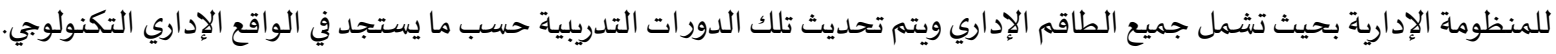

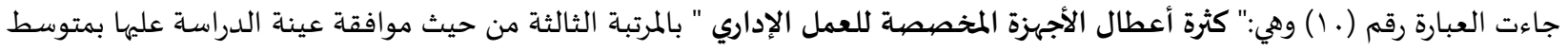

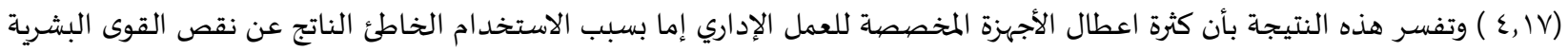

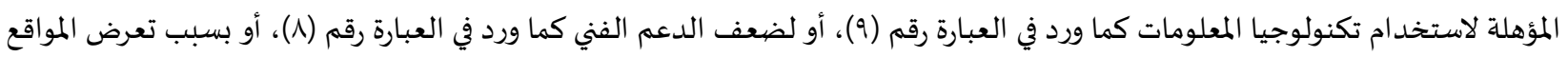


وأجهزة تكنولوجيا المعلومات للاختراق وضعف الحماية كما في العبارة رقم (11)، مما يزيد من بطء العمل ويقلل من الرغبة في تطبيق تكنولوجيا المعلومات في العمل الإداري.

ع. جاءت العبارة رقم (ז ا) وهي:" صعوبة التخطيط والتنسيق بين العمل الإداري الورقي والالكتروني " بالمرتبة الرابعة من حيث موافقة عينة

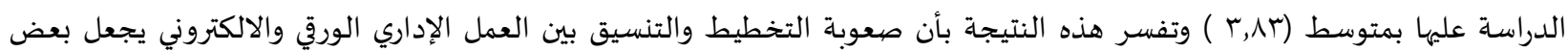
القيادات تميل للعمل الورقي فقط، ويعزى ذلك بأن الإدارات لازالت تستخدم المراسلات الورقية وذلك يمنحها هيمنة على وسائل الاتصال

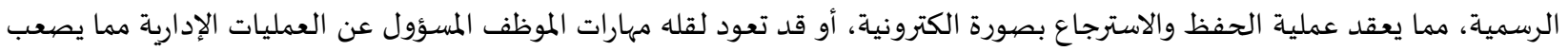
مهمة التنسيق بين الأعمال الورقية والالكترونية.

جاءت العبارة رقم (1) وهي:" تعرض المو اقع وأجهزة تكنولوجيا المعلومات للاختراق وضعف الحوفيهائ الحماية " بالمرتبة الخامسة من حيث موافقة عينة

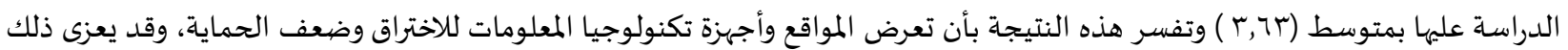

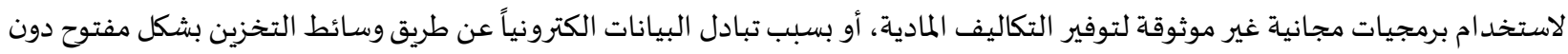

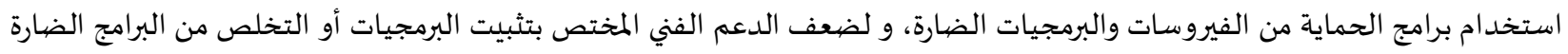

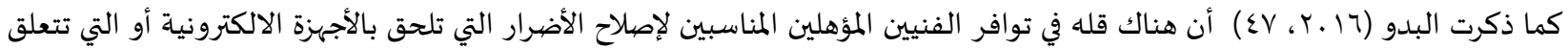
ببرمجة البرامج وقواعد البيانات في أجهزة الحاسوب، مما قد يزيد من الخدوف الخوف من الاعتماد على تكنولوجيا المعلومات في العمل الإداري. البُعد الثالث: المعوقات المالية:

للتعرف على المعوقات التي تحد من دور تكنولوجيا المعلومات في تنمية كفاءة الأداء الإداري لقائدات المدارس المتوسطة في منطقة المّات القصيم فيما يتعلق ببُعد المعوقات المالية ، تم حساب التكرارات، والنسب المئوية، والمتوسطات الحسابية، والانحرافات المعيارية، والرتب لاستجابات عينة الدراسـة

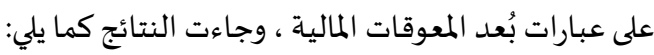

جدول (ع ()): المعوقات التي تحد من دور تكنولوجيا المعلومات في تنمية كفاءة الأداء الإداري لقائدات المدارس المتوسطة في منطقة القصيم فيما يتعلق ببُعد

\begin{tabular}{|c|c|c|c|c|c|c|c|c|c|c|c|}
\hline \multicolumn{12}{|c|}{ المعوقات المالية } \\
\hline \multirow[t]{2}{*}{ الرتبة } & \multirow{2}{*}{ التحقق درجة } & \multirow{2}{*}{ الانعراف } & \multicolumn{2}{|c|}{ المتوسط الحسسابي } & \multicolumn{4}{|c|}{ درجة الموافقة } & \multirow{2}{*}{ النسبة \% التكرار } & \multirow[t]{2}{*}{ العبارات } & \multirow[t]{2}{*}{ م } \\
\hline & & & & 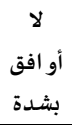 & لا أو افق & محايد & أو افق & 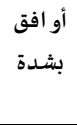 & & & \\
\hline \multirow[t]{2}{*}{1} & \multirow{2}{*}{ 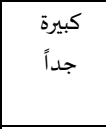 } & \multirow[t]{2}{*}{$\cdot, 10 \wedge$} & \multirow[t]{2}{*}{$\varepsilon, \varepsilon$. } & 1 & 9 & ir & $0 \leqslant$ & $1 . v$ & ك & \multirow{2}{*}{ 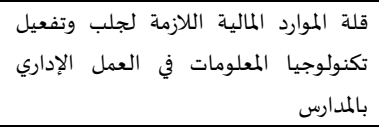 } & \multirow[t]{2}{*}{ ir } \\
\hline & & & &., 0 & $\varepsilon, q$ & 7,7 & $r 9,0$ & $0 \wedge, 0$ & $\%$ & & \\
\hline \multirow[t]{2}{*}{ r } & \multirow[t]{2}{*}{ كبيرة جداً } & \multirow[t]{2}{*}{$\cdot, \wedge \cdot 7$} & \multirow[t]{2}{*}{$\varepsilon, r$ r } & - & v & 11 & 77 & qr & ك & \multirow{2}{*}{ 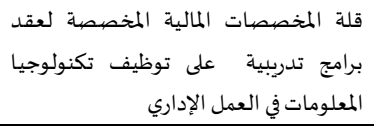 } & \multirow[t]{2}{*}{10} \\
\hline & & & & - & $r, \Lambda$ & $9, \wedge$ & $r, 1$ & $0 ., r$ & $\%$ & & \\
\hline \multirow[t]{2}{*}{$r$} & \multirow[t]{2}{*}{ كبيرة جداً } & \multirow[t]{2}{*}{., $91 \varepsilon$} & \multirow[t]{2}{*}{$\varepsilon, \Gamma$. } & - & ir & ri & 01 & 99 & ك & \multirow{2}{*}{ لتدرة الحوافز التي تقدم لقائدة المدرسة } & \multirow[t]{2}{*}{17} \\
\hline & & & & - & 7,7 & 11,0 & $r V, q$ & $0 \varepsilon$ & $\%$ & & \\
\hline \multirow[t]{2}{*}{$\varepsilon$} & \multirow[t]{2}{*}{ كبيرة جداً } & \multirow[t]{2}{*}{ איונ, } & \multirow[t]{2}{*}{$\varepsilon, Y\urcorner$} & - & 9 & tr & $7 r$ & 19 & ك & \multirow{2}{*}{ 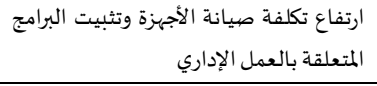 } & \multirow[t]{2}{*}{$1 \varepsilon$} \\
\hline & & & & - & $\varepsilon, q$ & $1 r, 7$ & $r r, q$ & $\varepsilon \wedge, \uparrow$ & $\%$ & & \\
\hline \multicolumn{3}{|c|}{.,$V Y \varepsilon$} & \multicolumn{2}{|c|}{$\varepsilon, r T$} & \multicolumn{7}{|c|}{ المتوسط العام } \\
\hline
\end{tabular}

يتضح من الجدول (ع ا) أن عينة الدراسـة موافقات بشدة على المعوقات التي تحد من دور تكنولوجيا المعلومات في تنمية كفاءة الأداء الإداري

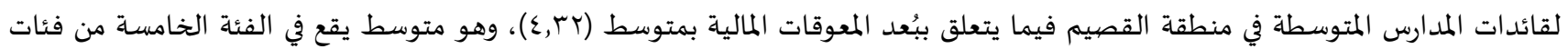

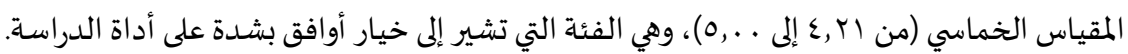

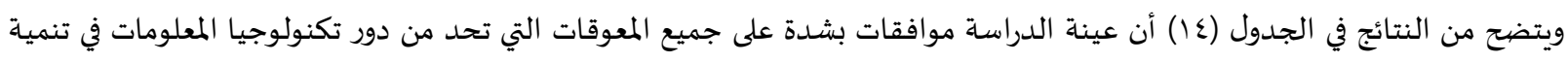

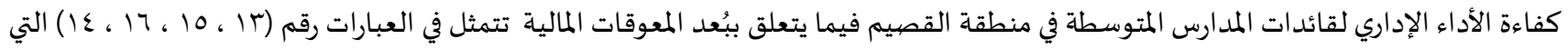
تم ترتيهها تنازلياً حسب موافقة عينة الدراسة عليها بشدة ، كالتالي:

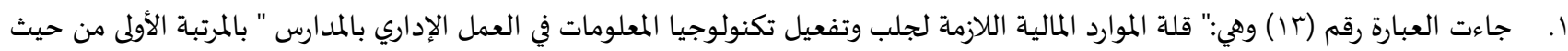

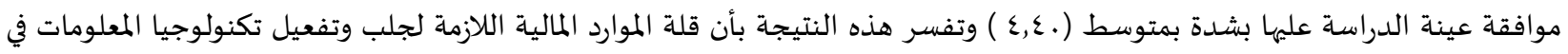

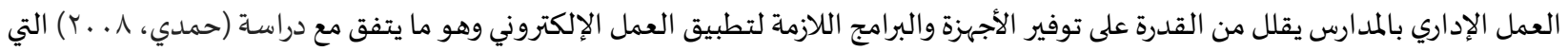


أوضحت أن هناك صعوبات مالية بسبب انعدام دور القطاع الخاص في المساهمة (المالية/ العينية)، ضآلة موارد المدرسة المالية، عدم تقديم دعم

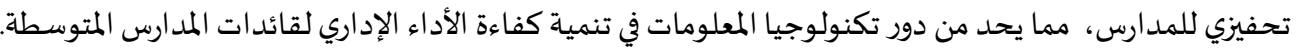

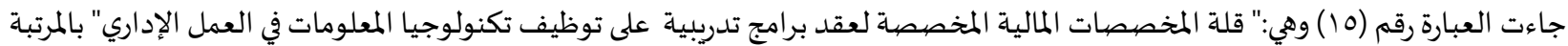

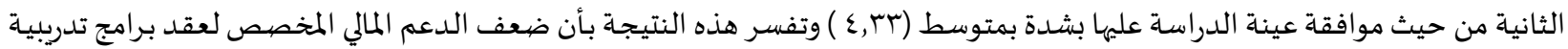

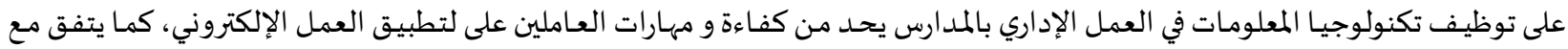

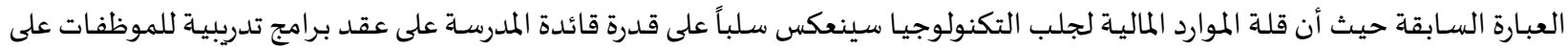

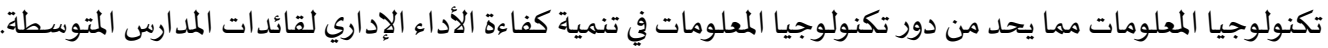
جاءت العبارة رقم (7 ا )وهي:" ندرة الحوافز التي تقدم لقائدة المدرسة لتفعيل تكنولوجيا المعلومات في أعمال الإدارة " بالمرتبـة الثالثة من حيث

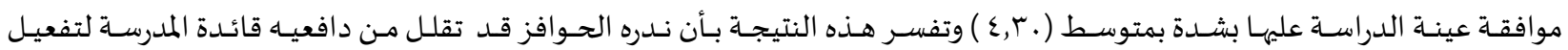
التكنولوجيا في العمل الإداري، كالمسابقات الإدارية بين المدارس بحيث تحصل المدرسة الأكثر تفعيلاً للتكنولوجيا في تعاملاتها على حوافز مادية تساعد في تهيئة البيئة التكنولوجياة في المدرسة.

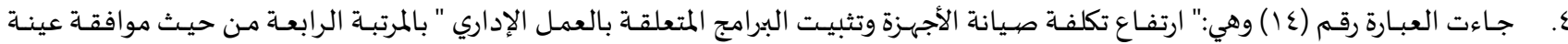

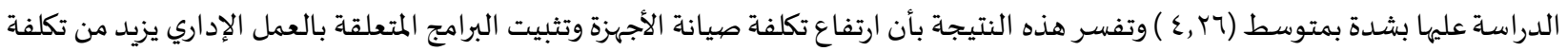

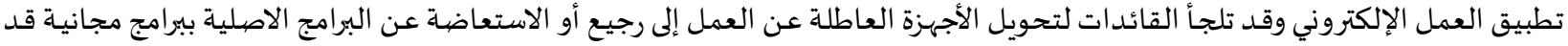

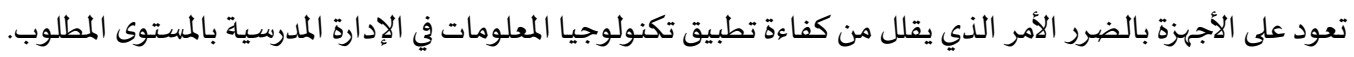

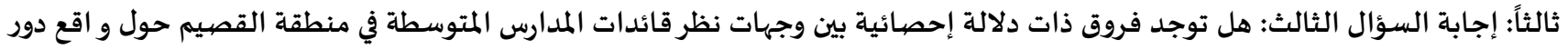

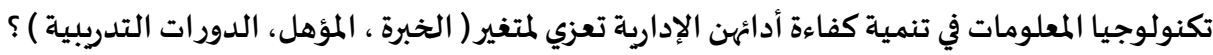
1. الفروق باختلاف متغير الخبرة:

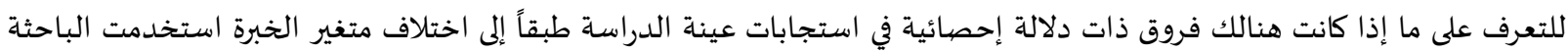

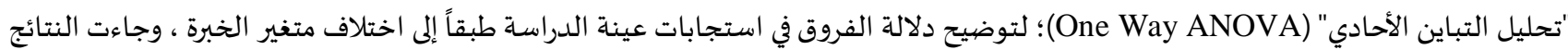
كما يوضحها الجدول التالي:

جدول (10 ): دلالة الفروق في استجابات عينة الدراسة طبقاً إلى اختلاف متغير الخبرة

\begin{tabular}{|c|c|c|c|c|c|c|c|}
\hline التعليق & الدلالة الإحصيائية & قيمة ف & متوسط المربعات & درجات الحرية & مجموع مربعات & مصيدر التباين & المحور \\
\hline \multirow[t]{3}{*}{ غير دالة } & \multirow[t]{3}{*}{.,$\varepsilon \mid V$} & \multirow[t]{3}{*}{$\cdot, \wedge$} & D TYY & r &.,$\leq \varepsilon \leq$ & بين المجموعات & \multirow{3}{*}{ المهام الإدارية لقائدة المدرسة } \\
\hline & & & , ror & 11. & $\left\{0, \varepsilon_{0}\right.$ & داخل المجموعات & \\
\hline & & & - & INT & $\{0,197$ & المجموع & \\
\hline \multirow[t]{3}{*}{ 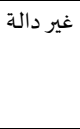 } & \multirow[t]{3}{*}{., 701} & \multirow[t]{3}{*}{$\cdot, \varepsilon Y$. } & $\cdot, 1 \cdot 1$ & $r$ &.,$Y 17$ & بين المجموعات & \multirow[t]{3}{*}{ التعامل مع البيانات الإدارية } \\
\hline & & & , rOV & 11. & $\varepsilon 7, r r$. & داخل المجموعات & \\
\hline & & & - & INT & $\{7,0 \leqslant 7$ & المجموع & \\
\hline \multirow[t]{3}{*}{ غير دالة } & \multirow[t]{3}{*}{.,10r } & \multirow[t]{3}{*}{$1,9 \cdot v$} &., $0 \leqslant 7$ & r & $1, .95$ & بين المجموعات & \multirow{3}{*}{ الاجراءات الإدارية } \\
\hline & & & .,YAT & 11. & $01,00 \varepsilon$ & داخل المجموعات & \\
\hline & & & - & INT & or, $T \leqslant 7$ & المجموع & \\
\hline \multirow[t]{3}{*}{ 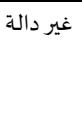 } & \multirow[t]{3}{*}{. TVY } & \multirow[t]{3}{*}{., 990} & , rVv & r & , vor & بين المجموعات & \multirow[t]{3}{*}{ العلاقات الإنسانية والاجتماعية } \\
\hline & & & . rVA & 11. & $7 \Lambda, 1 Y \Lambda$ & داخل المجموعات & \\
\hline & & & - & MT & $T \Lambda, \Lambda \Lambda T$ & المجموع & \\
\hline \multirow[t]{3}{*}{ غير دالة } & \multirow[t]{3}{*}{. זی. } & \multirow[t]{3}{*}{., $9 \vee T$} & .,Y.T & $r$ & .,E.r & بين المجموعات & \multirow{3}{*}{ 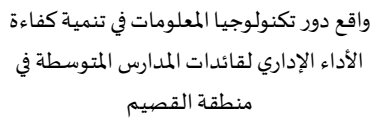 } \\
\hline & & & $\cdot, Y \cdot V$ & 11. & $r V, r \leqslant V$ & داخل المجموعات & \\
\hline & & & - & INT & rV,Vo. & المجموع & \\
\hline
\end{tabular}

يتضيح من خلال النتائج الموضحاة في الجدول(0) عدم وجود فروق ذات دلالة إحصائية عند مستوى (0. , .) فأقل في اتجاهات عينة الدراسة

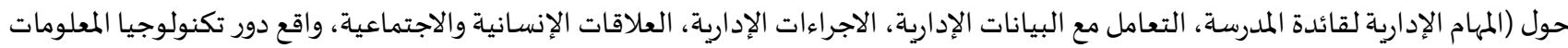

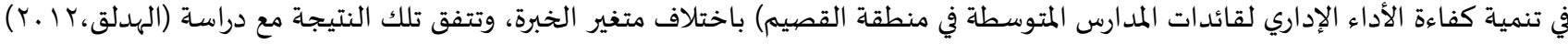
التي أوضحت انه لا توجد فروق ذات دلالة إحصائية تعزى إلى متغير الخبرة فيما يتعلق باستخدامات تطبيقات تلادئ تكنولوجيا المعلومات في الإدارة المدرسية. 


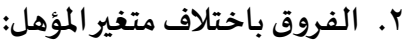

للتعرف على ما إذا كانت هنالك فروق ذات دلالة إحصائية في استجابات عينة الدراسة طبقاً إلى اختلاف متغير المؤهل استخدمت الدراسة "تحليل التباين الأحادي" (One Way ANOVA)؛ لتوضيح دلالة الفروق في استجابات عينة الدراسة طبقاً إلى اختلاف متغير المؤهل ، وجاءت النتائج

كما يوضحها الجدول التالي:

جدول (17): دلالة الفروق في استجابات عينة الدراسة طبقاً إلى اختلاف متغير المؤهل

\begin{tabular}{|c|c|c|c|c|c|c|c|}
\hline التعليق & الدلالة الإحصائية & قيمة ف & متوسط المربعات & درجات الحرية & مجموع مربعات & مصدر التباين & المحور \\
\hline \multirow[t]{3}{*}{ 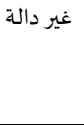 } & \multirow[t]{3}{*}{$., 7 r)$} & \multirow[t]{3}{*}{.,$\varepsilon V V$} &., $1 \% 1$ & $r$ &.,$r \varepsilon r$ & بين المجموعات & \multirow[t]{3}{*}{ المهام الإدارية لقائدة المدرسة } \\
\hline & & & , ros & 11. & $\{0,70\}$ & داخل المجموعات & \\
\hline & & & - & INT & $\{0, \wedge 97$ & المجموع & \\
\hline \multirow[t]{3}{*}{ 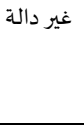 } & \multirow[t]{3}{*}{. Trt } & \multirow[t]{3}{*}{$1, \mid \varepsilon 1$} &., 491 & $r$ &., $0 \wedge r$ & بين المجموعات & \multirow[t]{3}{*}{ التعامل مع البيانات الإدارية } \\
\hline & & & .,, 00 & 11. & $\varepsilon 0,97 \mathrm{r}$ & داخل المجموعات & \\
\hline & & & - & MT & $\{7,0 \leqslant 7$ & المجموع & \\
\hline \multirow[t]{3}{*}{ 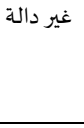 } & \multirow[t]{3}{*}{., .01} & \multirow[t]{3}{*}{$r, 9.1$} & . ATr & $r$ & $1,7 £ \varepsilon$ & بين المجموعات & \multirow[t]{3}{*}{ الاجراءات الإدارية } \\
\hline & & & . TAT & 11. & $01, \ldots r$ & داخل المجموعات & \\
\hline & & & - & Mr & or, $7 \leqslant 7$ & المجموع & \\
\hline \multirow[t]{3}{*}{ دالة } & \multirow[t]{3}{*}{$* ., . r q$} & \multirow[t]{3}{*}{$r, 7) r$} & $1, r+9$ & r & $r, 701$ & بين المجموعات & \multirow[t]{3}{*}{ العلاقات الإنسانية والاجتماعية } \\
\hline & & & . r.ר人 & 11. & 77, TTY & داخل المجموعات & \\
\hline & & & - & int & $\checkmark \Lambda, \Lambda \Lambda r$ & المجموع & \\
\hline \multirow[t]{3}{*}{ 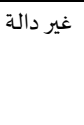 } & \multirow[t]{3}{*}{., 17} & \multirow[t]{3}{*}{$1,10 \varepsilon$} &., $\mathrm{rN1}$ & $r$ & .,VIT & بين المجموعات & \multirow{3}{*}{ والإداري لقور تكنولوات المدارسيا المعلومات في تنمسية في كفاءة الأداء } \\
\hline & & & ., Y.० & 11. & $r 7,9 \wedge \Lambda$ & داخل المجموعات & \\
\hline & & & - & INT & rv, vo. & المجموع & \\
\hline
\end{tabular}

يتضيح من خلال النتائج الموضحة في الجدول (7 (1) عدم وجود فروق ذات دلالة إحصائية عند مستوى (0 . ..) فأقل في اتجاهات عينة الدراسة حول (المهام الإدارية لقائدة المدرسة، التعامل مع البيانات الإدارية، الاجراءات الإدارية، واقع دور تكنولوجيا المعلومات في تنمية كفاءة الأداء الإداري لقائدات المدارس المتوسطة في منطقة القصيم) باختلاف متغير المؤهل، ويعزى ذلك لانتشار الثقافة التكنولوجية على نحو واسع بين فئات المجتمع

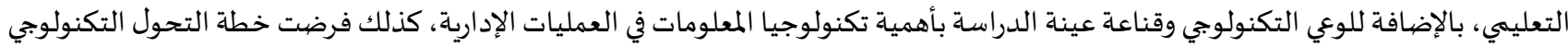

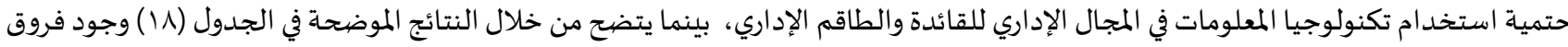

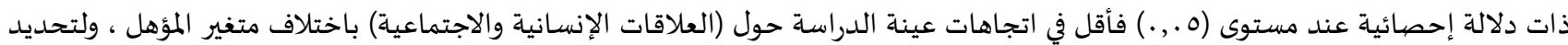
صالح الفروق بين فئات المؤهل تم استخدام اختبار شيفياه، والذي جاءت نتائجاه كالتالي:

جدول (IV) : نتائج اختبارشيفيه للتحقق من الفروق بين فئات المؤهل

\begin{tabular}{|c|c|c|c|c|c|c|}
\hline 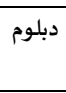 & 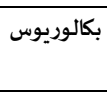 & ماجستير - دكتوراه) - دراهيات & المتوسط الحسابي & 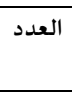 & 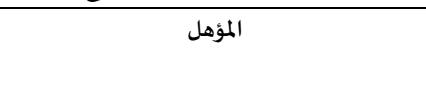 & 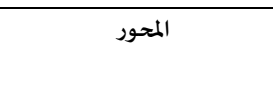 \\
\hline & * & - & $\{, 0\}$ & 10 & دراسات عليا (دبلوم تربوي - ماجستير - دكتوراه) & \multirow[t]{3}{*}{ العلاقات الإنسانية والاجتماعية } \\
\hline & - & & $\varepsilon, 11$ & irv & بكالوريوس & \\
\hline - & & & $\varepsilon, \varepsilon$. & ri & دبلوم & \\
\hline
\end{tabular}

يتضح من خلال النتائج الموضحة في الجدول (IV) وجود فروق ذات دلالة إحصائية عند مستوى (0., .) فأقل بين عينة الدراسة اللائي مؤهلهن

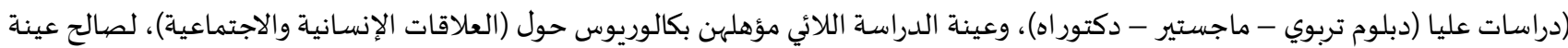
الدراسة اللائي مؤهلهن دراسـات عليا ( دبلوم تربوي - ماجستير - دكتور اه)، وقد يعزى ذلك لما تتمتع باه ذوات المؤهلات العليا من مخزون علمي وثقافي

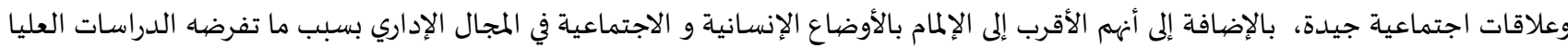
على الدارسين من القرب من الواقع و الاطلاع على المشاكل التربوية وسبل علاجها لغرض إتمام البحث العلمي فخبرتهم في الميدان الإداري خبرة علمية عملية.

r. الفروق باختلاف متغير الدورات التدرببية: للتعرف على ما إذا كانت هنالك فروق ذات دلالة إحصائية في استجابات عينة الدراسـة طبقاً إلى اختلاف متغير الدورات التدربية تلدية تم استخدام

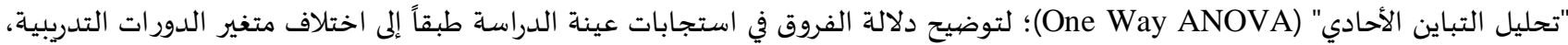
وجاءت النتائج كما يوضحها الجدول التالي: 
جدول (1/1): نتائج " تحليل التباين الأحادي " (One Way ANOVA) للفروق في استجابات عينة الدراسة طبقاً إلى اختلاف متغير الدورات التدرببية

\begin{tabular}{|c|c|c|c|c|c|c|c|}
\hline التعليق & الدلالة الإحصائية & قيمة ف & متوسط المربعات & درجات الحرية & مجموع مربعات & مصدر التباين & المحور \\
\hline \multirow[t]{3}{*}{ 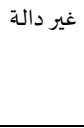 } & \multirow[t]{3}{*}{$\cdot, \mathrm{N} \vee \mathrm{O}$} & \multirow[t]{3}{*}{., $1 r \varepsilon$} &.,.$r \varepsilon$ & $r$ & $.,.\urcorner \wedge$ & بين المجموعات & \multirow[t]{3}{*}{ المهام الإدارية لقائدة المدرسة } \\
\hline & & &., 100 & is. & $\varepsilon 0, \Lambda \uparrow \wedge$ & داخل المجموعات & \\
\hline & & & - & INT & $\{0, \wedge 97$ & المجموع & \\
\hline \multirow[t]{3}{*}{ 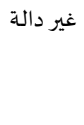 } & \multirow[t]{3}{*}{., 711} & \multirow[t]{3}{*}{., Үی } &., .99 & $r$ &., 191 & بين المجموعات & \multirow[t]{3}{*}{ التعامل مع البيانات الإدارية } \\
\hline & & & ., rov & 11. & $\varepsilon 7, r \varepsilon \wedge$ & داخل المجموعات & \\
\hline & & & - & int & $\{7,0 \leqslant 7$ & المجموع & \\
\hline \multirow[t]{3}{*}{ 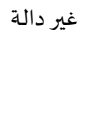 } & \multirow[t]{3}{*}{, NTO } & \multirow[t]{3}{*}{., $1 \wedge}$. & .,.or & $r$ &., 1.0 & بين المجموعات & \multirow[t]{3}{*}{ الاجراءات الإدارية } \\
\hline & & & ., T91 & 11. & $0 r, 0 \leqslant 1$ & داخل المجموعات & \\
\hline & & & - & MAT & or,TE7 & المجموع & \\
\hline \multirow[t]{3}{*}{ 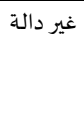 } & \multirow[t]{3}{*}{., vor } & \multirow[t]{3}{*}{. } &., $1 \cdot 1$ & $r$ &.,$Y 17$ & بين المجموعات & \multirow[t]{3}{*}{ العلاقات الإنسانية والاجتماعية } \\
\hline & & &., $\mathrm{rAl}$ & 11. & 71,770 & داخل المجموعات & \\
\hline & & & - & MT & $T \Lambda, \Lambda \Lambda Y$ & المجموع & \\
\hline \multirow[t]{3}{*}{ 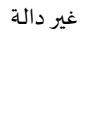 } & \multirow[t]{3}{*}{., vAr } & \multirow[t]{3}{*}{.,$Y \leq 0$} &., .01 & $r$ &., $1 . r$ & بين المجموعات & \multirow{3}{*}{ والأداء الإداري تلوائدات المدارس المعلومات في تنمية كفاءة المتوسطة في } \\
\hline & & &., 4.9 & $1 \mathrm{M}$. & $r V, T \leqslant V$ & داخل المجموعات & \\
\hline & & & - & IAT & $r v, v_{0}$. & المجموع & \\
\hline
\end{tabular}

يتضيح من خلال النتائج الموضحة في الجدول (1) عدم وجود فروق ذات دلالة إحصائية عند مستوى (0. , .) فأقل في اتجاهات عينة الدراسة حول (المهام الإدارية لقائدة المدرسة، التعامل مع البيانات الإدارية ، الاجراءات الإدارية، العلاقات الإنسانية والاجتماعية، واقع دور تكنولوجيا

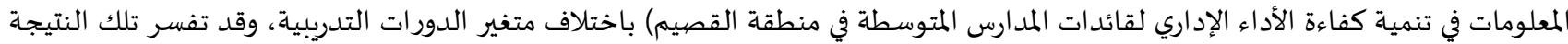
بوعي القائدات بأهمية التدربب والتطوير حتى مع عدم توفر الدورات التدرببة بشكل كاف، وسعي القائدات للتدربب ذاتياً على مستحدثات التقنية وهو

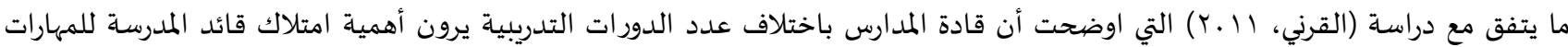
التكنولوجية ممثلة بالحاسب الآلي، كما قد تفسر هذه النتيجة باقتصار استخدام القائدات لتكنولوجيا المعلومات على الاستخدامات التقليدية التي قد لا تتطلب مهارات متقدمة. رابعاً: إجابة السؤال الر ابع: هل توجد فروق ذات دلالة إحصيائية بين وجهات نظر قائدات المدارس المتوسطة في منطقة القصيم حول المعوقات التي تحد من دور تكنولوجيا المعلومات في تنمية كفاءة أدائهن الإدارية تعزي لمتغير ( الخبرة ، المؤهل، الدورات الموات التدريبية ) ؟

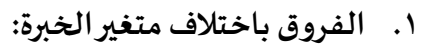

للتعرف على ما إذا كانت هنالك فروق ذات دلالة إحصائية في استجابات عينة الدراسة طبقاً إلى اختلاف متغير الخبرة استخدمت الباحثة "تحليل التباين الأحادي" (One Way ANOVA)؛ لتوضيح دلالة الفروق في استجابات عينة الدراسـة طبقاً إلى اختلاف متغير الخبرة ، وجاءت الدئات النتائج كما يوضحها الجدول التالي:

جدول (19): نتائج " تحليل التباين الأحادي " (One Way ANOVA) للفروق في استجابات عينة الدراسة طبقاً إلى اختلاف متغير الخبرة

\begin{tabular}{|c|c|c|c|c|c|c|c|}
\hline التعليق & الدلالة الإحصائية & قيمة ف & متوسط المربعات & درجات الحرية & مجموع مربعات & مصددر التباين & المحور \\
\hline \multirow{3}{*}{ دالة } & \multirow[t]{3}{*}{., $11 r$} & \multirow[t]{3}{*}{ r,rir } & $1,\{10$ & $r$ & $r, q \vee 1$ & بين المجموعات & \multirow[t]{3}{*}{ المعوقات الشخصية } \\
\hline & & & 列 & 14. & $|r \cdot, A Y|$ & داخل المججموعات & \\
\hline & & & - & INT & $|r r, v q|$ & المجموع & \\
\hline غير & \multirow[t]{3}{*}{. IV } & \multirow[t]{3}{*}{ 1,vרז } & .,WYI & r & $1,0 \leqslant r$ & بين المجموعات & \multirow[t]{3}{*}{ المعوقات الفنية } \\
\hline \multirow[t]{2}{*}{ 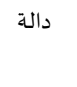 } & & & 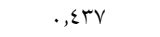 & 14. & $v \Lambda, V \varepsilon 1$ & داخل المججموعات & \\
\hline & & & - & MN & A., rAT & المجموع & \\
\hline غير & \multirow[t]{3}{*}{., .70} & \multirow[t]{3}{*}{ r, VYo } & $1, \varepsilon \mathrm{YM}$ & r & $r, 107$ & بين المجموعات & \multirow[t]{3}{*}{ المعوقات المالية } \\
\hline \multirow[t]{2}{*}{ 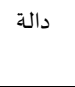 } & & & .010 & 14. & QT,TYT & داخل المجموعات & \\
\hline & & & - & IAT & $90, \varepsilon \vee \wedge$ & المجموع & \\
\hline غير & \multirow[t]{3}{*}{., 1.9} & \multirow[t]{3}{*}{$r, T \varepsilon \varepsilon$} & . VYA & r & 1,200 & بين المجموعات & \multirow{3}{*}{ 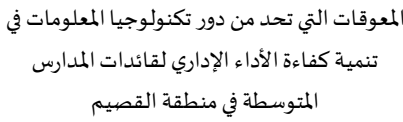 } \\
\hline \multirow[t]{2}{*}{ دالة } & & & . TYE & 11. & ol, ror & داخل المجموعات & \\
\hline & & & - & INT & $09, \wedge \cdot 1$ & المجموع & \\
\hline
\end{tabular}

يتضح من خلال النتائج الموضحة في الجدول (19) عدم وجود فروق ذات دلالة إحصائية عند مستوى (0 . . .) فأقل في اتجاهات عينة الدراسة حول (المعوقات الشخصية، المعوقات الفنية ، المعوقات المالية، المعوقات التي تحد من دور تكنولوجيا المعلومات في تنمية كفاءة الأداء الإداري لقائدات

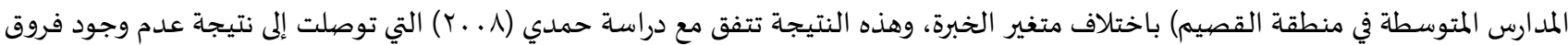

rV. 


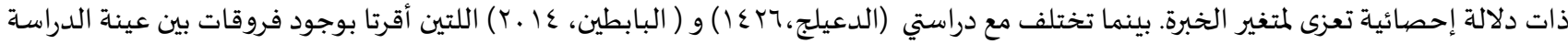
حول معوقات تطبيق تكنولوجيا المعلومات في المدارس تعزى لمتغير الخبرة.

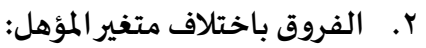

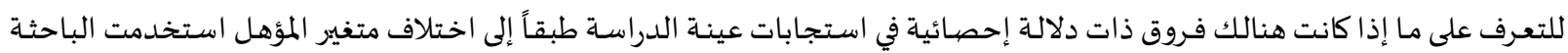
"تحليل التباين الأحادي" (One Way ANOVA)؛ لتوضيح دلالة الفروق في استجابات عينة الدراسة طبقاً إلى اختلاف متغير المؤهل.

جدول( ·) : نتائج " تحليل التباين الأحادي " (One Way ANOVA) للفروق في استجابات عينة الدراسة طبقاً إلى اختلاف متغير المؤهل

\begin{tabular}{|c|c|c|c|c|c|c|c|}
\hline التعليق & الدلالة الإحصائية & قيمة ف & متوسط المربعات & درجات الحرية & مجموع مربعات & مصبدر التباين & المحور \\
\hline \multirow[t]{3}{*}{ 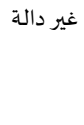 } & \multirow[t]{3}{*}{. TH } & \multirow[t]{3}{*}{1,010} & $1,$. ro & $r$ & r,.o. & بين المجموعات & \multirow[t]{3}{*}{ المعوقات الشخصية } \\
\hline & & &., $7 \vee 7$ & 11. & $M T, V \varepsilon r$ & داخل المجموعات & \\
\hline & & & - & INT & $|r r, v q|$ & المجموع & \\
\hline \multirow[t]{3}{*}{ غير دالة ل } & \multirow[t]{3}{*}{$\cdot$, ז } & \multirow[t]{3}{*}{1, ro7 } &., 097 & $r$ & 1,191 & بين المجموعات & \multirow[t]{3}{*}{ المعوقات الفنية } \\
\hline & & & . & 11. & $V 9, .9 r$ & داخل المجموعات & \\
\hline & & & - & INT & A., YAN & المجموع & \\
\hline \multirow[t]{3}{*}{ 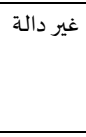 } & \multirow[t]{3}{*}{. TVV } & \multirow[t]{3}{*}{.,$r q 1$} &.,$Y .7$ & $r$ & .,हाT & بين المجموعات & \multirow[t]{3}{*}{ المعوقات المالية } \\
\hline & & &., $0 Y \Lambda$ & 11. & $90, .77$ & داخل المجموعات & \\
\hline & & & - & INT & $90, \varepsilon \vee 1$ & المجموع & \\
\hline \multirow[t]{3}{*}{ غير دالة ل } & \multirow[t]{3}{*}{.,rrq } & \multirow[t]{3}{*}{$1, \varepsilon \wedge V$} & 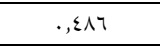 & $r$ &., $9 V \mathrm{YT}$ & بين المجموعات & \multirow{3}{*}{ 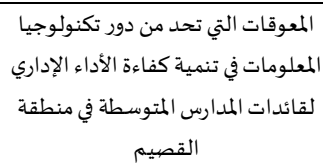 } \\
\hline & & &., $\mathrm{rTV}$ & 11. & Oᄉ,ArT & داخل المجموعات & \\
\hline & & & - & INT & $09,1 \cdot 1$ & المجموع & \\
\hline
\end{tabular}

يتضح من خلال النتائج الموضحة في الجدول (.ץ) عدم وجود فروق ذات دلالة إحصائية عند مستوى (0 . ..) فأقل في اتجاهات عينة الدراسة حول (المعوقات الشخصياة، المعوقات الفنية، المعوقات المالية، المعوقات التي تحد من دور تكنولوجيا المعلومات في تنمية كفاءة الأداء الإداري لقائدات

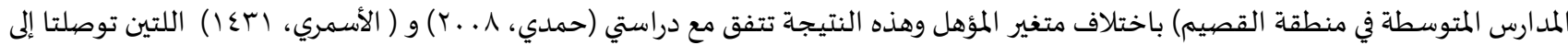
نتيجة عدم وجود فروق ذات دلالة إحصائية بالنسبة للمعوقات تعزى لمتغير المؤهل.

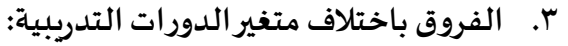

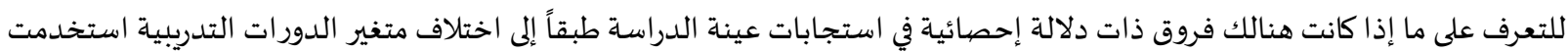
الدراسة "تحليل التباين الأحادي" (One Way ANOVA)؛ لتوضيح دلالة الفروق في استجابات عينة الدراسة طبقاً إلى اختلاف متغير الدورات التدربيية ، وجاءت النتائج كما يوضحها الجدائ الدي التدول التالي:

جدول (YI): نتائج " تحليل التباين الأحادي " (One Way ANOVA) للفروق في استجابات عينة الدراسة طبقاً إلى اختلاف متغير الدورات التدرببية

\begin{tabular}{|c|c|c|c|c|c|c|c|}
\hline التعليق & الدلالة الإحصائية & قيمة ف & متوسط المربعات & درجات الحرية & مجموع مربعات & مصدر التباين & المحور \\
\hline \multirow[t]{3}{*}{ غير دالة } & \multirow[t]{3}{*}{., ह94 } & \multirow[t]{3}{*}{.,VIT } & .,\&人T & $r$ &., $9 \vee \mathrm{Y}$ & بين المجموعات & \multirow[t]{3}{*}{ المعوقات الشخصية } \\
\hline & & & . TAY & 11. & ITT,AT. & داخل المجموعات & \\
\hline & & & - & IAT & $|r r, v q|$ & المجموع & \\
\hline \multirow[t]{3}{*}{ 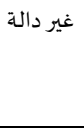 } & \multirow[t]{3}{*}{. ז人> } & \multirow[t]{3}{*}{., 901} & 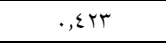 & $r$ &.,$\wedge \varepsilon 0$ & بين المجموعات & \multirow[t]{3}{*}{ المعوقات الفنية } \\
\hline & & &.,$\sum \varepsilon 1$ & 11. & $v 9, \varepsilon r \mu$ & داخل المجموعات & \\
\hline & & & - & IAT & A.,YAT & المجموع & \\
\hline \multirow[t]{3}{*}{ 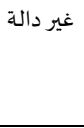 } & \multirow[t]{3}{*}{$\cdot, \wedge \vee q$} & \multirow[t]{3}{*}{., $1 \times 9$} &., .71 & $r$ &., $1 T V$ & بين المجموعات & \multirow[t]{3}{*}{ المعوقات المالية } \\
\hline & & & .,or. & 11. & $90, r \leqslant 1$ & داخل المجموعات & \\
\hline & & & - & MN & $90, \varepsilon \vee \wedge$ & المجموع & \\
\hline \multirow[t]{3}{*}{ 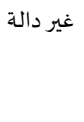 } & \multirow[t]{3}{*}{., 011} & \multirow[t]{3}{*}{. OTr } &., 187 & $r$ & . rOY & بين المجموعات & \multirow{3}{*}{ 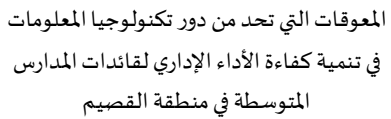 } \\
\hline & & & . & 11. & $09,\{07$ & داخل المجموعات & \\
\hline & & & - & IAT & $09,1 \cdot 1$ & المجموع & \\
\hline
\end{tabular}

يتضح من خلال النتائج الموضحة في الجدول (1) عدم وجود فروق ذات دلالة إحصائية عند مستوى (0 . ..) فأقل في اتجاهات عينة الدراسة حول (المعوقات الشخصية، المعوقات الفنية، المعوقات المالية، المعوقات التي تحد من دور تكنولوجيا المعات المعلومات في تنمية دوفية كفاءة الأداء الإداري لقائدات المدارس المتوسطة في منطقة القصيم) باختلاف متغير الدورات التدريبية، وهذا يشير إلى أن جميع قائدات المدارس باختلاف الدورات التدريبية التي

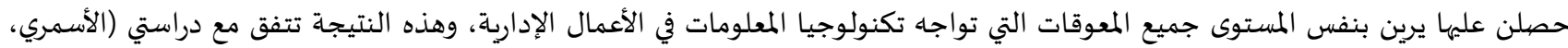




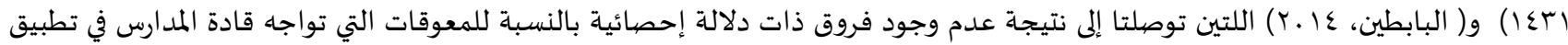
تكنولوجيا المعلومات تعزى لمتغير الدورات التدربيية. خامسـاً: إجابـة السـؤال الخـامس: مـا متطلبـات تطبيق تكنولوجيـا المعلومـات لتنميـة كفاءة الأداء الإداري لقائـدات المـدارس المتوسـطة في منطقـة القصيم ؟ آح

لتحديد متطلبات تطبيق تكنولوجيا المعلومات لتنمية كفاءة الأداء الإداري لقائدات المدارس المتوسطة في منطقة القصيم، تم حساب المتوسط الحسابي لهذه الأبعاد وصولاً إلى تحديد متطلبات تطبيق تكنولوجيا المعلومات لتنمية كفاءة الأداء الإداري لقائدات المدارس المتوسطة فئوسي في منطقة

القصيم.

جدول(Y ) : استجابات عينة الدراسة على أبعاد متطلبات تطبيق تكنولوجيا المعلومات لتنمية كفاءة الأداء الإداري لقائدات المدارس المتوسطة في منطقة القصيم

\begin{tabular}{|c|c|c|c|c|}
\hline الرتبة & الانحراف المعياري & المتوسط الحسابي & البعد & م \\
\hline r & .017 & $\varepsilon, r$. & المتطلبات الشخصية & 1 \\
\hline r & ., V10 & $\varepsilon, \varepsilon r$ & المتطلبات الفنية & r \\
\hline 1 &., 79 & $\varepsilon, \varepsilon V$ & المتطلبات المالية & $r$ \\
\hline - &., 010 & $\varepsilon, \varepsilon$. & نطقة القصيمة الأداء الإداري لقائدات المدارس المتوسطة في & \\
\hline
\end{tabular}

يتضح من خلال النتائج الموضحة أعلاه أن عينة الدراسة قد وافقت بشدة على متطلبات تطبيق تكنولوجيا المعلومات لتنمية كفاءة الأداء الإداري لقائدات المدارس المتوسطة في منطقة القصيم بمتوسط(.ع,ع )، وأتضح من النتائج أن أبرز متطلبات تطبيق تكنولوجيا المعلومات لتنمية

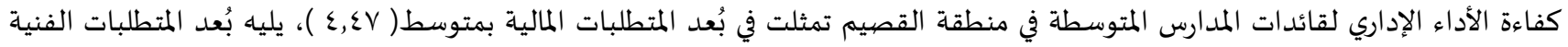

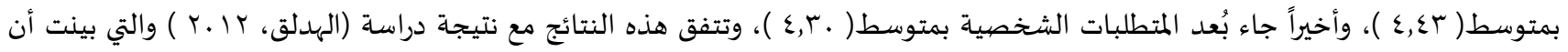

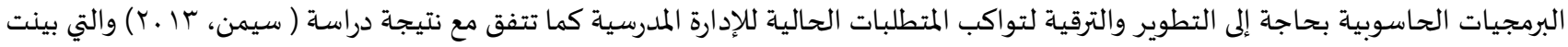

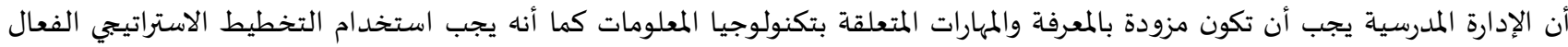

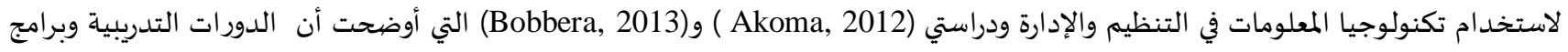

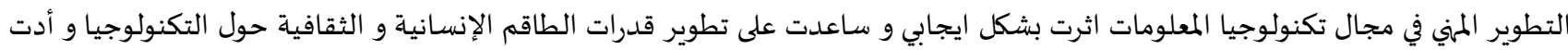
لتغيير أفضل في الممارسات الإدارية.

توصيات الدراسة:

في ضوء النتائج التي تم التوصل الهاو متطلبات تفعيل دور تكنولوجيا المعلومات توصي الدراسة بما يلى

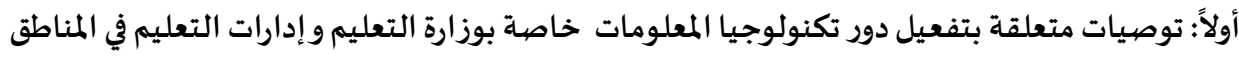

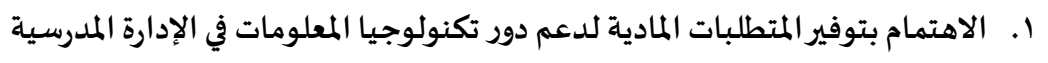

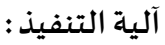

توفير خدمة انترنت بسرعة جيدة بالمدارس لتسهيل الأعمال الإلكترونية.

توفير الدعم المالي المطلوب لإدخال تكنولوجيا المعلومات بحسب متطلبات كل جهة إدارية.

دعم البرامج التدريبية المختصة بتوظيف تكنولوجيا المعلومات في العمل الإداري.

وضيع خطة استراتيجية لدعم التحول التكنولوجي تشمل اللوائح و الأساليب الجديدة للعمل و متطلبات تطبيقها وفق إطار السياسة الوطنية

$$
\text { والاحتياجات التعليمية. }
$$

ب اجراء دراسات جدوى قبل اجراء أي تحول تكنولوجي.

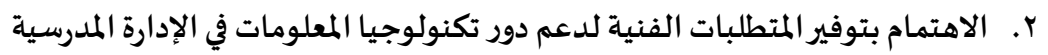

آلية التنفيذ :

• توفير مستوى عال من البنية التكنولوجية في مدارس التعليم العام و التي تتضمن شبكة حديثة للاتصالات، وبنية تحتية متطورة تشمل

$$
\text { الأجهزة والتجهيزات }
$$

• توفير الدعم الفني وصيانة الأجهزة والشبكات بصهورة دائمة.

• إتاحة الخدمات الادارية الالكترونية بشكل أوسع. 
r. الاهتمام بتوفير المتطلبات الشخصية لدعم دور تكنولوجيا المعلومات في الإدارة المدرسية آلية التنفيذ : (ألية

• تغيير أنماط الثقافة التنظيمية السائدة بما يتلاءم مع ثقافة تكنولوجيا المعلومات. • الاستفادة من الابحاث المتعلقة بتكنولوجيا المعلومات المختصية بالعمل الإداري.

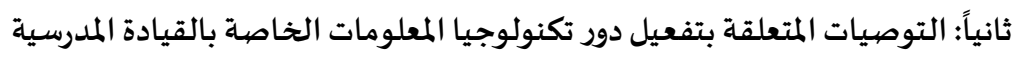
ا. الاهتمام بتوفير المتطلبات المادية لدعم دور تكنولوجيا المعلومات في الإدارة المدرسية آلية التنفيذ : - n • تفعيل دور المشاركة المجتمعية في دعم وتمويل التكنولوجيا في المدارس. • تخصيص جزء من الميزانية لإقامة الدورات التدريبية للطاقم الإداري. • • تخصيص جزء من الميزانية لتوفير الدعم الفني للصيانة والتطوير

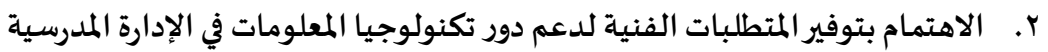

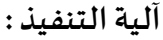
• العمل على صيانة الأجهزة وطلب الدعم الفني للأجهزة عوضاً عن اتلافها أو إرسالها للرجيع. • تهيئة مهارات بشرية من ذوي الخبرة والكفاءة للعمل على التكنولوجيا. • الاستفادة من العناصر المؤهلة في المدرسة بإقامة دورات تدربية دهودية داخلية. • وضع خطة مجدولة لتوفير الصيانة الدورية للأجهزة والبرمجيات لتفادي الاعطال المفاجئة. r. الاهتمام المتطلبات الشخصية لدعم دور تكنولوجيا المعلومات في الإدارة المدرسية

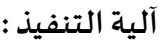
• تنمية الاتجاهات الإيجابية لدى الأفراد والعاملين نحو تطبيق تكنولوجيا المعلومات. • دعم وتشجيع العاملين على التعلم والتطوير الذاتي في مجال تكنولوجيا المعلومات. • تحفيز العاملين على العمل بروح الفريق وتدعيم روح المعاونة والمساندة. • تزويد العاملين بمهارات التعامل مع المعلومات ومهارات تشغيل الأجهزة • توعياة العاملين بأهمية امن المعلومات والبيانات. مقترحات للدراسـات المستقبلية: • دور رؤية المملكة العربية السعودية ــ •r في دعم التحول التكنولوجي في مدارس التعليم العام. • الاحتياجات التدربيية لقائدات مدارس التعليم العام في مجال تكنولوجيا المعلومات. • متطلبات اجراء تحول تكنولوجي في الإدارات المدرسية.

ا. آل محيا، يحيى عبدالله موسى، (10 ــ) معوقات تطبيق الإدارة الإلكترونية في المدارس المتوسطة بمنطقة عسير من وجهة نظر مديري المدارس

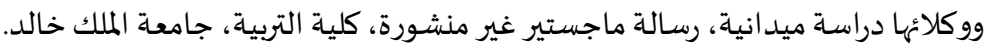

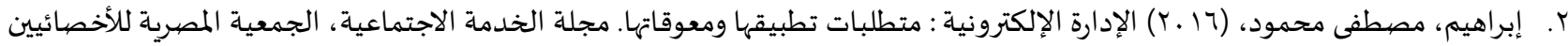

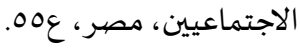

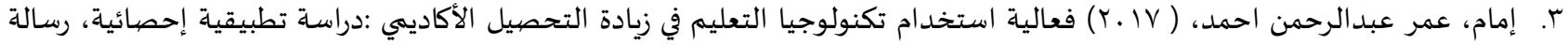
دكتور اه. جامعة ام درمان الإسلامية.

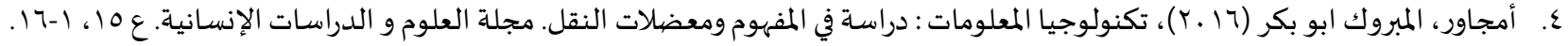

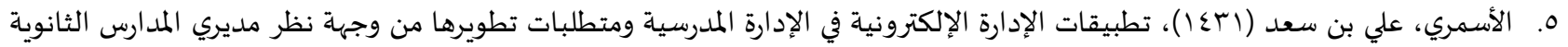
بمدينة الرياض، دراسة ماجستير غير منشورة، قسم التربية في كلية العلوم الاجتماعية بجامعة الإمام محمد بن سعود الإسلامية. 
7. بركات، خالد مصطفى (9. . . )، أثر تكنولوجيا المعلومات على مستويات الأداء في منظمات الأعمال : دراساة تحليلية نظرية. مجلة البحوث

$$
\text { الإدارياة: مصر. مج برداب، }
$$

V. البابطين، عبدالرحمن بن عبدالوهاب، (عا . r) درجة توافر الكفايات التقنية لدى قائد المدرسـة بمدينة الرياض. مجلة رسالة التربية وعلم

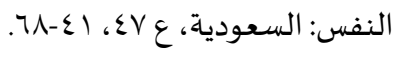

^. البدو، كفاح محمد، (7 ا ـ ( دور القيادة التربوية في دعم استخدام تكنولوجيا المعلومات والاتصالات في التعليم .مجلة رسالة المعلم، مجبه(1)،

9. جلال، آمال عبيد، (0. . . أثر تكنولوجيا المعلومات على الأداء الإداري. رسالة ماجستير غير منشورة، جامعة الاردن. • ا ـ حمّدي، موسى عبد الله محمد مهدي، (وبع ا) الصعوبات التي تواجـه استخدام الإدارة الإلكترونية في إدارة المدارس الثانوية للبنين بمدينة مكة المكرمة من وجهة نظر مديري المدارس ووكلائها، رسالة ماجستير غير منشورة، جامعة أم القرى. ا ا ـ الحبيب، عبدالرحمن، (0 إب) متطلبات تطوير نظام الإدارة التربوية " نظام نور " في مدارس التعليم العام بمدينة الرياض في ضوء التجارب العالمياة. مجلة كلية التربية: جامعة أسيوط - كلية التربية. مج اس ، ع؛. r ا . الدعيلج، فوزية بنت عبدالعزيز، (جبع ا) رؤية مستقبلية لتطبيق الإدارة الإلكترونية في ادارة المدارس الثانوية للبنين بمدينة مكة المكرمة من وجهة نظر مديري المدراس ووكلائها. رسالة ماجستير غير منشورة. كلية التربية. مكة المكرمة: جامعة أم القرى.

با . رضا، حاتم علي حسن، (عا عا ) الإبداع الإد اري وعلاقتاه بالأداء الوظيفي. رسالة ماجستير غير منشورة. أكاديمية نايف العربية للعلوم الحربية. عا ـ الراضي، خالد عبدالعزيز، (ها ــا برامج الإدارة الإلكترونية المدرسية في مدارس التعليم العام "الواقع و المعوقات". المجلة الدولية التربوية

المتخصصية، ع(Y).

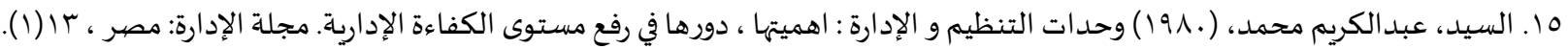
جا ـ الشناق، عبد السلام، (. 1 . ( دور الإدارة المدرسية في توظيف برامج تكنولوجيا المعلومات والاتصيالات. دار وائل للنشر، عمان.

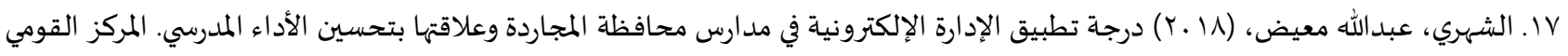

$$
\text { للبحوث، غزة. }
$$

11. الطاني، جعفر حسن جاسم، (11 • (Y) العرب وتحديات تكنولوجيا المعلومات. رسالة المكتبة- الاردن. مج 7ع. 9 ا. عاشور، محمد علي، (. ا . ا) درجة استخدام مديري ومديرات المدارس في الثانوية في محافظة إربد لتكنولوجيا المعلومات والاتصيالات. مجلة

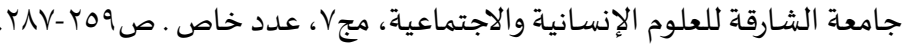

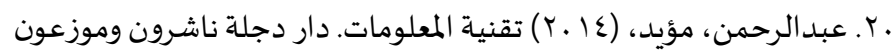

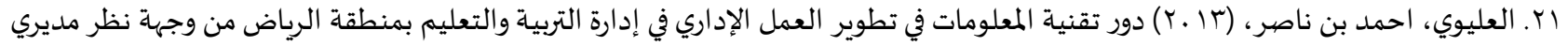
الإدارات ورؤسـاء الأقسام. رسـالة ماجستير غير منشـورة، جامعة الإمام محمد بن سعود الإسلامية، الرياض. r . القحطاني، عبدالمحسن؛ والخزي، فهد، (با ـ r) دور القيادة الإدارية المدرسية في ادارة التنمية المهنية لأعضياء الهيئة التعليمية في مجالات

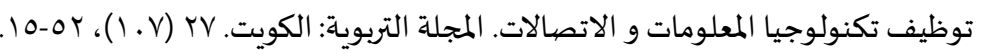
با. متولي، لبنى عبدالرحمن، (r ا ـ r) تطوير الأداء الإداري للمدارس باستخدام تكنولوجيا المعلومات والاتصالات الإدارية. مجلة كلية التربية ببور

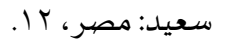

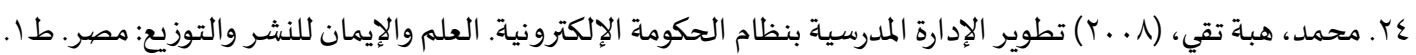

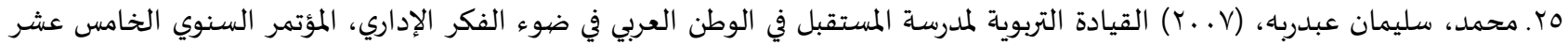
للجمعية المصرية للتربية المقارنة والادارة التعليمية.

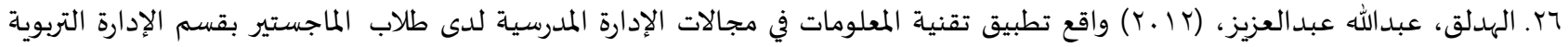

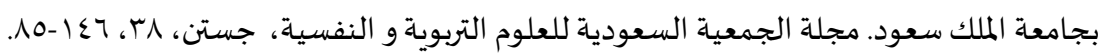

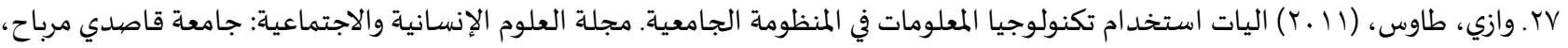

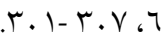


[1] Akoma. A. M., Decision-making, information communication technology, and data analysis by school leaders about student achievement (Doctoral dissertation, Teachers College, Columbia University), (2012)

[2] Angie. O., \& Ugwu. R. N., The Place of ICT (Information and Communication Technology) in the Administration of Secondary Schools in South Eastern States of Nigeria, (2013)

[3] Bobbera. R. L., Developing the principal's capacity to lead technology integration within the school: An action research study (Doctoral dissertation, Capella University), (2013)

[4] Ghavifekr. Simin., ICT Application for administration and Management: A Conceptual Review University of Malay: Malaysia, (2013)

[5] Makewa. L., Meremo. J., Role. E., \& Role. J., ICT in secondary school administration in rural southern Kenya: An educator's eye on its importance and use, International Journal of Education and Development Using ICT, 9(2)(2013).

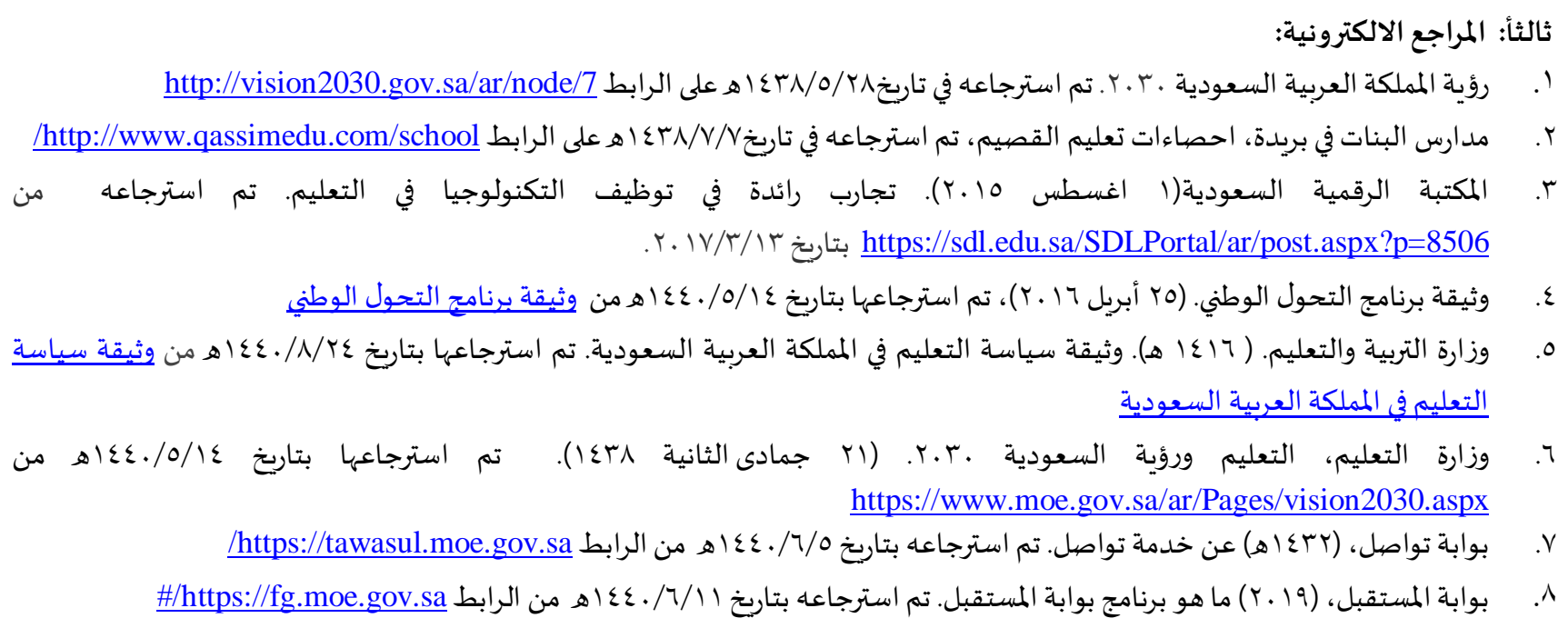




\title{
The Role Of Information Technology On The Efficient Administration Performance For Middle School Leaders In Al-Qassim Region From Their Perspective
}

\author{
Alyia Mohammad Sharaf \\ Associate Professor of Educational Administration- Qassim University- KSA \\ Dr.alyia@yahoo.com
}

\section{Sarah Abdul Latif Mohammad Al- Furaihy}

Master of Educational Administration- Faculty of Education- Qassim University- KSA sarafuraihy@gmail.com

\begin{abstract}
The study aimed to identify The Role Of Information Technology On The Efficient Administration Performance For Middle School Leaders In Al-Qassim Region From Their Perspective, of view in the light of the study variables ( years of experience, academic qualification, training courses) and the role of information technology in developing the efficiency of administrative performance. Besides the detection of obstacles that limit their role in the development of efficient administrative performance. To achieve the objectives of the study, the sample of the study was chosen in a simple random way according to the approved sampling schedule (Krejcie, R \& Morgan, D1970). the sample of the study consisted of (183) female leaders of schools in the region of Qassim, and the researcher used the questionnaire data collection tool.
\end{abstract}

Keywords: Information Technology, Administrative Performance, Efficiency, School Leader.

\section{References:}

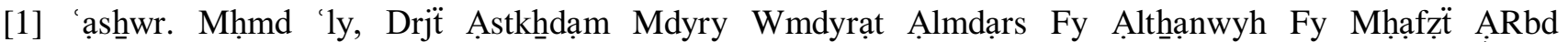

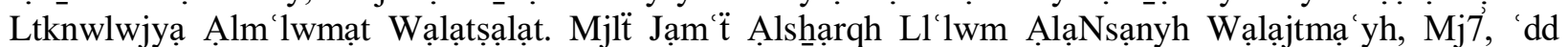
Khạs, (2010), pp.259-287.

[2] 'bdạlrḥmn. Mw̉yd, Tqnyë Ạlm lwmạt. Dạr Djlï Nạsḥrwn Wmwz' wn, (2014)

[3] Ábrạhym. Mștfy Mḥmwd, Ạlạdạrh ẠlạiLktrwnyh: Mtṭlbạt Tṭbyqhạ Wm wqạthạ. Mjlï Ạlkḥdmh Ạlạjtmạ 'yh, Ạljm yh Ạlmṣryh Llạ̉kḥsạỷyyn Ạlạjtmạ yyn, Mṣr, 55, (2016)

[4] Akoma. A. M., Decision-making, information communication technology, and data analysis by school leaders about student achievement (Doctoral dissertation, Teachers College, Columbia University), (2012)

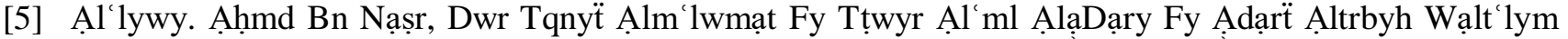

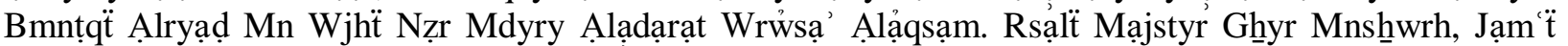
Ạlạmạm Mḥmd Bn S'wd Ạlạslạmyh, Ạlryạạ̣, (2013) 
[6] Ạlạ̉smry. 'ly Bn S`d, Tṭbyqạt Ạlạdạrh ẠlặLktrwnyh Fy Ạlạdạrh Ạlmdrsyh Wmtṭlbạt Tṭwyrhạ Mn Wjhë Nẓr Mdyry Ạlmdạrs Ạlthạanwyh Bmdynẗ Ạlryạd, Drạsẗ Mạjstyr Ghyr Mnshwwrh, Qsm Ạltrbyh Fy Klÿ̈ Ạl'lwm Ạlạjtmạ yh Bjạm ‘̈ Ạlạ̣Mạm Mḥmd Bn S'wd Ạlạslạmyh, (1431)

[7] Ạlbạbțyn. 'bdạlrḥmn Bn 'bdạlwhạb, Drjë Twạfr Ạlkfạyạt Ạltqnyh Lda Qạydd Ạlmdrsh Bmdynẗ Ạlryạḍ. Mjlẗ Rsạlẗ Ạltrbyh W’lm Ạlnfs: Ạls'wdyh, ' 47(2014), 41-68.

[8] Ạlbdw. Kfạh Mḥmd, Dwr Ạlqyạadh Ạltrbwyh Fy D'm Ạstkhndạm Tknwlwjyạ Ạlm lwmạt Wạlạtṣạạt Fy Ạlt' lym. Mjlë Rsạlẗ Ạlm'lm, 53(1)(2016), 48-43.

[9] Ạld'ylj. Fwzyh Bnt 'bdạl'zyz, Rw̉yä Mstqblyh Ltṭbyq ẠlạDạrh ẠlạLktrwnyh Fy Ạdạr Ạlmdạrs Ạlthạnwyh Llbnyn Bmdynẗ Mkh Ạlmkrmh Mn Wjḧ̈ Nzar M̉dyry Ạlmdrạs Wwklạyhhạ. Rsạlẗ Mạjstyr Ghyr Mnshwwrh, Klÿ̈ Ạltrbyh. Mkh Ạlmkrmh: Jạm‘̈̈ Ạ̉m Ạlqra, (1426)

[10] Ạlḥbyb. 'bdạlrḥmn, Mtțlbạt Tțwyr Nzạam Ạlạdạrh Ạltrbwyh " Nzạam Nwr " Fy Mdạrs Ạlt'lym Ạl ạm

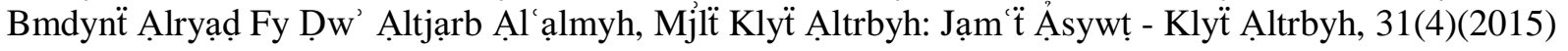

[11] Ạlhdlq. 'bdạllh 'bdạl'zyz, Wạq' Tṭbyq Tqnÿ̈ Ạlm'lwmạt Fy Mjạlạt Ạlạdạrh Ạlmdrsyh Lda Ṭlạb.

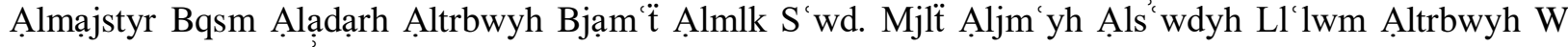
A.lnfsyh,Jstn, 38(2012), 146-85.

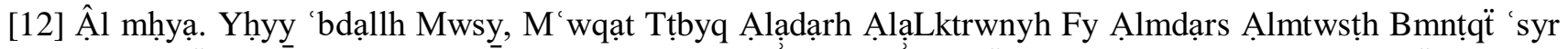
Mn Wjḧ̈ Nẓr Mdyry Almdạrs Wwklạyhạ Drạsh Mydạnyh, Rsạlẗ Mạjstyr Ghyr Mnshwwrh, Klÿ̈ Ạltrbyh, Jạm‘̋̈ Ạlmlk Khạld, (2015)

[13] Ạlqhțạny. 'bdạlmḥsn \& ạlkȟzy. Fhd, Dwr Ạlqyạdh Ạlạdạryh Ạlmdrsyh Fy Ạdạrt Ạltnmyh Ạlmhnyh Lạ 'ḍạ Ạlhyỷh Ạlt'lymyh Fy Mjạlạt Twzyf Tknwlwjyạ Ạlm lwmạt W Ạlạtṣạạt. Ạlmjlh Ạltrbwyh: A.lkwyt. 27(107)(2013), 52-15.

[14] Ạlrạ̣dy. Khạald 'bdạl'zyz, Brạmj Ạlạiạarh Ạlạ́Lktrwnyh Ạlmdrsyh Fy Mdạrs Ạlt'lym Ạl 'ạm "Ạlwạq' W Ạlm 'wqạt". Ạlmjlh Ạldwlyh Ạltrbwyh Ạlmtkḥș̣̦h, 4(2)(2015), 137-119.

[15] Ạlshhry. 'bdạllh M'yḍ, Drjë Tṭbyq Ạlạdạrh Ạlạlktrwnyh Fy Mdạrs Mhạaẓ̇̈ Ạlmjạrdh W'lạqthạ Bthṣyn Ạlạ̉dạ' Ạlmdrsy. Ạlmrkz Ạlqwmy Llbḥ̉wth̆, Ghzhzh, (2018)

[16] Ạlshnạq. 'bdạlslạm, Dwr Ạlạdạrh Ạlmdrsyh Fy Twzyf Brạmj Tknwlwjyạ Ạlm lwmạt Wạlạtṣạlạt. Dạr Wậ̉l Llnsh̆r, 'mạn, (2010)

[17] Ạlsyd. 'bdạlkrym Mḥmd, Wḥdạt Ạltnzym W Ạlạjdạrh: Ạhmythạ , Dwrhạ Fy Rf' Mstwy Ạlkfạ’h Ạlạdạryh. Mjlï Ạlạiạrh: Mṣr, 13(1)(1980).

[18] Ạlțạny. J'fr Ḥsn Jạsm, Ạl'rb Wthdyạt Tknwlwjyạ Ạlm lwmạt. Rsạlï Ạlmktbh-Ạlạrdn. Mj 46(2011)

[19] Amạm. 'mr 'bdạlrḥmn Ạhmd, F'ạlyẗ Ạstkhַdạm Tknwlwjyạ Ạlt'lym Fy Zyạdẗ Ạltḥ̣syl Ạlạ̉kạdymy: Drạsh

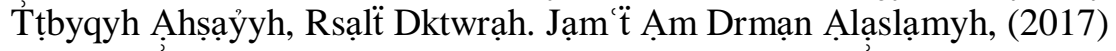

[20] Ạ̉mjậwr. Ạlmbrwk Ạbw Bkr, Tknwlwjyạ Ạlm'lwmạt : Drạsh Fy Ạlmfhwm Wm' ḍlạt Ạlnql. Mjlt Ạl'lwm W Ạldrạsạt Ạlạnsạnyh, ' 15(2016), 1-16.

[21] Angie. O., \& Ugwu. R. N., The Place of ICT (Information and Communication Technology) in the Administration of Secondary Schools in South Eastern States of Nigeria, (2013)

[22] Bobbera. R. L., Developing the principal's capacity to lead technology integration within the school: An action research study (Doctoral dissertation, Capella University), (2013) 
[23] Brkạt. Khạald Mṣṭa, Ạ̉ther Tknwlwjyạ Ạlm lwmạt 'la Mstwyạt Ạlạ̉dạ' Fy Mnẓmạt Ạlạ̉ mạl: Drạsh Tḥlylyh Nẓryh, Mjlï Ạlbḥwth Ạlạjạryh: Mṣr. Mj 27(2009) .

[24] Ghavifekr. Simin., ICT Application for administration and Management: A Conceptual Review University of Malay: Malaysia, (2013)

[25] Ḥmdy. Mwsa 'bdạllh Mḥmd Mhdy, Ạlṣ wbạt Ạlty Twạjh Ạstkhِdạm ẠlạdạrhẠlạlktrwnyh Fy Adạrẗ Ạlmdạrs Ạltḥạnwyh Llbnyn Bmdynẗ Mkh Ạlmkrmh Mn Wjhẗ Nẓr Mdyry Ạlmdạrs Wwklạyhạ, Rsạlẗ Mạjstyr Ghyr Mnshwwrh, Jạm‘đ̈ Ạm Ạlqra, (1429)

[26] Jlạl. Ậmạl 'byd, Ạ̉tḥr Tknwlwjyạ Ạlm lwmạt 'ly Ạlạ̉dạ’ Ạlạjdạry, Rsạlẗ Mạjstyr Ghyr Mnshowrh, Jạm ‘̛̣ Ạlạrdn, (2005)

[27] Makewa. L., Meremo. J., Role. E., \& Role. J., ICT in secondary school administration in rural southern Kenya: An educator's eye on its importance and use, International Journal of Education and Development Using ICT, 9(2)(2013).

[28] Mḥmd. Hbh Tqy, Tṭwyr Ạlạdạrh Ậlmdrsyh Bnzạm Ạlḥkwmh Ạlạiktrwnyh, Ạl'lm Wạlạł Ymạn Llnsḥr Wạltwzy': Mṣr. Ț1, (2008)

[29] Mḥmd. Slymạn 'bdrbh, Ạlqyạdh Ạltrbwyh Lmdrsẗ Ạlmstqbl Fy Ạlwṭn Ạl'rby Fy Ḍw' Ạlfkr Ạlạdạry, Ạlmw̉tmr Ạlsnwy Ạlkh̄ạms 'sḥr Lljm yh Ạlmșryh Lltrbyh Ạlmqạarnh Wạaạdạrh Ạlt' lymyh, (2007)

[30] Mtwly. Lbna 'bdạlrḥmn, Tțwyr Ạlạ̉dạ' Alạdạry Llmdạrs Bạstkhِdạm Tknwlwjyạa Ạlm lwmạt Wạaạtṣạạt Ạlạjạ̣ryh. Mjl̈̈ Klÿ̈ Ạltrbyh Bbwr S yd: Mṣr, 12(2012)

[31] Rḍạ. Hạtm 'ly Hạn, AlạBdạ' Alạ̣Dạry W'lạqth Bạlạ̉dạ’ Ạlwzyfy. Rsạlẗ Mạjstyr Ghyr Mnshwwrh. Ạ̉kạdymyh Nạyf Ạl'rbyèt L'l' lwm Ạlḥrbyh, (1424)

[32] Wạzy. Ṭạws, Ạlyạt Ạstkḥdạm Tknwlwjyạ Ạlm 'lwmạt Fy Ạlmnẓwmh Ạljạm'yh. Mjlt Ạl 'lwm Ạlạnsạnyh Wạlạjtmạ yh: Jạm‘̋̈ Qạṣdy Mrbạh, 6(2011), 307-301. 